Old Dominion University

ODU Digital Commons

Mechanical \& Aerospace Engineering Theses \&

Dissertations

Mechanical \& Aerospace Engineering

Winter 2018

\title{
A Monolithic Internal Strain-Gage Balance Design Based on Design for Manufacturability
}

Thomas Ladson Webb III

Old Dominion University, ladsonwebb@gmail.com

Follow this and additional works at: https://digitalcommons.odu.edu/mae_etds

Part of the Aerospace Engineering Commons, and the Mechanical Engineering Commons

\section{Recommended Citation}

Webb, Thomas L.. "A Monolithic Internal Strain-Gage Balance Design Based on Design for Manufacturability" (2018). Master of Science (MS), Thesis, Mechanical \& Aerospace Engineering, Old Dominion University, DOI: 10.25777/zb72-k741

https://digitalcommons.odu.edu/mae_etds/171

This Thesis is brought to you for free and open access by the Mechanical \& Aerospace Engineering at ODU Digital Commons. It has been accepted for inclusion in Mechanical \& Aerospace Engineering Theses \& Dissertations by an authorized administrator of ODU Digital Commons. For more information, please contact digitalcommons@odu.edu. 


\title{
A MONOLITHIC INTERNAL STRAIN-GAGE BALANCE DESIGN
}

\section{BASED ON DESIGN FOR MANUFACTURABILITY}

by

Thomas Ladson Webb III

B.S. May 2001, Virginia Polytechnic Institute and State University

B.S. December 2017, Old Dominion University

\author{
A Thesis Submitted to the Faculty of \\ Old Dominion University in Partial Fulfillment of the \\ Requirements for the Degree of \\ MASTER OF SCIENCE \\ MECHANICAL ENGINEERING \\ OLD DOMINION UNIVERSITY \\ December 2018
}

Approved by:

Drew Landman (Director)

Gene R. Hou (Member)

Hüseyin Sarper (Member) 


\title{
ABSTRACT \\ A MONOLITHIC INTERNAL STRAIN-GAGE BALANCE DESIGN \\ BASED ON DESIGN FOR MANUFACTURABILITY
}

\author{
Thomas Ladson Webb III \\ Old Dominion University, 2018 \\ Director: Dr. Drew Landman
}

This paper proposes an alternative approach to internal strain-gage balance design driven by Design for Manufacturability (DFM) principles. The objective of this research was a reduction in fabrication time and, subsequently, cost of a balance by simplifying its design while maintaining basic stiffness and sensitivity. Traditionally, the National Aeronautics and Space Administration (NASA) Langley Research Center (LaRC) balance designs have relied on Electro-Discharge Machining (EDM), which is a precise but slow and, therefore, expensive process. EDM is chosen due to several factors, including material hardness, surface finish, and complex geometry, including blind cuts. The new balance design objectives require no blind cuts, and offered a significant reduction in fabrication time, sufficient stiffness, and an acceptable level of sensitivity at the gages for the current design loads. The FF09X is designed to be a direct replacement for the NASA Langley FF09, retaining the same external dimensions, 2-inch x 2-inch x 6-inch, as well as the same load requirements and mounting configuration. Starting with the existing FF09A design, multiple design concepts were considered, including several two-piece designs, before a single-piece design was chosen. The final design is a monolithic balance with the center bored at both the metric and non-metric end and all fillets and rounds not less than 0.0625-inch in radius. Using Design of Experiments (DOE), a Central Composite Design (CC) was used to optimize the cage beam cross-sectional areas and moments of inertia. The FF09X was shown to measure applied forces and moments as effectively as the FF09, while only realizing a small increase in total deflection and decrease in resonant frequency. The overall manufacturing time required to fabricate the FF09X was estimated at 160 hours, which represents a $73 \%$ reduction in time when compared to the FF09. 
Copyright, 2018, by Thomas Ladson Webb III, All Rights Reserved. 
This thesis is dedicated to Xandria, a woman without equal, whom I have the privilege of calling my wife, and to our son, Ladson.

None of this would have been possible without your unwavering support.

I am blessed beyond measure to "do life together" with you! 


\section{ACKNOWLEDGMENTS}

A special thanks to my advisor, Dr. Landman, for his faith in me and his encouragement of my research and analysis. When I set out to study Mechanical Engineering, I never imagined that I would be working with NASA on a funded research project. Dr. Landman is credited with securing both the research topic and the funding from NASA, and he has served tirelessly in the role of advisor on this project. I am especially grateful for his patience and for his fielding of my seemingly endless, and often rudimentary, engineering questions. It has been a pleasure working under his tutelage, both on this research project and as his student. Thanks also go to Dr. Devin Burns, Balance Engineer at NASA Langley Research Center, for his guidance and support throughout the project, including, but not limited to, balance design theory, a supply of technical manuals from the annals of NASA, and his countless hours of proofing and editing of my work. Thanks go to Dr. Peter Parker, Team Lead at NASA Langley Research Center, for sharing his unparalleled knowledge of balance design theory and for his support of my design and analysis efforts. My thanks go to Nicholas Sadowski for his exceptional work on the ODU15X15 balance project, which laid the foundation for this follow-on research project. Thanks also to Dr. Gene Hou, Professor at Old Dominion University, for lending his expertise in the area of solid mechanics and beam theory. Thanks, as well, to Dr. Hüseyin Sarper, Master Lecturer at Old Dominion University, for lending his expertise in the areas of manufacturing and fabrication. Lastly, my thanks go to Dr. Sebastian Bawab, Chair of the Mechanical \& Aerospace Engineering Department at Old Dominion University, for believing in me and for supporting my development as an engineer throughout my time at Old Dominion University. 
NOMENCLATURE

\begin{tabular}{|c|c|}
\hline A & Cross-Sectional Area \\
\hline $\mathrm{AF}$ & Axial Force \\
\hline BMC & Balance Moment Center \\
\hline $\mathrm{b}$ & Base of Beam \\
\hline c & Distance to Beam Outer Fiber \\
\hline $\mathrm{D}$ & Depth, thickness \\
\hline $\mathrm{E}$ & Elastic Modulus \\
\hline $\mathrm{F}$ & Force \\
\hline G & Modulus of Rigidity \\
\hline GF & Gage Factor \\
\hline GL & Gage Length \\
\hline GLW & Gage Length Width \\
\hline $\mathrm{h}$ & Height of Beam \\
\hline I & $2^{\text {nd }}$ Moment of Inertia \\
\hline $\mathrm{k}$ & Spring Constant \\
\hline $\mathrm{L}$ & Length \\
\hline 1 & Length \\
\hline M & Moment \\
\hline $\mathrm{N}$ & Load Proportion \\
\hline $\mathrm{n}$ & Number of Beams \\
\hline NF & Normal Force \\
\hline PM & Pitching Moment \\
\hline $\mathrm{R}$ & Resistance \\
\hline $\mathrm{RM}$ & Rolling Moment \\
\hline $\mathrm{r}$ & Distance from BMC to Centroid of Cage Beam \\
\hline $\mathrm{SF}$ & Side Force \\
\hline $\mathrm{T}$ & Internal Moment \\
\hline $\bar{x}$ & Distance to Centroid, Moment-Area Diagram \\
\hline YM & Yawing Moment \\
\hline y & Displacement \\
\hline
\end{tabular}




\begin{tabular}{ll}
\multicolumn{2}{l}{ Greek Symbols } \\
$\beta$ & Twist Correction Factor \\
$\epsilon$ & Twist Correction Factor \\
$\gamma$ & Normal Strain (Engineering Strain) \\
$\delta$ & Spring Constant Correction Factor \\
$\theta$ & Deflection \\
$\sigma$ & Angle, Slope \\
$\tau$ & Normal Stress \\
$\kappa$ & Shear Stress \\
$v$ & Shear Coefficient (Timoshenko) \\
& Poisson's Ratio
\end{tabular}

\section{Subscripts}

$\begin{array}{ll}\mathrm{m} & \text { Measurement Beam } \\ \mathrm{f} & \text { Flex Beam } \\ \mathrm{s} & \text { Strap } \\ \mathrm{e} & \text { Effective Length } \\ \mathrm{o} & \text { Reference Point } \\ \mathrm{T} & \text { Total } \\ \mathrm{X} & \text { related to, along x-axis } \\ \mathrm{y} & \text { related to, along y-axis } \\ \mathrm{z} & \text { related to, along } \mathrm{z} \text {-axis }\end{array}$




\section{TABLE OF CONTENTS}

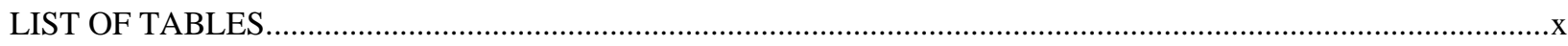

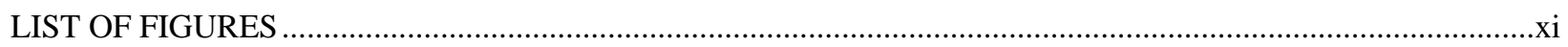

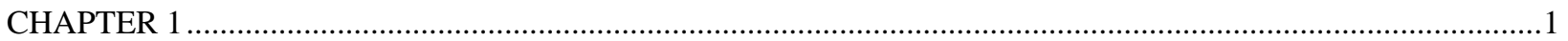

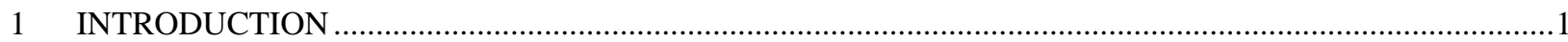

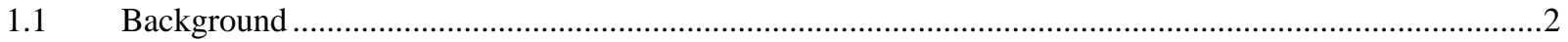

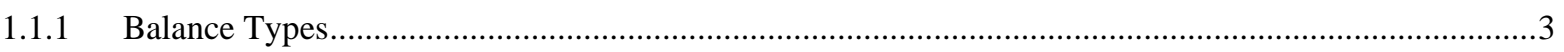

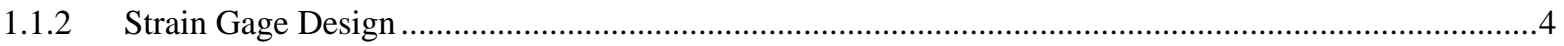

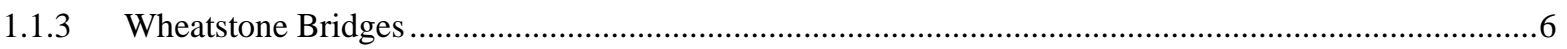

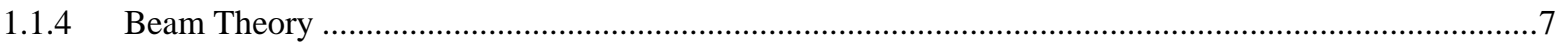

1.1.5 Governing Equations and Application to Axial Section Design .............................................................8

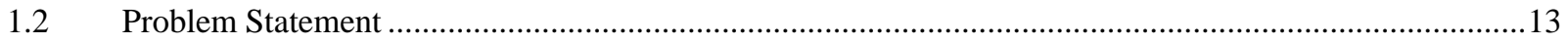

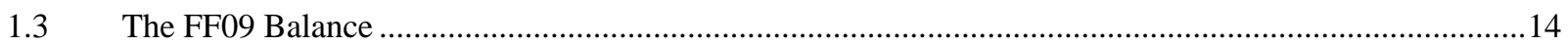

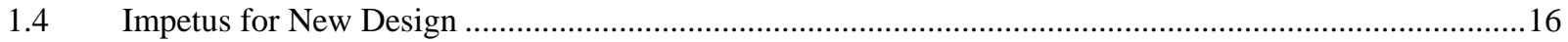

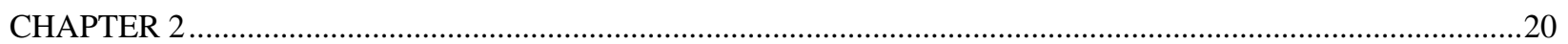

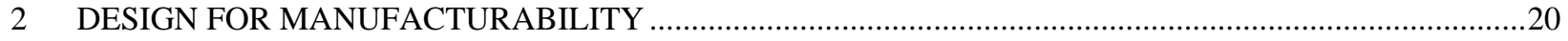

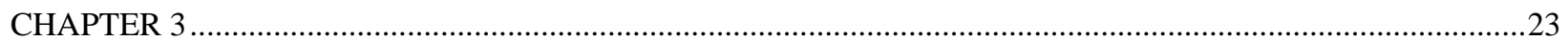

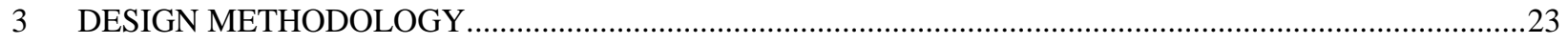

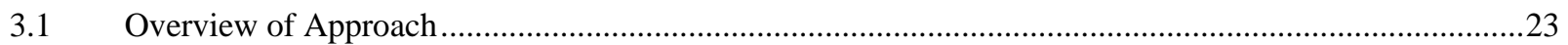

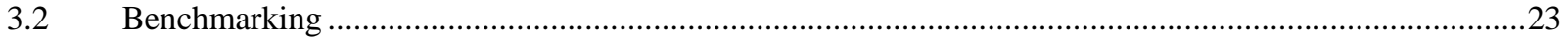

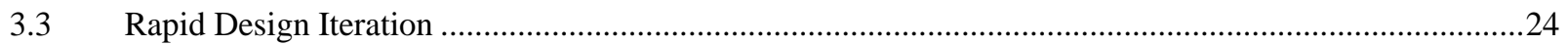

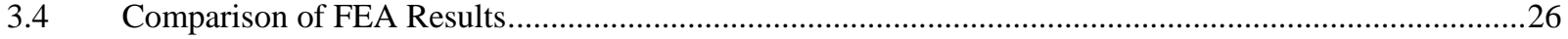




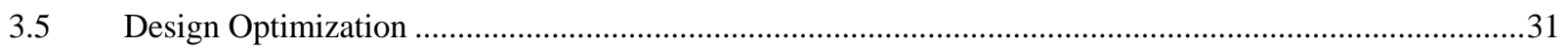

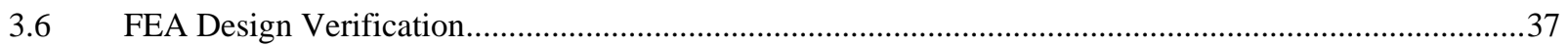

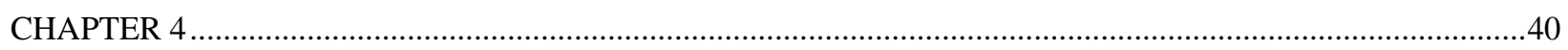

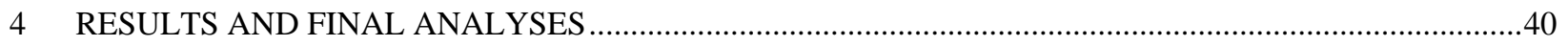

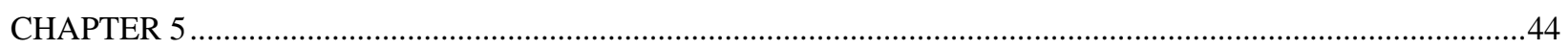

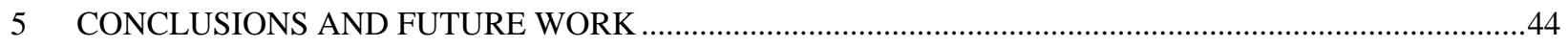

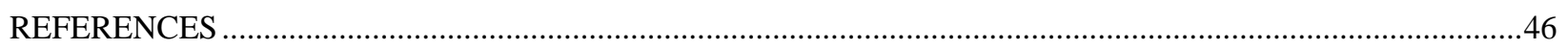

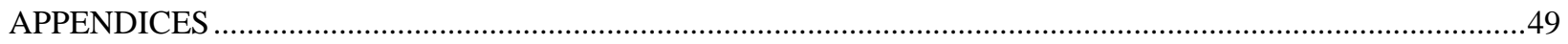

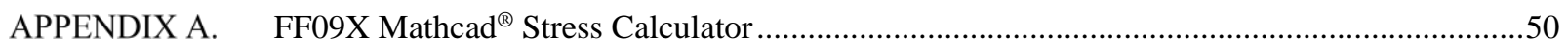

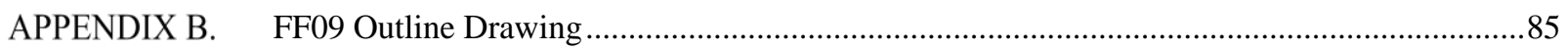

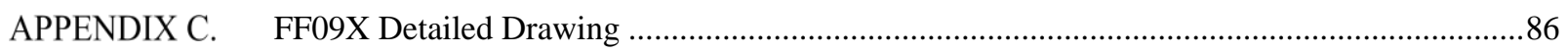

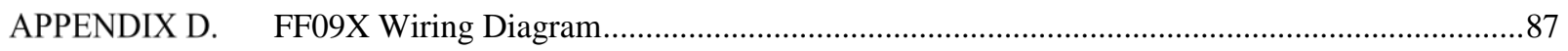

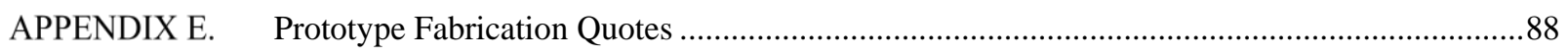

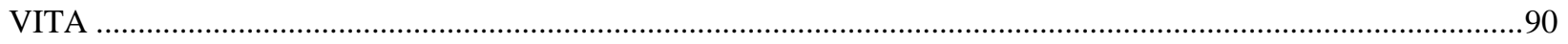




\section{LIST OF TABLES}

Table 1. FF09 Load Requirements.

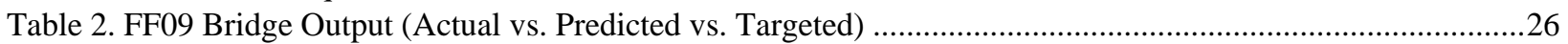

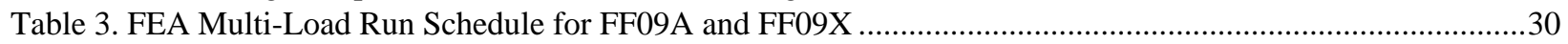

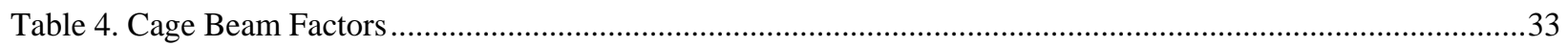

Table 5. Cage Beam Factor Combinations for Initial 33 Runs (dimensions in inches) .............................................35

Table 6. Cage Beam Factor Combinations for Additional 12 Runs (dimensions in inches).......................................36

Table 7. FF09X Range of Factors \& Responses from Analytical Stress Calculator Optimization..............................37

Table 8. DOE Optimized FF09X Factors and Responses with 99\% Desirability .......................................................37

Table 9. Single-Load Numerical (FEA) vs. Analytical Results for FF09X with Optimized Cage Section ..................38

Table 10. FEA Multi-Load Schedule Results $(\mathrm{r} 1=0.94$ in. $)$ - Target Bridge Output 15 ksi......................................38

Table 11. FEA Multi-Load Schedule Results ( $\mathrm{r} 1=0.95$ in.) - Target Bridge Output 15 ksi......................................39

Table 12. FF09A vs. FF09X - von Mises, Maximum Deflection, and Factor of Safety .............................................42

Table 13. FF09A Bridge Output - Calibration Data vs. Predicted ..........................................................................42

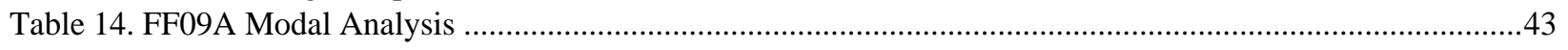

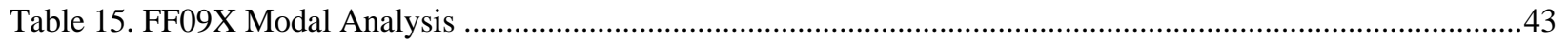




\section{LIST OF FIGURES}

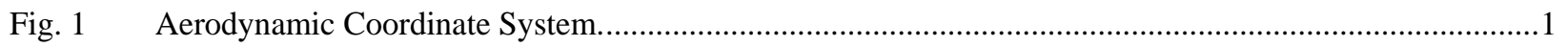

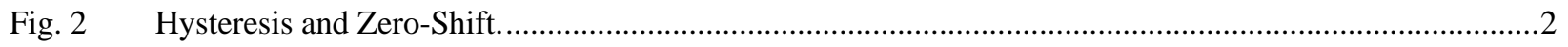

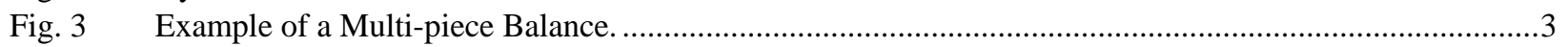

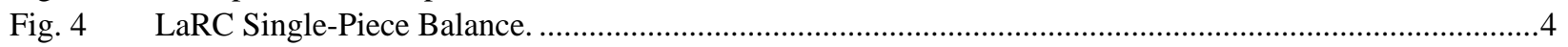

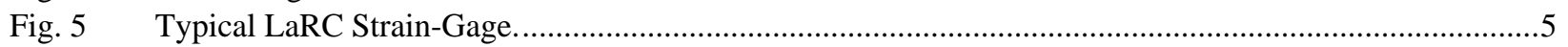

Fig. 6 Wheatstone Bridge with Temperature Sensitive Wiring....................................................................

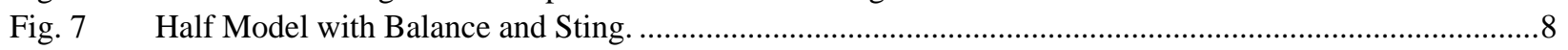

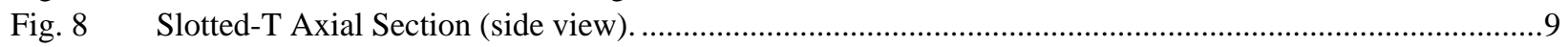

Fig. 9 Free Body Diagram of Strap-Measurement Beam in Axial Section. ...................................................10

Fig. 10 Free Body Diagram of Internal Forces and Moments at Point A.........................................................11

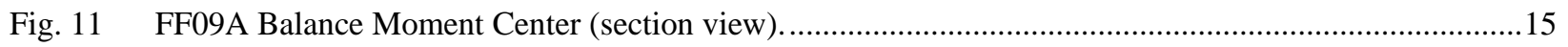

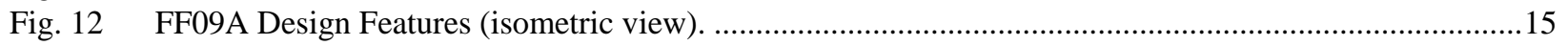

Fig. 13 Sample Axial Strain-Gage Orientation (detail view)............................................................................

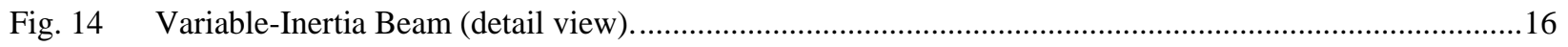

Fig. 15 Sample End Mill and Core Diameter Description..................................................................................17

Fig. 16 ODU15X15 Thrust/Torque Balance (isometric view). ..........................................................................18

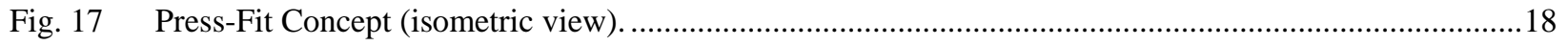

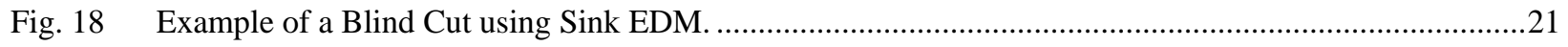

Fig. 19 Sample of End Mill Selection Parameters ADOC and RDOC..............................................................22

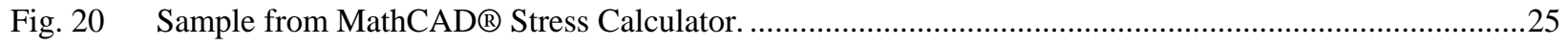

Fig. 21 Parametric Sketch of FF09X Axial Section (detail view). ....................................................................27

Fig. 22 Test Coupon with Partial Axial Section Conventionally Machined.........................................................28

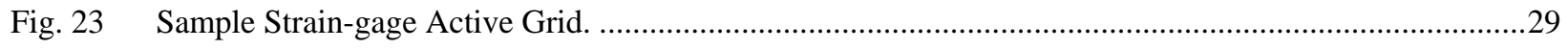

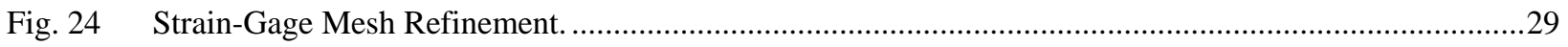

Fig. 25 Multi-Load Run Results for Initial FF09X Design. ...............................................................................

Fig. 26 Cage Beam Factors and Dimensional Constraints (dimensions in inches). ...............................................33

Fig. 27 FF09X Final Design (side \& isometric view) (dimensions in inches). ....................................................40

Fig. 28 FF09A Design (side \& isometric view) (dimensions in inches) ..............................................................41 


\section{CHAPTER 1}

\section{INTRODUCTION}

Wind tunnel testing of scale aerodynamic models is a necessary step in the development process of many flight vehicles. NASA Langley Research Center (LaRC) uses internal strain-gage balances to measure forces and moments applied directly to those models in a wind tunnel [1]. The reference to "internal" comes from the fact that the balance is physically located inside of the model, which represents one of the many design constraints. A balance is an electro-mechanical transducer made up of structural spring elements, or flexures, that are instrumented with foilresistive strain gages. Output is in an electrical signal proportional to the strain produced in the flexures by an applied load [2]. The balance development process can range anywhere from seven to twelve months, with balance design and fabrication typically taking five to eight months. At the time of this writing, the cost of a single balance can range from $\$ 50 \mathrm{~K}$ to $\$ 750 \mathrm{~K}$, and much of that cost is in the design and fabrication process. Therefore, it is advantageous to develop a less complex balance design, preferably with no blind cuts, that will eliminate the need for slow and costly fabrication methods, such as Computer Numerical Control (CNC) Electro-Discharge Machining (EDM), while maintaining the desired sensitivity at the strain-gages. The purpose of this design study was to simplify the design of an existing six-component LaRC balance, incorporating Design for Manufacturability (DFM) guidelines, to reduce the fabrication time and cost. A six-component internal balance is designed to measure three forces (Normal, Axial, and Side) and three moments (Pitch, Roll, and Yaw) [2]. The aerodynamic coordinate system used by LaRC has an origin at the balance moment center, with positive directions, as indicated in Fig. 1.

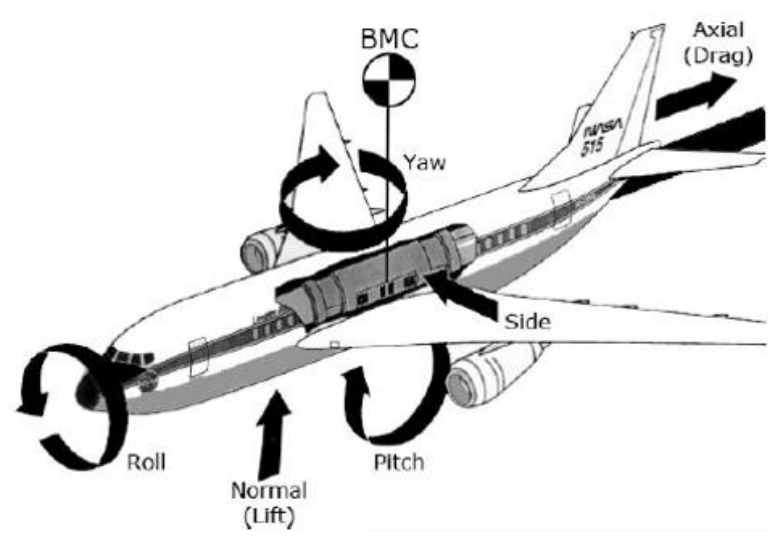

Fig. 1 Aerodynamic Coordinate System. 
NASA LaRC has designed and utilized both single and multi-piece balances to test aerodynamic models in its wind tunnels. In the late 1950s, with the introduction of EDM, LaRC began to design and using single-piece, or monolithic, balances nearly exclusively, in lieu of multi-piece designs. EDM expanded manufacturing capabilities to allow for more complex geometry, e.g. blind cuts, that had not previously been possible using conventional machining practices. Prior to the advent of EDM, multi-piece balances were used to measure six-component loads, and pieces had to be machined separately and then bolted or welded together. However, during the calibration process, it was observed that multi-piece balances were prone to shifting at the joints under an applied load, which introduced two issues: hysteresis and zero shift, as shown in Fig. 2 [3].

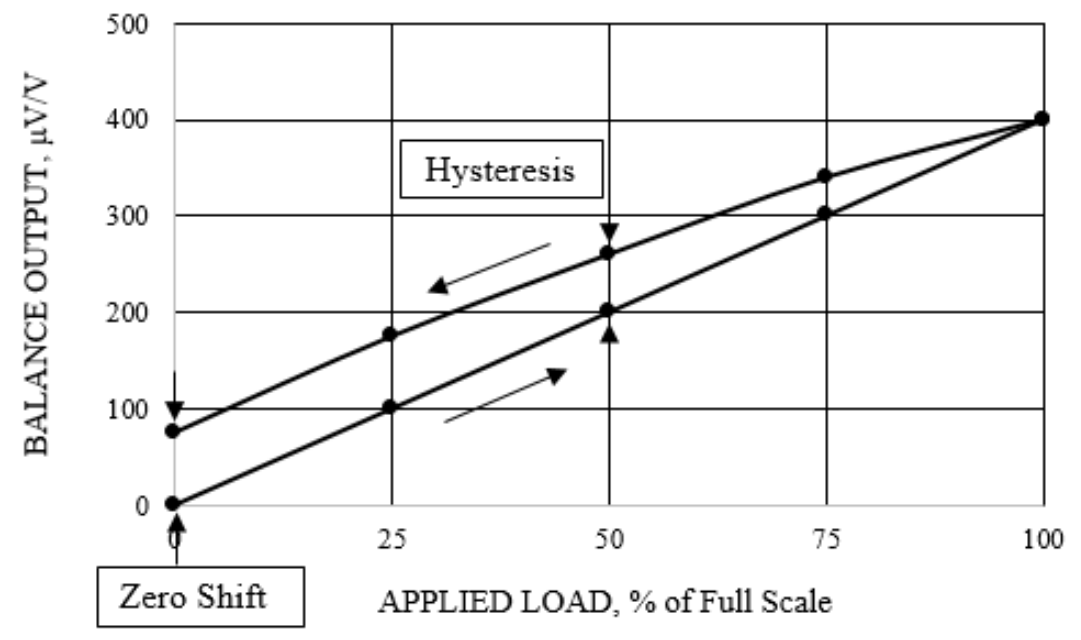

Fig. 2 Hysteresis and Zero-Shift.

\section{$1.1 \quad$ Background}

Internal balances vary in size and load range, but, in general, all internal balances can be categorized as either a force, a moment, or a direct-read balance. Each type of balance has its unique advantages and disadvantages; however, common to all three types of balances are: 1) a section for measuring axial load only, 2) at least one cage section for measuring all other forces and moments, 3) a mounting interface between model and balance (metric 
end), 4) a mounting interface between balance and sting (non-metric end), and 5) the use of Wheatstone Bridges, which will be discussed in more detail below.

\subsubsection{Balance Types}

Force balances are multi-piece designs that consist of an inner rod and outer shell with flexures, or webs, mounted with strain gages, which measure strain due to direct tension or compression. Force balances measure five forces - one axial, two normal and two side, and one moment: rolling. Advantages of this type of balance include that they are less expensive to fabricate and safer (due to self-capturing design in event of failure), that they have higher stiffness and higher load capacity, and that second order interaction terms are less critical. Disadvantages include: their minimum diameter of one-inch due to multi-piece design, their diminished accuracy due to load path and induced stress, and that mathematical modeling and calibration is more complex, and requires higher order terms [2]. An example of a multi-piece force balance is shown in Fig. 3.
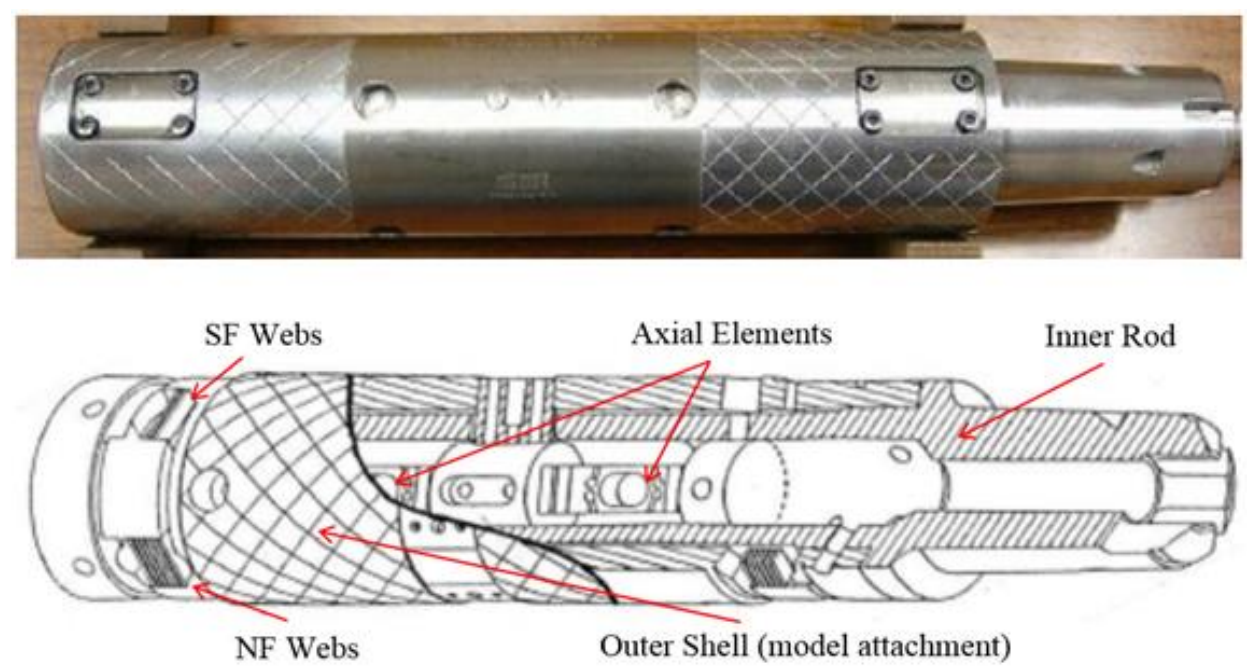

Fig. 3 Example of a Multi-piece Balance.

Moment balances are typically a single-piece design with gaged cantilever beams that measure strain that results from single or double-bending. Moment balances measure one force (axial force), and five moments (two pitching, two yawing and one rolling moment). The advantages of this type of balance are better accuracy and smaller diameters ( 0.25-inches) possible due to single-piece construction; second-order calibration model designs 
are acceptable, requiring fewer calibration points. Disadvantages of moment balances include that they are more expensive due to single-piece design, that they have larger deflection due to lower stiffness, that they require greater model clearance, and that their catastrophic failure mode requires higher Factor of Safety. An example of a singlepiece moment balance is shown in Fig. 4.

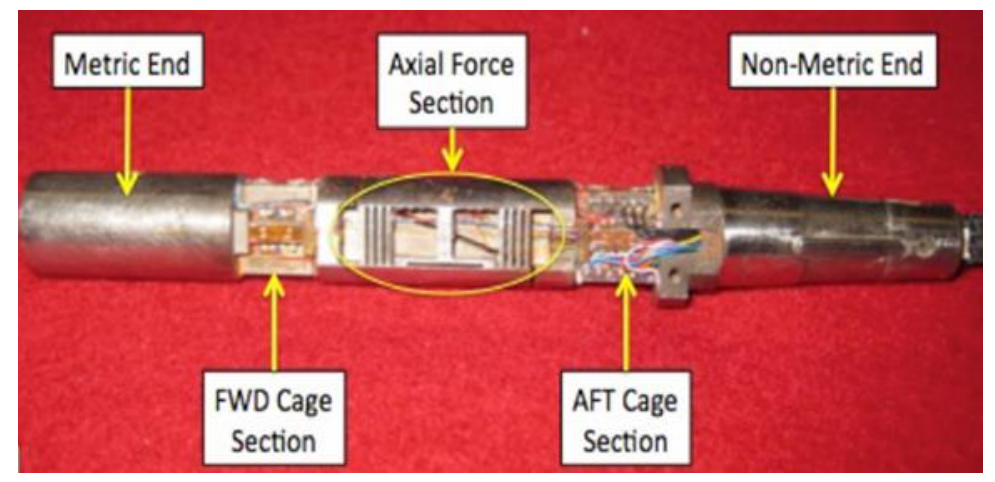

Fig. 4 LaRC Single-Piece Balance.

Direct-read balances are a combination of a direct-read electrical design and a moment or force balance mechanical design. The main advantage of direct-read balances is the ability to resolve applied loads into three forces (normal, axial and side force) and three moments (pitching, yawing, and rolling moment). The disadvantages are temperature compensation and more complex troubleshooting. The majority of LaRC balances are direct-read, moment balances, and, going forward, the term "balance" will refer to such balances, specifically [2].

\subsubsection{Strain Gage Design}

A balance is a "complex structural spring element" used to indirectly measure stress due to an applied load [1]. Strain, or $\epsilon$, is the change in length $(\Delta \mathrm{L})$ divided by the original length $(\mathrm{L})$, and the quotient is a dimensionless quantity, since both values are in units of length [4]. Within the elastic range of a material, stress and strain have a linear relationship that can be expressed by Hooke's Law, as shown in equation 1. In a balance, strain is measured using a serpentine-patterned metal wire, or resistor, known as a strain gage. The strain gage is secured to the balance using an adhesive and it measures variation in electrical resistance. The change in electrical resistance is proportional to the strain. Strain gage filaments are made from several different types of material, and each material 
has a unique sensitivity to strain, referred to as its Gage Factor (GF). GF is a ratio of the fractional change in electrical resistance to the fractional change in length (strain), which can be seen in equation 2 [5]. Constantan, a common material used in strain gages, has a typical GF of 2.0. Strain gages with a higher GF are better able to amplify the electrical signal, and LaRC uses strain gages that have a GF of 2.2 [2].

$$
\begin{gathered}
\sigma=E \epsilon \\
G F=\frac{\left(\frac{\Delta R}{R}\right)}{\left(\frac{\Delta L}{L}\right)}=\frac{\left(\frac{\Delta R}{R}\right)}{\epsilon}
\end{gathered}
$$

Strain gages vary in terms of active grid size and filament type; however, strain gages used for balances are almost always uniaxial. A typical strain gage used in a balance has the following components: filament wire, backing material, solder pads, and an active grid. The filament is a thin wire, approximately 0.001 inches thick. The backing, or carrier matrix, is a thin insulated material that acts as a support structure for the strain gage. The solder pads are used to wire gages in a Wheatstone bridge. The active grid consists of filaments connected, in series, with end loops. The gage length (GL) is the distance from the edge of the strain gage backing material to the center of the active grid, along the longitudinal axis. The layout of a typical strain gage can be seen in Fig. 5 .

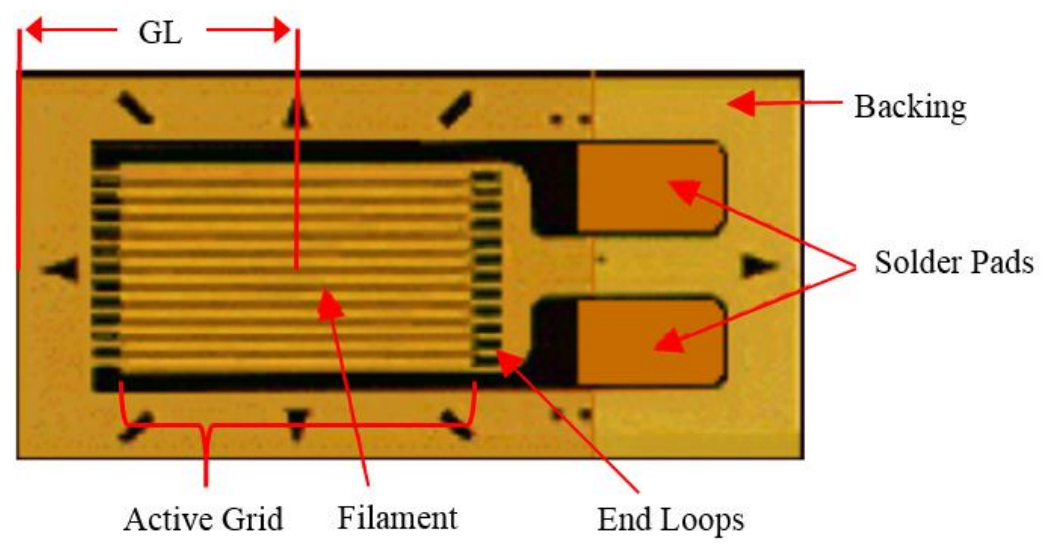

Fig. 5 Typical LaRC Strain-Gage. 


\subsubsection{Wheatstone Bridges}

A Wheatstone bridge is made up of four strain gages that are mounted, in deliberate locations, to flexure beams within the axial and cage sections. The strategy for locating and configuring strain gages has several objectives. First, strain gages are arranged such that the odd-numbered gages (\#1 and \#3) are in tension and the even-numbered gages (\#2 and \#4) are in compression, for a positive applied load. The gages in tension increase in resistance as a result of the elongation of the active grid filament, and the gages in compression decrease in resistance as a result of the contraction of the active grid filament. Next, gages are positioned such that the magnitude of the measured strain, for each pair of gages in tension and compression, are equal and opposite. For example, when an axial load of $50 \mathrm{lbf}$ is applied to the balance, gages \#1 and \#3 should each return a positive value of 412 micro-strain and gages \#2 and \#4 should each return a negative value of 412 micro-strain. The third objective is to locate each gage within the bridge such that interactions from loads other than the intended applied load are

minimized. Lastly, gages are positioned such that the resultant magnitude for each component is as close to equal as possible, i.e. such that individual bridge outputs for NF, AF, SF, PM, YM and YM are each approximately equal to $1100 \mu \mathrm{V} / \mathrm{V}$. The output of the Wheatstone bridge, in micro-volts per volt of excitation voltage, is given by equation 3.

$$
\text { Output }(\mu V / V)=\sigma(G F / E) * 10^{6}
$$

There are advantages and disadvantages to using four-gage Wheatstone Bridges. The main advantages are: maximizing sensitivity of the bridge output, averaging out the interaction effects that result from gage misalignment and deflections, and averaging out thermal effects. The main disadvantages are changes to the resistance, due to temperature and humidity. Temperature fluctuations result in zero shift. Temperature compensation is a highly iterative process that involves adding a temperature-sensitive wire, in series with one of the gages, to offset the resistance of the bridge, in concert with changes in temperature. LaRC strain gages are wired into the Wheatstone 
bridge such that the natural voltage offset from zero is maintained within $\pm 400 \mu \mathrm{V} / \mathrm{V}$ [6]. An example of a Wheatstone bridge with temperature sensitive wiring can be seen in Fig. 6.

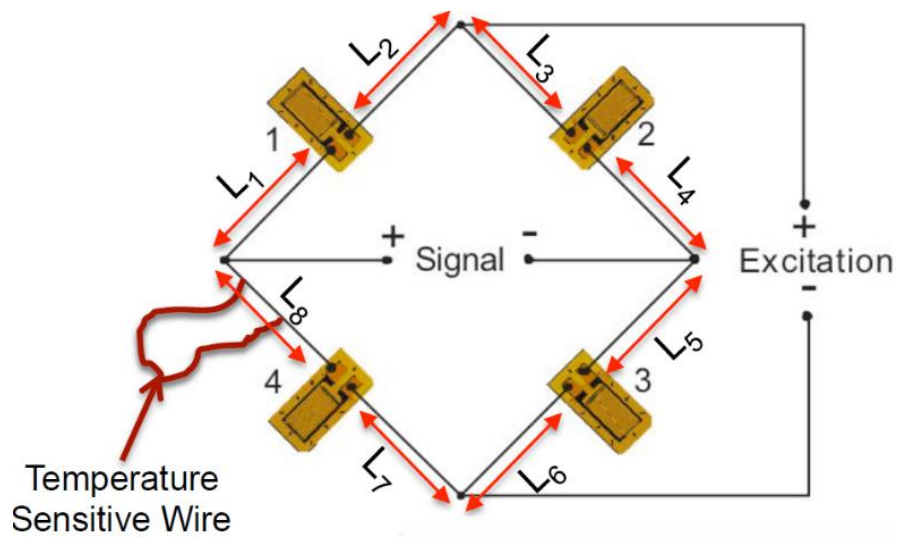

Fig. 6 Wheatstone Bridge with Temperature Sensitive Wiring.

\subsubsection{Beam Theory}

Balance design requires a thorough understanding of solid mechanics, mechanics of materials, and beam theory, specifically the effects of applied loads on cantilever beams. A balance can be modeled as a cantilever beam when mounted in a wind tunnel. The non-metric end of the balance, or fixed end, is mounted to the sting, and the aerodynamic model is mounted to the metric end, or free end, of the balance. A typical wind tunnel model-balance configuration is shown in Figure 7.

In Elastic-Beam Theory (EBT), beam deformation is the result of two components, internal shear force and bending moment. The largest contributor to deformation in an elastic beam is due to bending, when the ratio of beam length to beam depth (L/D) is very large, i.e. greater than 10:1. The deformation effects due to shear will be negligible, due to the plane sections remaining plane and can be ignored for simplification of calculations [7]. However, the L/D ratio of the beam elements in a FF-series balance is less than 10:1; therefore, EBT and its assumption are insufficient to accurately solve for deformation. Instead, the Timoshenko Beam Theory (TBT) provides a more accurate estimate of deformation for beam elements, with an L/D ratio less than 10:1, commonly referred to as short beams. TBT accounts for deformation due to shear force with the addition of the (Timoshenko) 
shear coefficient $(\mathrm{k})$, which is the ratio of average shear strain on a section to the shear strain at the centroid [8]. In this paper, the accepted value for the shear correction factor $(\mathrm{k}=5 / 6)$ for quasi-static beams was used. The body of a balance is treated as a rigid body with respect to the measurement beams in both the axial and the cage section.

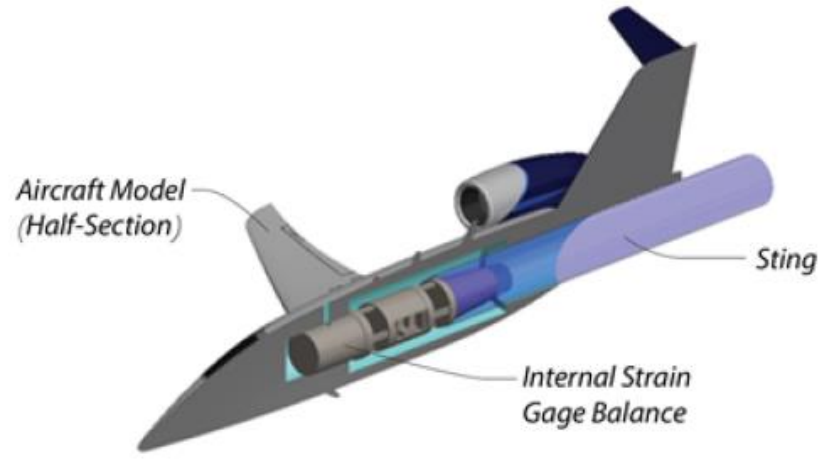

Fig. 7 Half Model with Balance and Sting. ${ }^{1}$

\subsubsection{Governing Equations and Application to Axial Section Design}

Over the years, LaRC engineers have developed closed-form analytical equations to estimate the stress, due to individually-applied component loads, in both the axial and cage sections of a balance. The stress analysis and the Factor of Safety estimation assumes that the maximum stresses for each component load are resolved at the same point within the balance. Given the unlikelihood of such an occurrence, the stress analysis underestimates the maximum stress and the Factor of Safety by as much as 10-15\% [6]. This section provides a sample of the stress equations and derivation for the axial section under an applied pure axial force. The process of deriving the stress equations is similar for each component load in both the axial and cage section, with minor variations. A complete listing of the stress equations used in the design of the FF09A and FF09X can be found in Appendix A.

The axial section is designed to measure strain from an applied axial load only, while isolating the gaged measurement beams from all other component interaction. The slotted-T design is used in the axial section of many LaRC balances for this purpose, and it consists of two distinct features: a strap and a measurement beam. The strap

\footnotetext{
${ }^{1}$ Aircraft model courtesy of Elias Gonzalez.
} 
runs parallel to the axial direction, and the measurement beam is normal to the axial direction. The measurement beam is connected at the midpoint of the strap to form a single T-shaped element. An example of typical LaRC axial section with a slotted-T design is shown in Figure 8. The thin strap has lower inertia and is therefore more compliant, relative to the measurement beam and body of the balance. The strap is fixed to the body at both the fore and aft ends and it translates in unison with the body. Under an applied axial load, the strap deforms in a doublebending mode, or S-bend, due to its relative compliance. As a result, the measurement beam can be modeled as a cantilever beam with a fixed end at the base and with the intersection with the strap serving as the free end. The measurement beam deforms in a single-bending mode that creates a shallower stress gradient, as well as more predictable stress output, at the gage location shown in Figure 9. The slotted-T configuration and the supporting flex beams fore and aft of the measurement beam aid in reducing the magnitude of interaction from loads other than axial, specifically normal force. A free body diagram of the strap-measurement beam is shown in Figure 9.

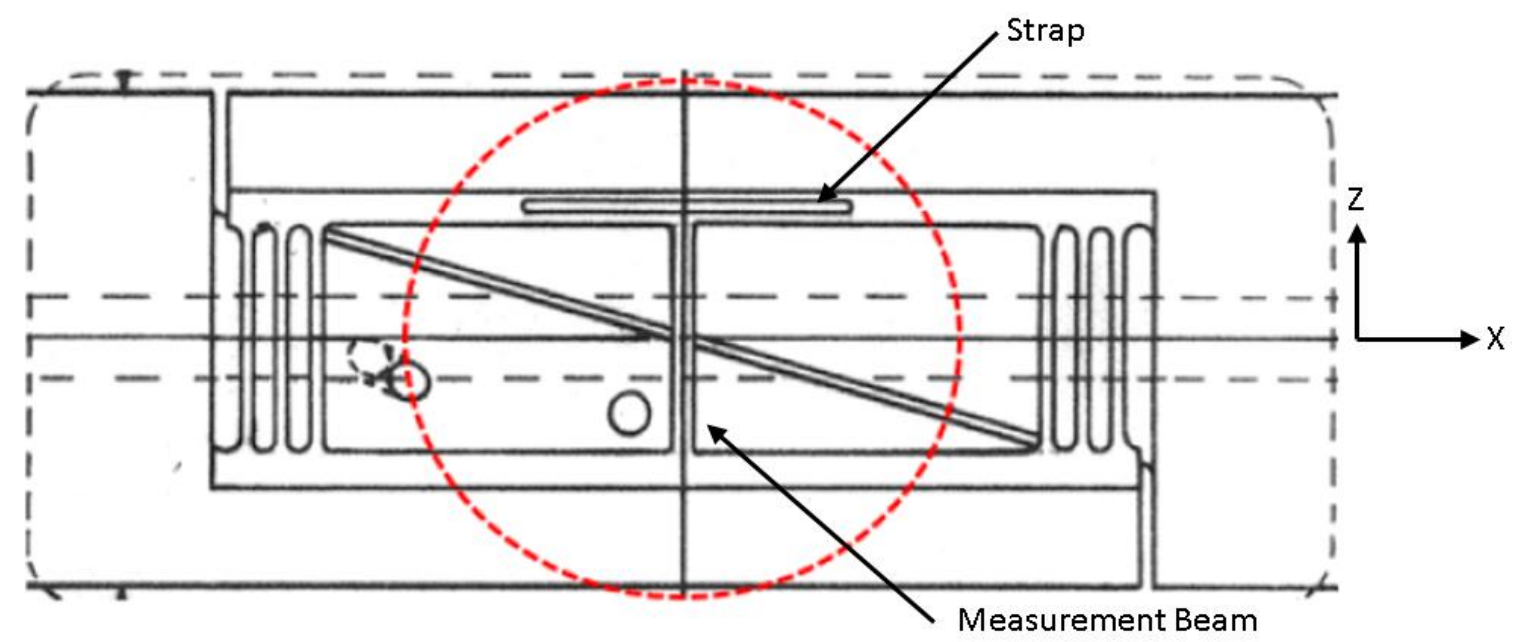

Fig. 8 Slotted-T Axial Section (side view). 

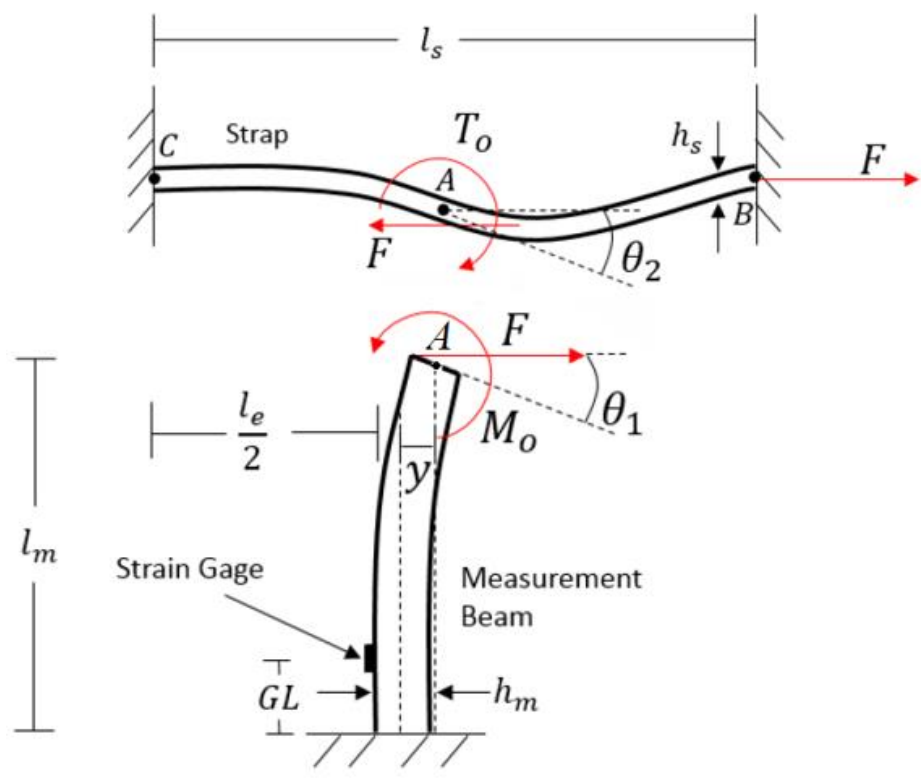

Fig. 9 Free Body Diagram of Strap-Measurement Beam in Axial Section.

This section will outline the procedure for calculating the stress at the strain gage location in Fig. 9. Total displacement of the measurement beam, denoted as $(y)$ in Fig.9, is the summation of four separate components of deflection, due to bending, shear, axial, and rotation, which are resolved at Point A, shown in Figs. 9 and 10. To determine the deflection in the measurement beam, the spring constant and the respective load distributions for the strap, measurement beam, and support flexures (flex) beams must be found.

Solving for deflection requires determining the slopes of the measurement beam and strap at Point A. The slope of the free end of the measurement beam $\left(\theta_{1}\right)$ is given by equation 4 .

$$
\theta_{1}=\frac{F l_{m}^{2}}{2 E I_{m}}-\frac{M_{0} l_{m}}{E I_{m}}
$$

The slope of the strap $\left(\theta_{2}\right)$ and the deflection $\left(\delta_{A}\right)$ are determined using the Moment-Area Theorems \#1 and \#2, respectively, given by equations 5 and 6 , based on the internal reaction force $\left(R_{A}\right)$ and internal moment $\left(T_{0}\right)$ shown in Fig. 10. 


$$
\begin{gathered}
\theta_{2}=\frac{1}{E I}[\text { Area of the Moment Diagram }]_{A-B} \\
\delta_{A}=\frac{1}{E I}[\text { Area of the Moment Diagram }]_{A-B} \bar{x}_{A}
\end{gathered}
$$

where $\left(\bar{x}_{A}\right)$ is the distance to the composite centroid of the M/EI diagram [7].

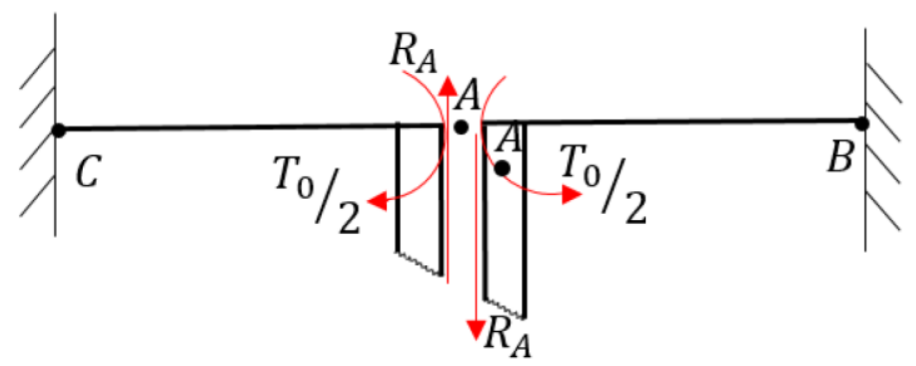

Fig. 10 Free Body Diagram of Internal Forces and Moments at Point A.

The measurement beam and the strap are connected at Point A, allowing equations 4 and 5 to be set as equal to one another, and the new equation can be used to solve for the moment, $\left(M_{0}\right)$. Having determined the moment, the total deflection at the free end of the measurement beam $\left(\delta_{m}\right)$ can be determined at Point A by summing the individual deflection components in equation 7 ,

$$
\delta_{m}=\frac{F l_{m}^{3}}{3 E I_{m}}\left(1+\frac{3 h_{s}}{4 l_{m}}-\frac{3 \beta}{2}\left(1+\frac{h_{s}}{l_{m}}\right)+\frac{3 E}{10 G}\left(\frac{h_{m}}{l_{m}}\right)^{2}+\frac{l_{e} h_{s}^{2} I_{m}}{16 l_{m}^{3} I_{s}}\right)
$$

where $(\beta)$ is a numerical factor for torsional stiffness. 
Having solved for the deflection at Point A, the spring constants for both the strap-measurement beams $\left(k_{m, s}\right)$ and the flex beams $\left(k_{f}\right)$ can determined using equations 8 and 9 , respectively,

$$
\begin{gathered}
k_{m, s}=\frac{F}{\delta_{m}}=\frac{3 E I_{m}}{l_{m}^{3}} \alpha \\
k_{f}=\frac{n_{f} b_{f} h_{f}^{3} E \gamma_{A F}}{l_{f}^{3}}=\frac{12 E I_{f} \gamma_{A F}}{L l_{f}^{3}}
\end{gathered}
$$

where $(\alpha)$ is a numerical factor for shear stress from torsion at the free end of the beam given by equation 10

$$
\alpha=\left(1+\frac{3 h_{s}}{4 l_{m}}-\frac{3 \beta}{2}\left(1+\frac{h_{s}}{l_{m}}\right)+\frac{3 E}{10 G}\left(\frac{h_{s}}{l_{m}}\right)^{2}+\frac{l_{s} h_{s}^{2} I_{m}}{16 l_{m}^{3} L_{s}}\right)^{-1}
$$

and $\left(\gamma_{A F}\right)$ is the spring constant correction factor given by equation 11

$$
\gamma_{A F}=\left(\left(\frac{h_{f}}{l_{f}}\right)^{2} 2.4(1+v)+1\right)^{-1}
$$

where $(v)$ is Poisson's ratio.

The total spring constant is the sum of the spring constants for strap-measurement beam and flex beams, $\left(k_{T}=k_{m, s}+k_{f}\right)$. The load proportions for the measurement beam $\left(N_{m, s}\right)$ and the flex beams $\left(N_{f}\right)$ are given in equations 12 and 13, respectively.

$$
\begin{gathered}
N_{m, s}=\frac{k_{m, s}}{k_{T}} \\
N_{f}=\frac{k_{f}}{k_{T}}
\end{gathered}
$$


The axial section is designed so that $60 \%$ of the load is carried by the measurement beams and $40 \%$ is carried by the flex beams; however, it is acceptable to distribute the load proportion between 60:40 and 50:50. The maximum stress in the measurement beam $\left(\sigma_{\max _{m_{A F}}}\right)$ due to an applied axial force is given by equation 14 .

$$
\sigma_{\max _{m_{A F}}}=\frac{6 A F N_{m, s} l_{m}(1-\beta)}{n_{m} b_{m} h_{m}^{2}}
$$

The stress in the measurement beam at the gage location, assuming a linear stress gradient, is given by equation 15

$$
\sigma_{\text {gage }_{m}}=\frac{6 A F N_{m, s}\left(l_{m}(1-\beta)-G L_{A F}\right)}{n_{m} b_{m} h_{m}^{2}}
$$

where $\left(G L_{A F}\right)$ is the distance from the measurement bulkhead to the center of the active grid of the strain gage. The gage output in $(\mu V / V)$ can be determined by converting the maximum gage stress, using equation 16 .

$$
\text { Counts }_{A F}=\sigma_{\text {gage }_{\text {mF }}}\left(\frac{G F}{E}\right) 1 * 10^{6}
$$

The process outlined above is repeated for each of the five remaining forces and moments applied to the axial section to determine the maximum stress and the load proportions carried by the measurement beam, strap, and flex beam groups. Once the cage section beam configuration is designed, the same process for deriving the stress equations is applied to the cage section. Results for all calculations can be found in Appendix A.

\subsection{Problem Statement}

The purpose of this research is to determine the feasibility of reducing the fabrication time and the cost associated with the manufacturing of a new balance, while maintaining the target strain-gage sensitivity of 1100 $\mu \mathrm{V} / \mathrm{V}$. The new design should be a direct replacement for the FF09 single-cage balance. The design must follow 
general DFM guidelines and must exclude the use of Sink EDM as a method for fabrication. Balance geometry should be simplified as much as possible, i.e. with no blind cuts, and with fabrication to be completed using line-ofsight machining operations. Constraints inherent to a direct replacement design are the maintenance of the existing mounting configuration and external balance dimensions, material selection (17-4 PH), and the presence of an axial and single-cage section.

\subsection{The FF09 Balance}

A typical single-piece balance consists of the following areas: the axial section, one or more cage sections, and provisions for securing the balance to both the model end, or metric end (ME), and the model support system, or non-metric end (NME). Model support is typically provided by a support arm, known as a sting. The FF09A is a single-cage balance made from a billet of 17-4 PH high-strength stainless steel that has been heat treated to H925 with a resulting hardness between 40 and 45 on the Rockwell Hardness C scale (HRC). The overall dimensions of the FF09A are 2-inch x 2-inch x 6-inch. The Balance Moment Center (BMC) is located 0.5-in from the forward bulkhead at the center of the cage, coincident with the longitudinal centerline, as seen in Fig. 11. The FF09A is symmetrical about the XZ-plane, as seen in Fig. 12.

The axial section is designed to resist effects from all loads other than axial force, and it contains three key geometric features: flexure beams, straps, and measurement beams. The FF09A axial section has four flexure beam groups, and each group consists of four flexure beams which isolate the measurement beams from all loads other than an applied axial load [9]. The straps are thin beams, oriented along the longitudinal axis (x-direction). The measurement beams are centered between the forward and aft flexure beam groups and are oriented perpendicularly to the longitudinal axis. Each measurement beam is connected to a strap at its mid-length to form a T-shape, and, due to their large base-to-height ratio, the strap and measurement beams experience double and single bending deflection, respectively, under an applied axial load. Strain-gages are placed at the base of the measurement beams, on both the front and rear face, adjacent to the fillet at the beam-pedestal junction. A sample of the axial strain-gage orientation is shown in Fig. 13.

The cage section is designed to measure the remaining five-component loads. It contains two beam groups, and each group has two variable-inertia beams which have large radii machined in the outer face. A detailed view of the variable-inertia beam is shown in Fig. 14. Each cage beam is centered along the face parallel to the longitudinal axis 
and is recessed a minimum of 0.020 -inches to provide clearance for strain-gages and related wiring and to prevent binding between model and balance. A general schematic of the FF09A can be found in Appendix B.

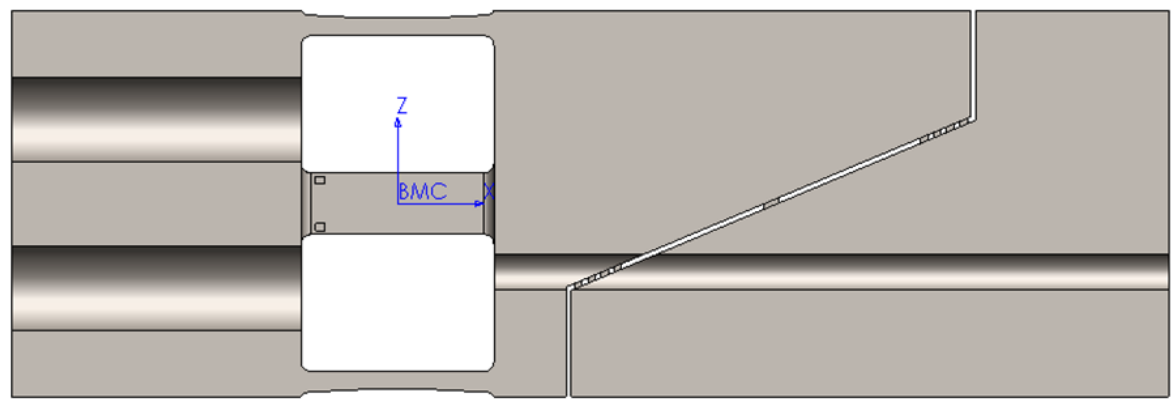

Fig. 11 FF09A Balance Moment Center (section view).

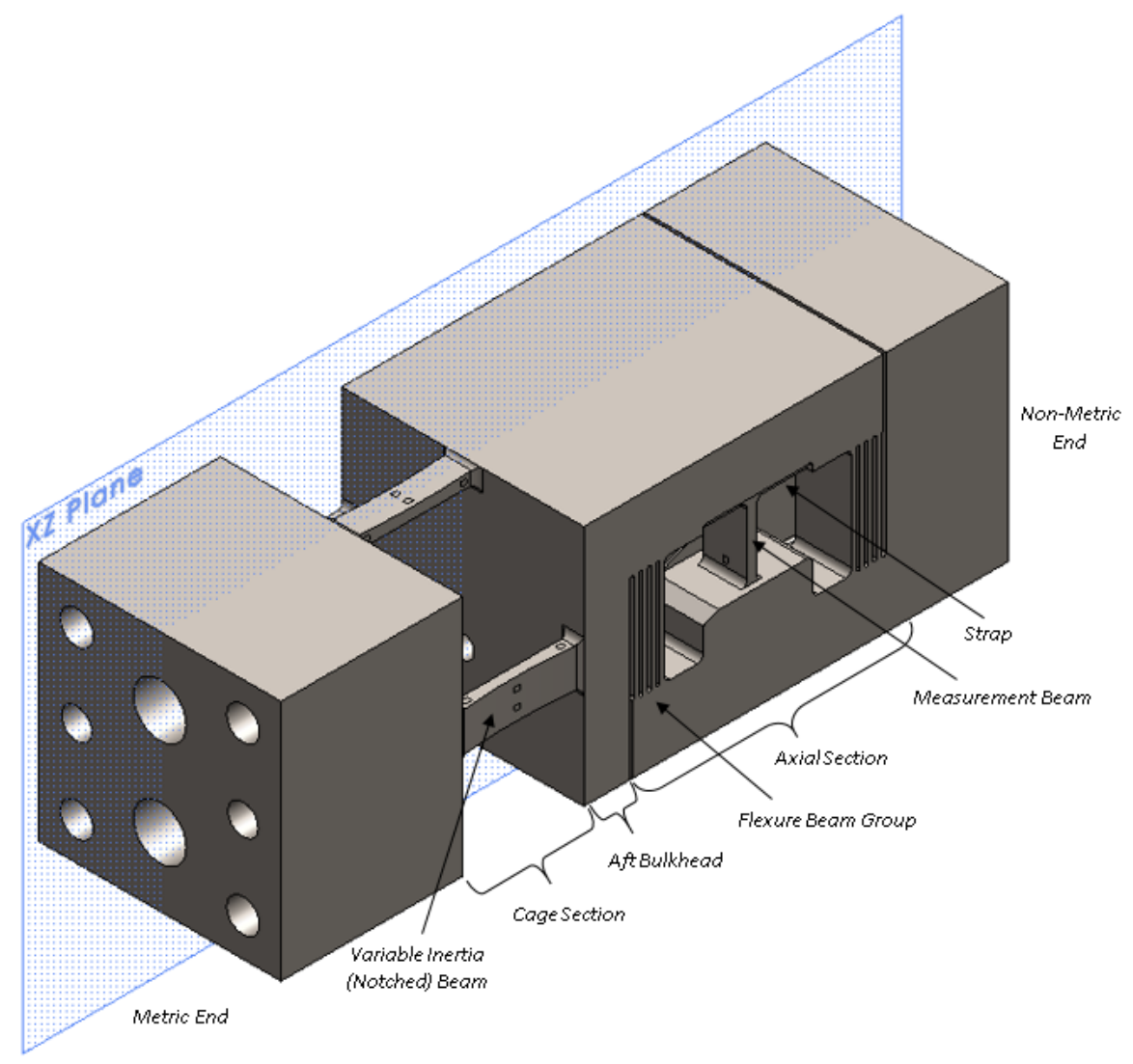

Fig. 12 FF09A Design Features (isometric view). 


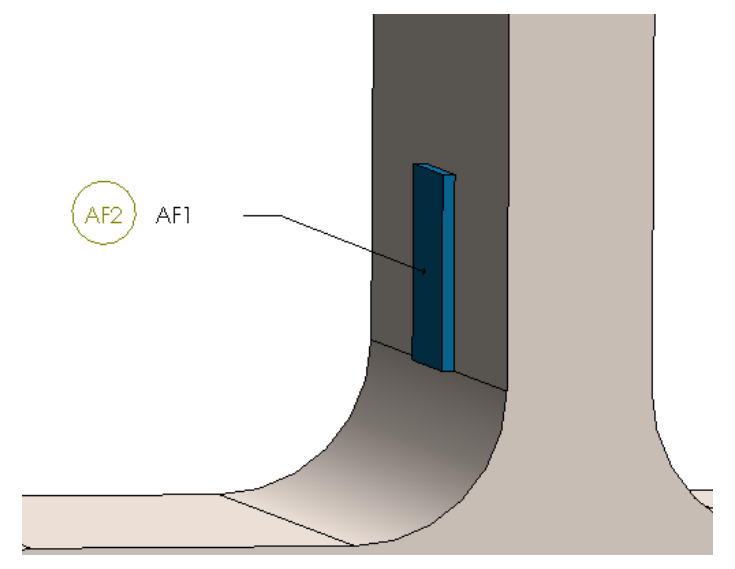

Fig. 13 Sample Axial Strain-Gage Orientation (detail view).

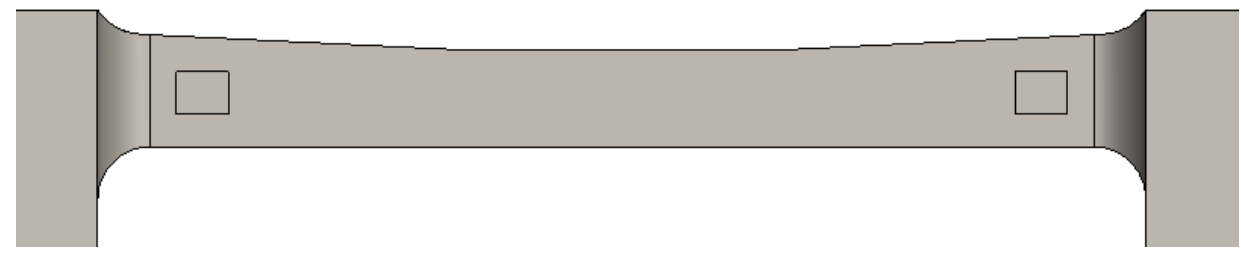

Fig. 14 Variable-Inertia Beam (detail view).

\subsection{Impetus for New Design}

The process of designing and manufacturing a balance is time-intensive, due to its complex nature.

Successful design of a new balance involves making tradeoffs between competing factors, all of which are highly valued by the designer. This paper presents a balance design methodology that builds upon the successful research of a two-component (Thrust/Torque) aluminum balance, called the ODU15X15, fabricated solely by conventional machining methods [10]. The ODU15X15 balance shares key design features with other LaRC balance designs, such as a single cage section with two beam groups, and an axial section with four multi-flexure beam groups and a pair of measurement beams. A key difference with the ODU15X15 design was its full-length center bore; a typical LaRC balance has a solid, or T-shaped, cross section throughout the balance except for the cage section. The slots between the flexure beams and bulkheads in the axial section, known as flex gaps and end gaps, respectively, have larger radii than traditional LaRC balances. A minimum radius is driven by conventional machine tooling requirements, such as the tool core diameter (Fig. 15), to reduce tool deflection resulting from applied cutting forces. 
Tool deflection is lessened as the core diameter increases, due to increased rigidity. The larger slot radius, the softer material, and the addition of the center bore were a few design factors that facilitated the exclusive use of conventional machine tools when fabricating the ODU15X15 balance.
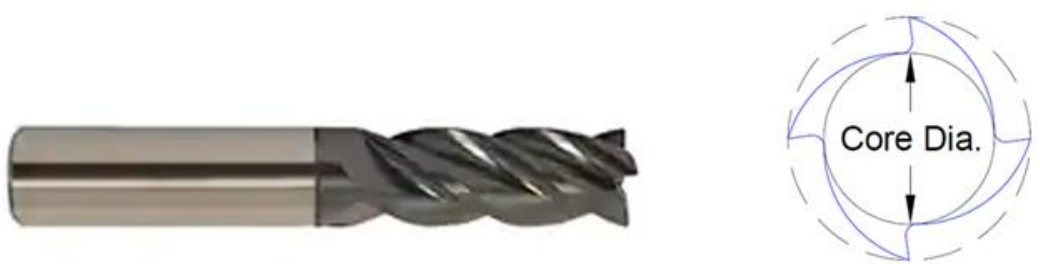

Fig. 15 Sample End Mill and Core Diameter Description.

The initial design iterations for this study were based upon the successful design of the ODU15X15, as seen in Fig. 16. The FF09A has five distinct areas within the balance: Axial Section, Cage Section, T-Section, model mounting points (ME), and sting mounting points (NME). Early FF09X iterations included two-piece designs consisting of a main body which housed the sting mounting holes, the axial and cage sections, an end cap which housed the model mounting holes, and a center bore. Two methods for fusing the main body and the end cap together were evaluated: Press-Fit (Fig. 17) and Welded-Fit. The press-fit method would require heating the main body to 300-degrees Fahrenheit while simultaneously cooling the end cap to 32-degrees Fahrenheit, in order to minimize the force required to press the end cap into the main body. The welded-fit method would require pressing the end cap into the main body and then using plug welds to secure the two solid bodies together. In addition to known issues related to multi-piece balances, i.e. hysteresis and zero shift, the process of fusing two pieces together created several additional challenges, including, but not limited to:

- Damage to one or both parts during press-fit or welding

- Fabrication of special jigs to ensure accuracy in part alignment

- Tight tolerances $(<0.0005$ in.) between interfacing surfaces

- Large or unknown residual stresses in one or both pieces, post-fusion

- Adverse effects to material properties in the heat-affected zone "HAZ" from welding (welding softens, or over-ages, the precipitation-hardened $(\mathrm{PH})$ material, requiring a complete reannealing and secondary heattreatment to restore desired strength and hardness) 


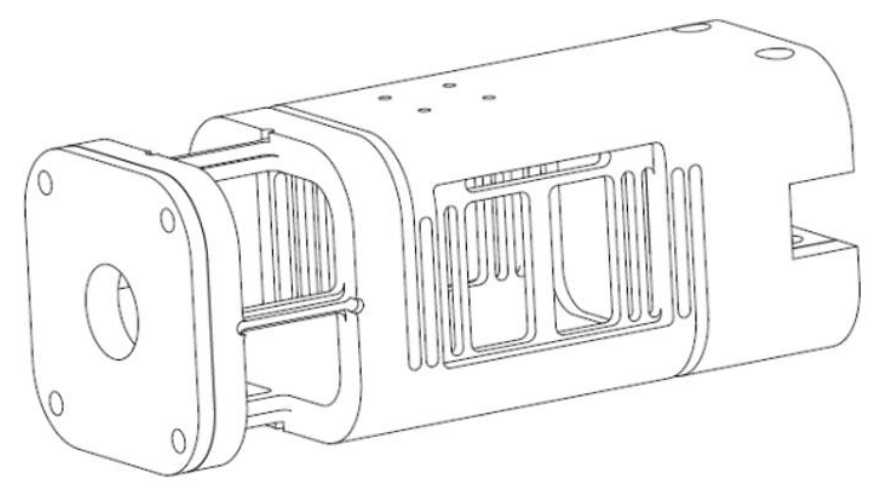

Fig. 16 ODU15X15 Thrust/Torque Balance (isometric view).

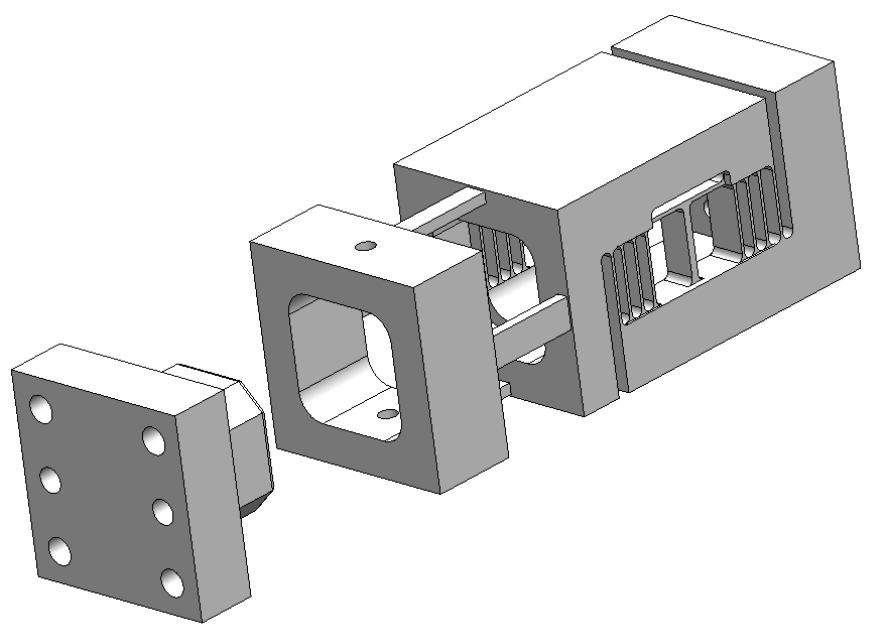

Fig. 17 Press-Fit Concept (isometric view).

Each balance has a unique a set of design requirements driven by the testing environment. The design requirements for a balance fall into four categories: 1) Size/volume, 2) Loads, 3) Measurement output and resolution, and 4) Factor of Safety [2]. The design goal for the FF09X was to be a direct replacement for the FF09A that was cheaper and easier to fabricate. The FF09X needed to match the existing specifications for its predecessor, specifically in terms of size, loads, and mounting configuration. The FF09X load requirements can be found in Table 1. Material selection, Factor of Safety, and the design of both the cage and axial sections were variables to be 
driven by DFM guidelines. Additionally, the FF09X needed to perform as well or better than the FF09A, in terms of strain-gage output sensitivity. LaRC design practices target a strain-gage output of $1100 \mu \mathrm{V} / \mathrm{V}[6]$.

Table 1. FF09 Load Requirements.

\begin{tabular}{|c|c|c|c|}
\hline \multicolumn{4}{|c|}{ FF09 Load Requirements } \\
\hline Force & {$[$ [lbf] } & Moment & {$[$ in-lb] } \\
\hline Normal & 100 & Pitch & 480 \\
\hline Axial & 50 & Roll & 180 \\
\hline Side & 60 & Yaw & 540 \\
\hline
\end{tabular}




\section{CHAPTER 2}

\section{DESIGN FOR MANUFACTURABILITY}

Design for Manufacturability (DFM) is a design-based approach to product development aimed at reducing manufacturing time and cost. DFM guidelines are incorporated during the design phase, where the relative costs of changes to a design are significantly lower than during production [11]. Improvements in machining technology have reduced the gap between conventional and non-conventional machining methods, in terms of both time and cost. Five-axis CNC mills reduce the number of required setups, and high-speed machining has broadened the selection of machinable materials. However, line-of-sight tool paths remain a limiting factor of conventional machining, and non-conventional machining practices have also benefited from technological advances. Optimization studies on CNC EDM parameters have further reduced costs while increasing material removal rates, reducing tool wear rates and improving surface roughness [12]. The design approach for the FF09X, presented below, incorporates the following general DFM guidelines:

- Simplify the overall design

- Avoid sharp corners where possible

- Minimize the number of required setups

- Design for low-labor-cost production methods.

DFM is subjective, and it does not necessitate the use of one machining method in favor of another. Cost and fabrication time were the drivers for the selection of the machining method, and both conventional and nonconventional machining methods were initially evaluated; from this, two approaches formed the basis of comparison: 1) conventional machining only, and 2) Wire EDM and conventional machining.

In a balance, flexure beam groups contain multiple flexures, sometimes no more than 0.030 -inch thick and separated by a gap equally as thin. Precision machine tools, tight tolerances $(<0.0005$-inches $)$ and blind cuts are required to create the flexures. Blind cuts require the use of special manufacturing processes and non-conventional machine tools, such as EDM. EDM is a thermal erosion process that melts away material at a fixed distance by passing a voltage across a gap from an electrode to the work piece [13]. There are three main types of EDM: Sink, Wire, and Hole-Drill. Sink EDM (SEDM) uses a graphite electrode, called a sinker die, to create complex features in a work piece, e.g. a blind cut, by "sinking" the die into the work piece. For blind cuts, the electrode is the positive 
complement to the cavity, as illustrated in Fig. 18. The work piece is submerged in dielectric fluid, typically deionized water, which controls the spark, provides cooling, and flushes waste material away from the work piece. Wire EDM (WEDM) uses a thin wire as the electrode, which passes continuously through the work piece to remove material, while flushing the gap with dielectric fluid. Hole-Drill EDM (HEDM) inserts a rotating probe-like electrode into the work piece, which removes material within the fixed gap around its full circumference. Similarly, dielectric fluid flushes away waste material and cools the work piece. The benefits of EDM include improved surface finish, no need for cutting forces applied to work piece, the ability to cut sharp internal corners, and the maintenance of tight tolerances. Conversely, the disadvantages are the slow material removal rate for both WEDM and SEDM and the additional time and cost required to make the electrodes for SEDM. Another limiting factor of EDM is that the work piece must also be conductive. The FF09A was fabricated using primarily SEDM and WEDM and required an estimated 600 hours to fabricate ${ }^{2}$.

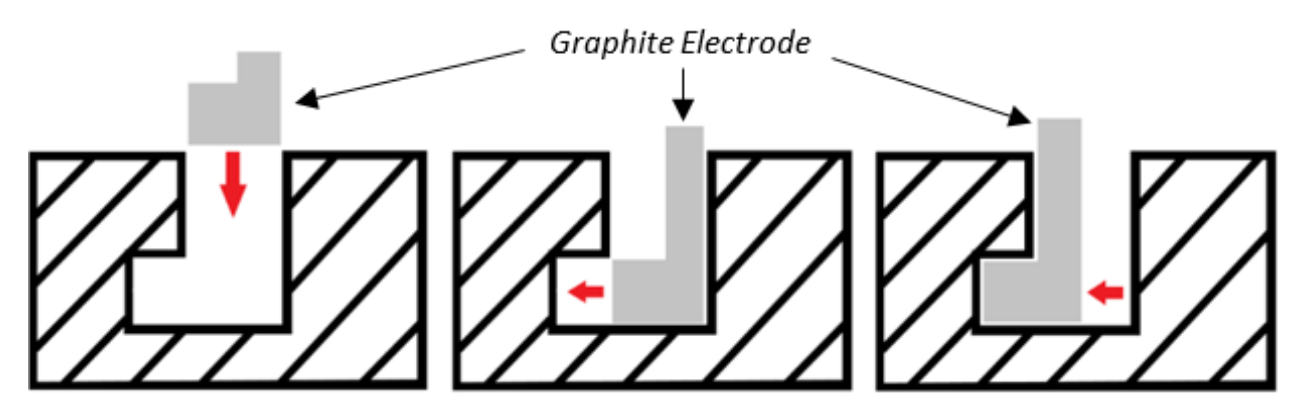

Fig. 18 Example of a Blind Cut using Sink EDM.

Slots between the flexure beams and the end gaps had to be enlarged, so that conventional machining could be used to create the axial section geometry. Keeping with DFM, a minimum radius of 0.0625 -inches was chosen for the entire work piece, in order to minimize number of setups and tool changes. Tool deflection, tool damage, and part quality are concomitants of machining methods and of tooling selection. Two critical parameters related to machine tool selection are Axial Depth of Cut (ADOC) and Radial Depth of Cut (RDOC), as shown in Fig. 19. ADOC is the distance a tool engages the work piece along its centerline, and RDOC is the distance the tool is

\footnotetext{
${ }^{2}$ Conversation with P.A. Parker, Team Lead at NASA LaRC
} 
stepping over into the work piece [14]. The hardness of 17-4 PH requires the use of the more rigid machine tools, e.g. carbide end mills, with special coatings, e.g. Aluminum Titanium Nitride (AlTiN), which reduces friction between the tool and the work piece and extends tool life.

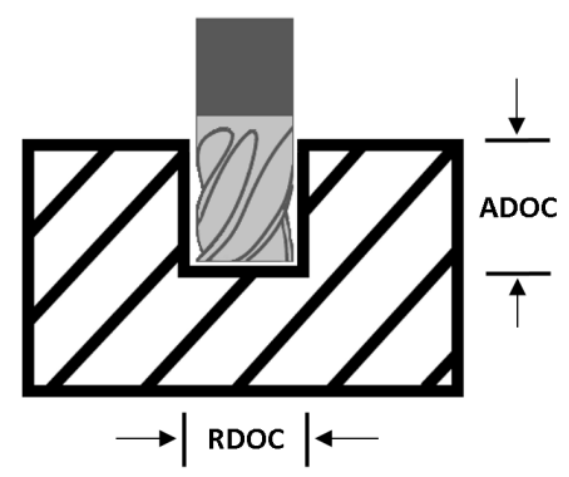

Fig. 19 Sample of End Mill Selection Parameters ADOC and RDOC. 


\section{CHAPTER 3}

\section{DESIGN METHODOLOGY}

\subsection{Overview of Approach}

When designing a new balance, the designer is encouraged to first determine whether an existing balance will meet the design criteria; if so, the designer may simply utilize the existing balance, in lieu of designing a new one [6]. However, the objective of this design study excluded the use of an existing design, so the next step was to determine how much of an existing balance design could be carried over into the new design. Ideally, the FF09X, where X stands for experimental, would be a direct replacement for the FF09A. The FF09X design would have the same external dimensions, load requirements, mounting configuration, and level of performance as the FF09A, but it could be made in less time and at a lower cost. As a direct replacement balance, the FF09X could be used with existing FF09A wind tunnel models without the need for mounting adaptors, which would save additional time and cost. The next step was to establish a starting point for the design iteration process. A systematic design methodology was employed to ensure the validity of both the design process and the end results. The design methodology was broken down into five phases, which are outlined below:

- Benchmarking FF09A stress analysis

- Rapid design iteration using an auto-updating analytical stress estimation tool

- FEA comparison between FF09A and initial FF09X concept

- FF09X Optimization - Cage beam geometry

- $\quad$ FEA-based FF09X design verification

\subsection{Benchmarking}

The first phase was to establish a benchmark for comparing the stress outputs from the original FF09A closed-form analytical calculations with future design iterations using Computer-Aided Design (CAD) and Finite Element Analysis (FEA). LaRC engineers used closed-formed analytical calculations to estimate the stress imposed upon the FF09A under the specified loads. The analytical approach is a conservative method for estimating the maximum stress and the factor of safety in a balance, because it assumes that the maximum stress, a summation of all six individual component loads, will occur simultaneously at a single point in the balance [6]. The likelihood of the combined stresses from multiple loads occurring at one location is very low; in fact, empirical evidence has shown that the analytical stress equations overestimate stresses by as much as 10 to 15 percent. 
FEA is a well-known numerical method that can predict, or approximate, how the balance will respond to a single load or a combination of loads. FEA software tools provide a visualization of stress, strain, and deflection, in addition to computed values. FEA results can provide valuable global information, such as the maximum magnitude of stress, or the stress at a specific location resulting from a given load, which may be more difficult if not available from the analytical results. Therefore, it was not reasonable to compare the FF09A analytical results with FEA results without first establishing a benchmark. An acceptable benchmark would be corroboration between the FEA stress analysis from an FF09A CAD model and the original closed-form analytical results from the Balance FF-09 report [15].

The Balance FF-09 report provides stress output results for single load cases only, so the FF09A FEA was set up and run for single-load cases only, as well. For further validation, two FF09A CAD models were generated in different CAD packages, and FEA results were compared against each other and against the analytical results. Given the known over-estimation of the analytical calculations, reasonable agreement (with 10-15\%) between the FEA results and the analytical results would substantiate the FF09A FEA results and the CAD model as a benchmark for future FF09X designs.

\subsection{Rapid Design Iteration}

The second phase of the design process was the development of a user-friendly stress prediction tool to facilitate a more rapid iterative design process. The stress prediction tool included closed-form analytical calculations using beam theory from LaRC's extensive design memo library; all equations were cross-referenced for accuracy against structural mechanics texts, including Timoshenko Beam Theory $[4,6,8,16]$. At LaRC, balance designers have access to a design guide [6] that outlines the theory and derives the governing equations used to predict stress in a balance and a spreadsheet-based stress calculator. Stress outputs were compared against results from the Balance FF-09 report, in order to validate the tool. The stress prediction tool was used to iterate preliminary balance designs, specifically axial and cage beam configurations, more quickly.

The existing spreadsheet calculator accepts user input in the form of geometric parameters and outputs stress values, based upon the equations from the design guide. Currently, the spreadsheet serves as the starting point for new LaRC balance designs, and it drives the initial geometry in the cage and axial sections. The format is 
tailored to the design of double-cage cylindrical balances, which vary enough from a square balance, e.g. the FF09A, to necessitate modifications to aid in the initial FF09X design.

A user-friendly spreadsheet alternative, based on a MathCAD ${ }^{\circledR}$ worksheet, was constructed in place of the spreadsheet-based calculator to create an editable, auto-updating stress prediction calculator (stress calculator) with all equations readily visible. The stress calculator automatically updated corresponding outputs, based upon the serial order of equation evolution outlined in the DG; first, the axial section was designed, followed by the cage section. The stress calculator modernized the design iteration process in two ways: 1) it reduced data input/output time, and 2) it eliminated need for FEA runs on infeasible designs. Figure 20 provides a sample of stress calculator inputs and equation structure.

\begin{tabular}{|c|c|c|c|c|}
\hline & & \multicolumn{3}{|c|}{ Axial Stress Equations } \\
\hline & \multicolumn{2}{|c|}{ Axial Section } & & Flexible Beam \\
\hline Measurement Beam & Flex Beams & Strap & Material Properties & $S_{A f}:=\frac{3 \cdot P_{A} \cdot N_{f} \cdot l_{f}}{n_{f} \cdot b_{f} \cdot h_{f}^{2}}=6549 \mathrm{psi}$ \\
\hline $\begin{array}{l}n_{m}:=2 \\
l_{m}:=0.600 \text { in } \\
b_{m}:=0.360 \text { in } \\
h_{m}:=0.076 \text { in }\end{array}$ & $\begin{array}{l}n_{f}:=16 \\
l_{f}:=0.900 \text { in } \\
b_{f}:=0.460 \cdot \text { in } \\
h_{f}:=0.038 \text { in }\end{array}$ & $\begin{array}{l}n_{s}:=2 \\
l_{s}:=0.900 \text { in } \\
b_{s}:=0.360 \text { in } \\
h_{s}:=0.030 \text { in }\end{array}$ & $\begin{array}{l}E \equiv 28.5 \cdot 10^{6} p s i \\
G \equiv 11.2 \cdot 10^{6} p s i \\
\mu \equiv 0.272 \\
G F \equiv 2.2\end{array}$ & $\begin{array}{l}\text { Measurement Beam } \\
S_{A m}:=\frac{6 \cdot P_{A} \cdot N_{m} \cdot l_{m} \cdot\left(1-\beta_{\text {axial }}\right)}{2}=16813 \mathrm{psi}\end{array}$ \\
\hline Forces & Moments & Gage Information & & $n_{m} \cdot b_{m} \cdot h_{m}^{2}$ \\
\hline $\begin{array}{l}P_{A}:=50 \mathrm{lbf} \\
P_{N}:=100 \mathrm{lbf} \\
P_{S}:=60 \mathrm{lbf}\end{array}$ & $\begin{array}{l}M_{P}:=480 \mathrm{in} \cdot \mathrm{lbf} \\
M_{R}:=180 \mathrm{in} \cdot \mathrm{lbf} \\
M_{Y}:=540 \mathrm{in} \cdot \mathrm{lbf}\end{array}$ & $G L_{m}:=0.1025$ in & & $S_{\text {Agage }}:=\frac{6 \cdot P_{A} \cdot N_{m} \cdot\left(l_{m} \cdot\left(1-\beta_{\text {axial }}\right)-G L_{m}\right)}{n_{m} \cdot b_{m} \cdot h_{m}{ }^{2}}=13231 \mathrm{psi}$ \\
\hline
\end{tabular}

Fig. 20 Sample from MathCAD® Stress Calculator.

The stress calculator predictions for stresses in the FF09A were all higher and closer to the target output, compared to the original as-built measured FF09A calibration data. A summary of that data can be found in Table 2. 
Table 2. FF09 Bridge Output (Actual vs. Predicted vs. Targeted)

\begin{tabular}{|c|c|c|c|c|}
\hline \multirow{3}{*}{ Load } & $\begin{array}{c}\text { Actual } \\
\text { FF09A }\end{array}$ & $\begin{array}{c}\text { Predicted } \\
\text { FF09A } \\
\text { MathCAD }^{\circledR}\end{array}$ & Target & \% Diff \\
\cline { 2 - 5 } & $\begin{array}{c}\text { Bridge } \\
\text { Output }\end{array}$ & $\begin{array}{c}\text { Bridge } \\
\text { Output }\end{array}$ & $\begin{array}{c}\text { Bridge } \\
\text { Output }\end{array}$ & $\begin{array}{c}\text { Actual vs. } \\
\text { Predicted }\end{array}$ \\
\cline { 2 - 5 }$[\boldsymbol{\mu} \mathbf{V} / \mathbf{V}]$ & {$[\boldsymbol{\mu V} / \mathbf{V}]$} & {$[\boldsymbol{\mu V} / \mathbf{V}]$} & {$[\%]$} \\
\hline Normal & 802 & 874 & 1100 & $9 \%$ \\
\hline Axial & 899 & 1021 & 1100 & $13 \%$ \\
\hline Side & 846 & 892 & 1100 & $5 \%$ \\
\hline Pitch & 1149 & 1193 & 1100 & $4 \%$ \\
\hline Roll & 1058 & 1139 & 1100 & $7 \%$ \\
\hline Yaw & 1090 & 1002 & 1100 & $8 \%$ \\
\hline
\end{tabular}

\subsection{Comparison of FEA Results}

The next step was the comparison of FEA results between the FF09A and FF09X CAD models. The FF09A CAD model was constructed from a detailed drawing provided by LaRC, and a simplified schematic of the FF09A can be found in Appendix B. An initial FF09X CAD model was designed, based on the ODU15X15 concept, the FF09A design features, and the DFM guidelines. In addition, the following constraints were imposed on the overall design:

- Minimum radius of 0.0625 in driven by 0.125 in diameter end mill with cut length greater than 0.5 in

- $\quad$ Minimum of (4) flexure beams per group in the axial section (16 total)

- $\quad$ Maintain FF09A mounting configuration

- Maintain adequate aft bulkhead thickness (approx. 0.375 in)

- Maximum of (2) constant-inertia beams per group in cage section

A target gage stress of $15 \mathrm{ksi}$ was set for each of the six components, which corresponded to a Wheatstone bridge output of $1158 \mu \mathrm{V} / \mathrm{V}$, to ensure adequate gage output resolution [6]. Using the stress calculator, iterations of the critical geometric parameters, which were based initially on the FF09A geometry, were input, until the FF09X stress outputs were within $+/-10 \%$ of the target gage stress. The corresponding geometric parameters were then imported into the FF09X CAD model. A sample of the parameterized FF09X Axial Section is shown in Fig. 21. A detailed schematic of the FF09X can be found in Appendix C. 


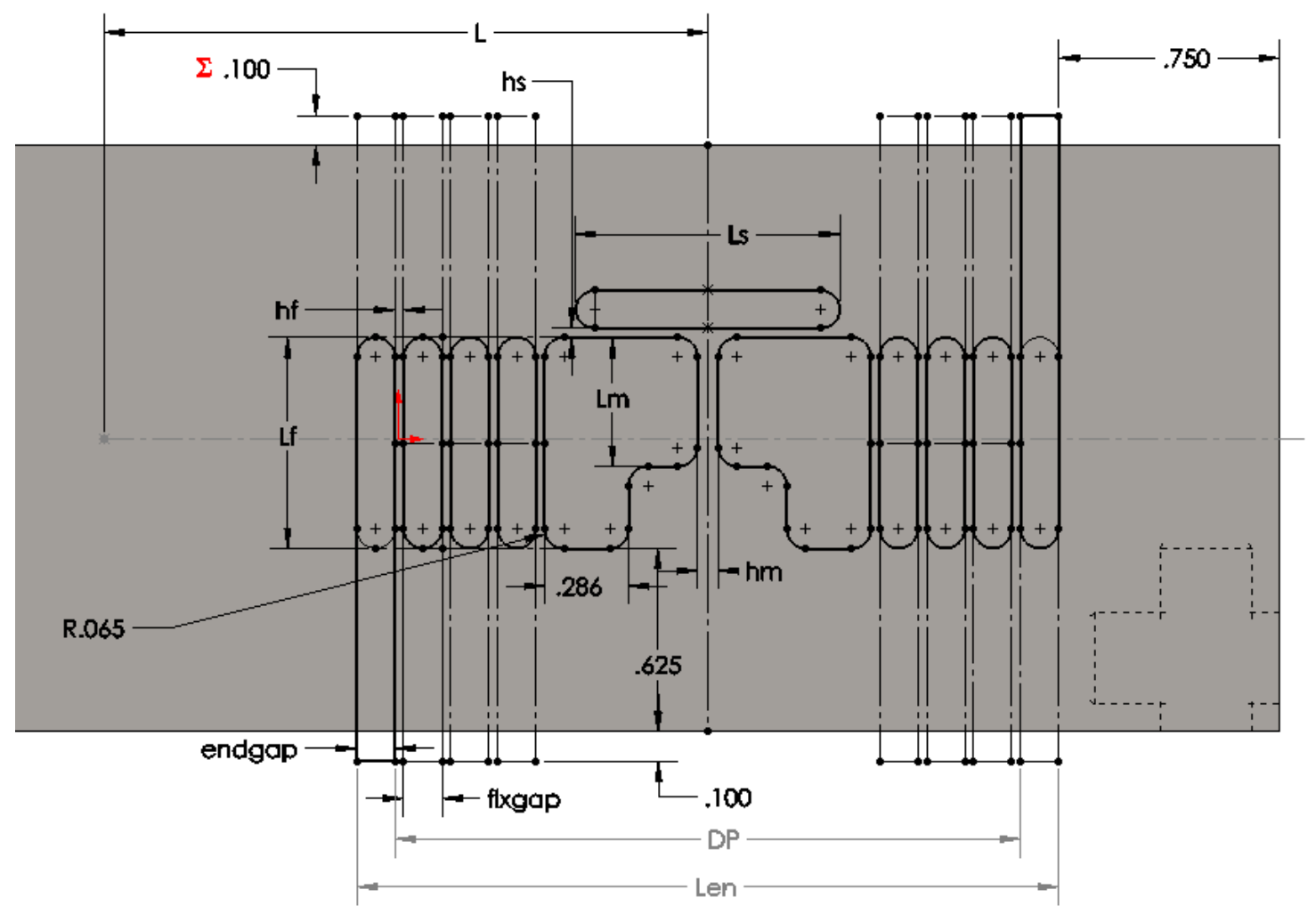

Fig. 21 Parametric Sketch of FF09X Axial Section (detail view).

The design study was predicated on conventionally machining the new balance design, and the axial section geometry (specifically the narrow slots) was expected to be the most challenging area to machine. Therefore, a portion of the initial axial section design was conventionally machined into a test coupon, as shown in Fig. 22, to verify the machinability of the 17-4 PH material in its H925 heat treated condition. The test coupon, 2-inch x 2-inch x 0.5-inch, was fabricated on a Haas ${ }^{\circledR}$ V2 CNC machine, using a 0.125 -inch diameter and a 5/8-inch cut length AlTiN-coated carbide end mill. The 0.125-inch diameter end mill was the minimum diameter that would have the required rigidity and cut length without excessive risk of breakage and tool chatter, which would have diminished the quality of the finished work piece. 

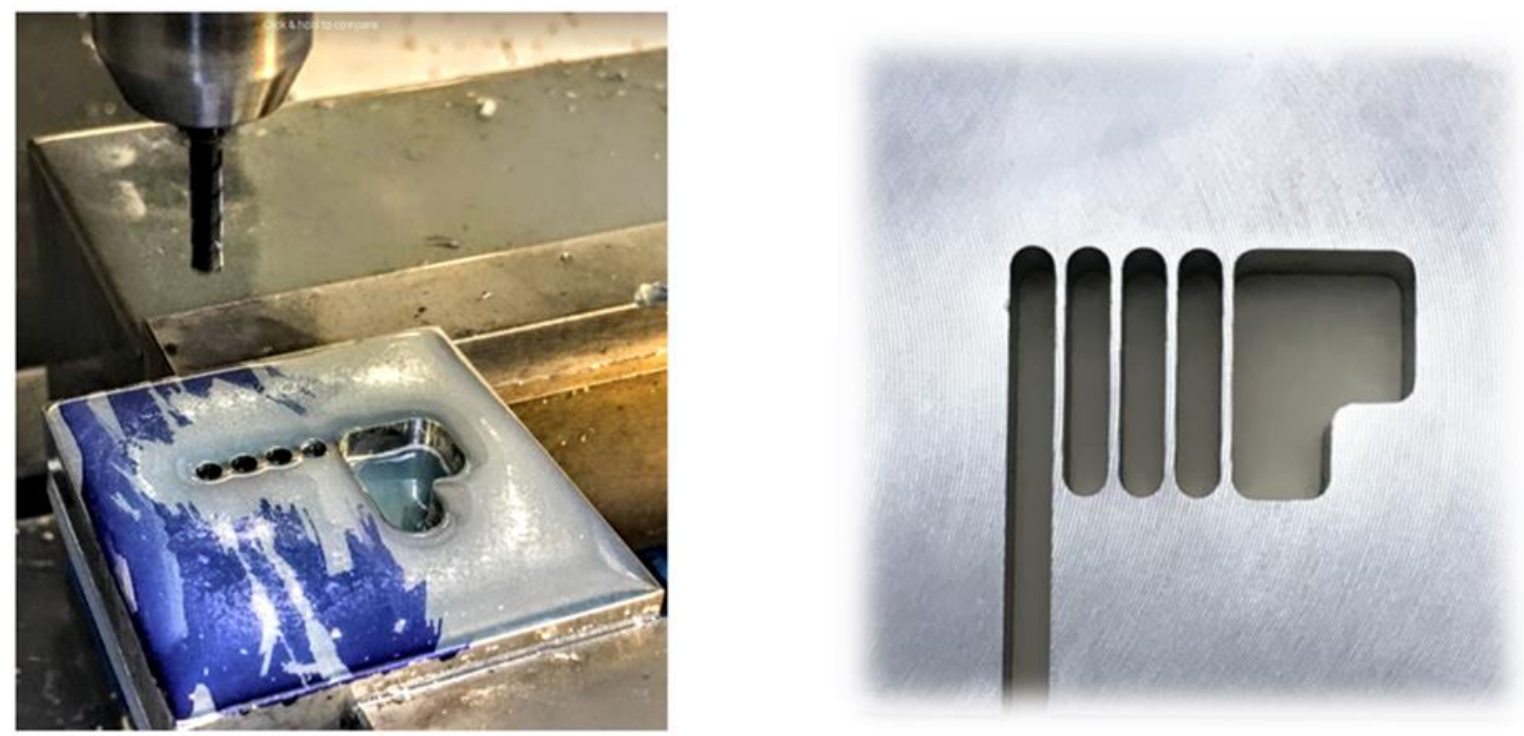

Fig. 22 Test Coupon with Partial Axial Section Conventionally Machined.

Next, geometry, representative of the strain-gages to be used with the physical balance, was added to both the FF09A and FF09X CAD models. Rectangular area segments were created in each model to represent the active grid of the strain-gage, and each area segment was located on the corresponding flexures used to measure each load. A detailed wiring diagram for the FF09X can be found in Appendix D.

A curvature-based mesh with medium detail was applied to the entire model to minimize computer resources, and local mesh refinements were applied to the rectangular area segments to enhance resolution. Stress outputs were calculated by combining the average stress value from each of the four area segments, (+) for tension and (-) for compression, using the bridge output equations in equations 17 and 18 [6]. The bridge will yield a positive output for positive applied loads when gages 1 and 3 are in tension and 2 and 4 are in compression.

$$
\begin{gathered}
\sigma_{\text {bridge }}(p s i)=\left[\left(\left(\sigma_{1}+\sigma_{3}\right)-\left(\sigma_{2}+\sigma_{4}\right)\right) / 4\right] \\
\text { Bridge Output }(\mu V / V)=\sigma_{\text {bridge }}(G F / E) * 10^{6}
\end{gathered}
$$


The subscripts denote the gage number within each respective Wheatstone bridge, and the corresponding gage values are the normal stress in units of pounds force per square inch (psi). Figures 23 and 24 are samples of the area segment and mesh refinement detail, respectively, for a sample strain-gage.

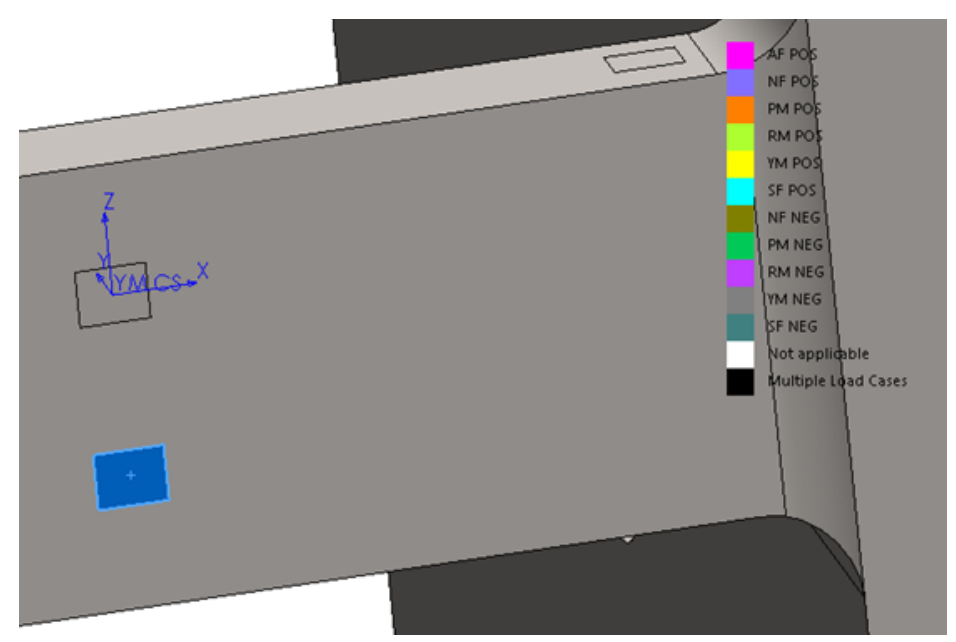

Fig. 23 Sample Strain-Gage Active Grid.

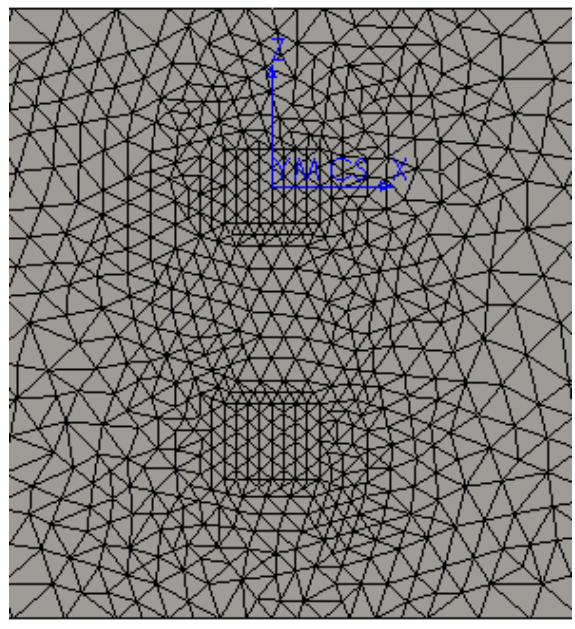

Fig. 24 Strain-Gage Mesh Refinement.

Design of Experiments (DOE) is a systematic method to determine a cause-and-effect relationship between a set of factors and responses [17]. FEA facilitated the evaluation of both single and multi-load cases, whereas the 
analytical predictions were limited to single load cases only. A $2^{\mathrm{k}}$, full factorial design was selected, where $\mathrm{k}=4$ represents the total number of factors exercised in the experiment, each over two levels. Using Design Expert ${ }^{\circledR}$ software, the $2^{4}$, design was constructed for the FEA multi-case load schedule used for both the FF09A and FF09X [18]. The initial five factors are NF, PM, RM, YM, and SF. AF, the load applied to a wind-tunnel model primarily due to drag force, was treated as independent and only applied in the positive direction according to Fig. 1. Due to symmetry of the balance along the Normal-Axial plane, only the positive SF load cases were run, which facilitated the $2^{4}$ design, reducing the total number of runs to 16 . Three test cases were run with negative SF to verify the symmetry assumption. Table 3 shows the multi-load schedule with factors given in coded units. The +1 indicates a full-scale load in the positive direction, the -1 the negative direction.

Table 3. FEA Multi-Load Run Schedule for FF09A and FF09X

\begin{tabular}{|c|c|c|c|c|c|c|}
\cline { 2 - 7 } \multicolumn{1}{c|}{} & $\mathbf{A F}$ & $\mathbf{N F}$ & $\mathbf{P M}$ & $\mathbf{R M}$ & $\mathbf{Y M}$ & $\mathbf{S F}$ \\
\hline $\mathbf{R u n}$ & {$[\mathbf{l b f}]$} & {$[\mathbf{l b f}]$} & {$[\mathbf{i n}-\mathbf{l b}]$} & {$[\mathbf{i n}-\mathbf{l b}]$} & {$[\mathbf{i n}-\mathbf{l b}]$} & {$[\mathbf{l b f}]$} \\
\hline $\mathbf{1}$ & 1 & -1 & -1 & -1 & -1 & 1 \\
\hline $\mathbf{2}$ & 1 & -1 & -1 & -1 & 1 & 1 \\
\hline $\mathbf{3}$ & 1 & -1 & -1 & 1 & -1 & 1 \\
\hline $\mathbf{4}$ & 1 & -1 & -1 & 1 & 1 & 1 \\
\hline $\mathbf{5}$ & 1 & -1 & 1 & -1 & -1 & 1 \\
\hline $\mathbf{6}$ & 1 & -1 & 1 & -1 & 1 & 1 \\
\hline $\mathbf{7}$ & 1 & -1 & 1 & 1 & -1 & 1 \\
\hline $\mathbf{8}$ & 1 & -1 & 1 & 1 & 1 & 1 \\
\hline $\mathbf{9}$ & 1 & 1 & -1 & -1 & -1 & 1 \\
\hline $\mathbf{1 0}$ & 1 & 1 & -1 & -1 & 1 & 1 \\
\hline $\mathbf{1 1}$ & 1 & 1 & -1 & 1 & -1 & 1 \\
\hline $\mathbf{1 2}$ & 1 & 1 & -1 & 1 & 1 & 1 \\
\hline $\mathbf{1 3}$ & 1 & 1 & 1 & -1 & -1 & 1 \\
\hline $\mathbf{1 4}$ & 1 & 1 & 1 & -1 & 1 & 1 \\
\hline $\mathbf{1 5}$ & 1 & 1 & 1 & 1 & -1 & 1 \\
\hline $\mathbf{1 6}$ & 1 & 1 & 1 & 1 & 1 & 1 \\
\hline
\end{tabular}

An ideal balance design minimizes interactions from applied loads other than the one being measured. For example, the normal bridge should only measure applied loads due to normal force and would be isolated from all other loads. 
The multi-load FEA runs allowed for the comparison of each bridge output across all 16 runs, and the range in values correlates to possible interactions. A small range in values suggests that little-to-no interaction exists, whereas a larger range would suggest that there is a noticeable interaction. In general, a range of less than $10 \%$ of the average bridge output is an acceptable level of interaction to be identified during calibration, based on historical experience. The stress and voltage output for each bridge, for each of the 16 multi-load runs, can be found in Fig.

25.

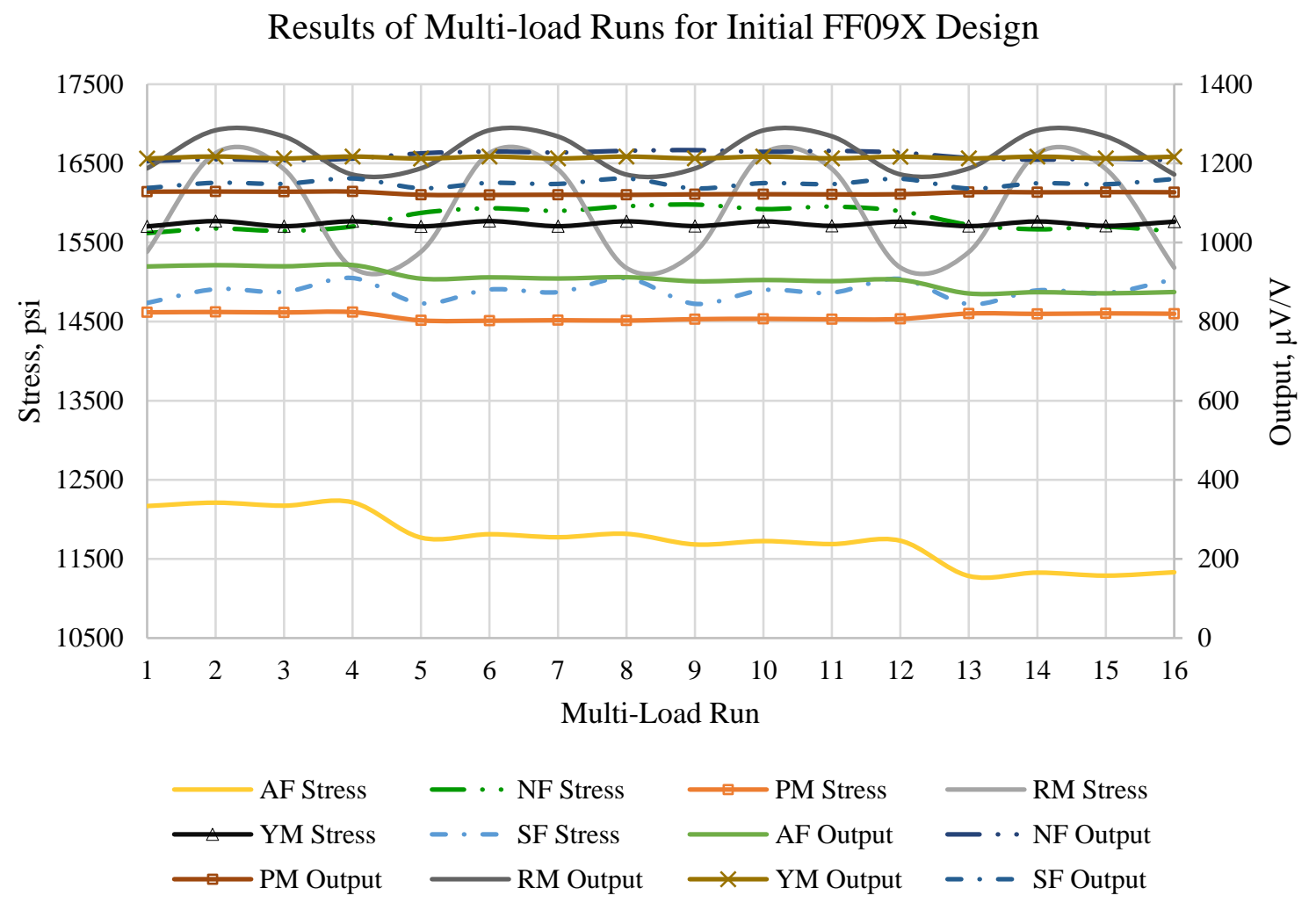

Fig. 25 Multi-Load Run Results for Initial FF09X Design.

\subsection{Design Optimization}

Two major challenges in the design of the cage section were deciding which of the many design-related factors to change and deciding how to evaluate the outcomes of such changes. Initial sensitivities to parameter variation for the cage design were assessed using a One Factor at a Time (OFAT) approach, which was quickly 
deemed inadequate due to the interactive relationship between factors. Initial attempts were made to limit or to eliminate factors, in accordance with DFM guidelines, and to ensure that the FF09X would serve as a direct replacement for the FF09A. For example, the number of beam groups and the number of beams per group in the FF09X remained unchanged at two and two, respectively. Use of constant-inertia beams, rather than variable-inertia or "notched" beams, simplified the design and eliminated an additional variable: notch radius. Six remaining factors were selected and were optimized, as listed in Table 4.

The center bore and external boundary of the balance further limited the range of possible values for the beam width, $\left(b_{i}\right)$ and the beam height, $\left(h_{i}\right)$, as well as the distance from the BMC to the beam centroids, $\left(r_{i}\right)$ along the yz-plane. The range of values for beam width, beam height, and centroidal distance along the y and z-axis were based on the FF09A. The smallest cross-sectional area from the FF09A notched beams, located at the mid-length of each beam, served as the mean value for beam width and beam height. The range for each of the two factors was $\pm 10 \%$, using a bracketed approach. Determining the range for possible distances from the BMC to the beam centroid was more challenging, due to the hollow cross-section. At the model end, the wall thickness varied between 0.375-inch and 0. 5-inch, and $\left(r_{i}\right)$ values had to fall within the available wall cross-section. Accounting for straingages and wiring that will be applied to the outer-facing surfaces of the cage beams further constrained the extreme values, both for $\left(r_{1}\right)$ and for $\left(r_{2}\right)$. A 0.023 -inch gap between the outer beam surface and the external boundary of the balance, closely mirroring the FF09A configuration, was chosen, to prevent possible fouling of the balance. The cage beam factors and dimensional constraints can be seen in Fig. 26. 
Table 4. Cage Beam Factors

\begin{tabular}{|c|c|}
\hline \multicolumn{2}{|c|}{ Cage Beam Factors } \\
\hline Beam Group & Beam Group \\
$\mathbf{1}$ & $\mathbf{2}$ \\
\hline$[$ in] & [in] \\
\hline b1 & b2 \\
\hline h1 & h2 \\
\hline r1 & r2 \\
\hline
\end{tabular}

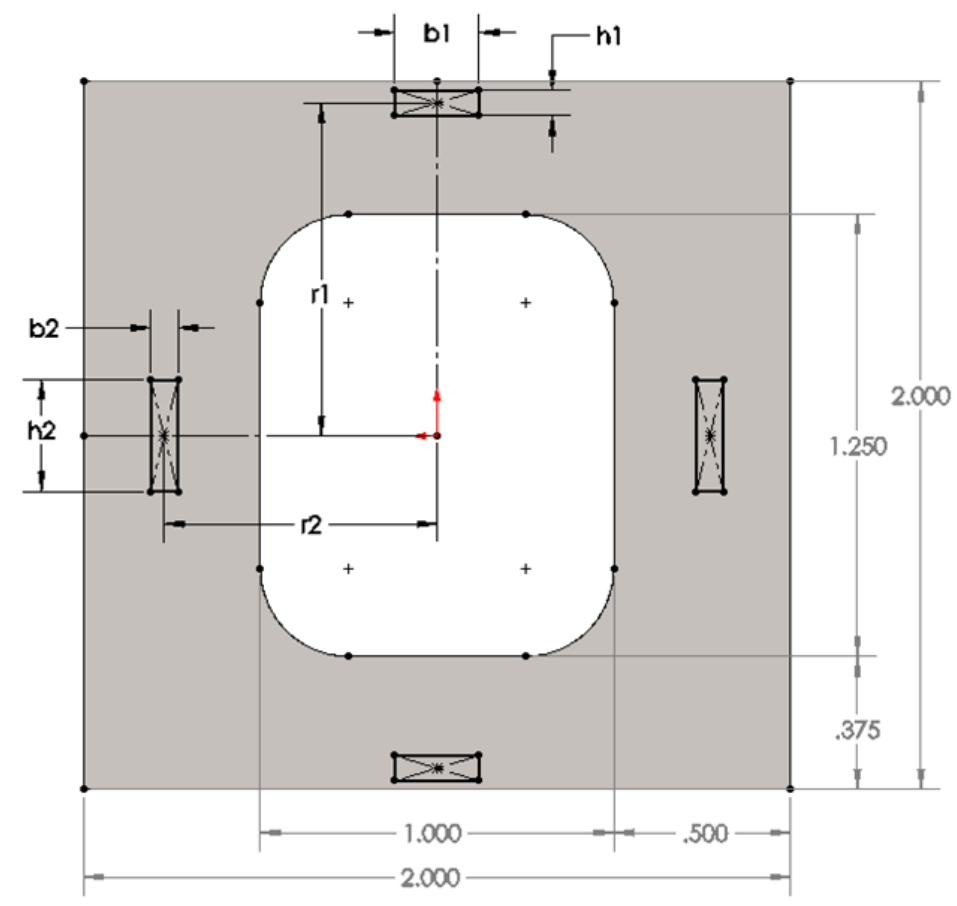

Fig. 26 Cage Beam Factors and Dimensional Constraints (dimensions in inches).

A DOE screening experiment was designed, to identify the factors that had the most significant effect on cage stress outputs. A $2^{6-1}$ Fractional Factorial, Resolution VI design was used to optimize the cage factors. Resolution VI designs allow low-risk identification of effects up to 3FI. The higher order interactions, 3FI through 6FI, were likely negligible and could therefore be disregarded, a principle known as Sparsity of Effects [17]. The initial design consisted of 33 factor combinations, as shown in Table 5. Once generated, the factors for each of the 
33 runs were input into the stress calculator software. The responses were average bridge gage stress outputs (AF, NF, PM, YM, RM, SF). Since the factors were input into a computer-based tool, there was no random variation in the outputs, i.e. the model was deterministic. The coefficient of determination family of statistics, or the $\mathrm{R}^{2}$ values, were useful in determining the model's adequacy. All $\mathrm{R}^{2}$ values range from 0 to 1 . "An $\mathrm{R}^{2}$ value of zero means that the model cannot predict a dependent variable based on an independent variable, and an $\mathrm{R}^{2}$ value of 1 means that the model can predict a dependent variable from an independent variable without error [19]." The $\mathrm{R}^{2}$ values from the first-order-plus-interaction model were well below 90\%, which suggests that the model had room for improvement. 
Table 5. Cage Beam Factor Combinations for Initial 33 Runs (dimensions in inches)

\begin{tabular}{|c|r|r|r|r|r|r|}
\cline { 2 - 7 } \multicolumn{1}{c|}{} & Factor & Factor & Factor & Factor & Factor & Factor \\
\cline { 2 - 7 } & \multicolumn{1}{c|}{ b1 } & \multicolumn{1}{c|}{ h1 } & \multicolumn{1}{c|}{ r1 } & \multicolumn{1}{c|}{ b2 } & \multicolumn{1}{c|}{ h2 } & \multicolumn{1}{c|}{ r2 } \\
\hline Run & \multicolumn{1}{c|}{ [in] } & \multicolumn{1}{c|}{ [in] } & \multicolumn{1}{c|}{ [in] } & \multicolumn{1}{c|}{ [in] } & \multicolumn{1}{c|}{ [in] } & \multicolumn{1}{c|}{ [in] } \\
\hline $\mathbf{1}$ & 0.198 & 0.06 & 0.94 & 0.05 & 0.288 & 0.94 \\
\hline $\mathbf{2}$ & 0.198 & 0.06 & 0.94 & 0.085 & 0.352 & 0.94 \\
\hline $\mathbf{3}$ & 0.198 & 0.095 & 0.6 & 0.05 & 0.352 & 0.6 \\
\hline $\mathbf{4}$ & 0.198 & 0.095 & 0.6 & 0.05 & 0.288 & 0.94 \\
\hline $\mathbf{5}$ & 0.198 & 0.095 & 0.94 & 0.085 & 0.352 & 0.6 \\
\hline $\mathbf{6}$ & 0.242 & 0.095 & 0.94 & 0.05 & 0.288 & 0.94 \\
\hline $\mathbf{7}$ & 0.242 & 0.095 & 0.6 & 0.05 & 0.352 & 0.94 \\
\hline $\mathbf{8}$ & 0.242 & 0.095 & 0.94 & 0.085 & 0.352 & 0.94 \\
\hline $\mathbf{9}$ & 0.198 & 0.06 & 0.94 & 0.05 & 0.352 & 0.6 \\
\hline $\mathbf{1 0}$ & 0.198 & 0.06 & 0.6 & 0.085 & 0.288 & 0.94 \\
\hline $\mathbf{1 1}$ & 0.198 & 0.095 & 0.94 & 0.085 & 0.288 & 0.94 \\
\hline $\mathbf{1 2}$ & 0.242 & 0.095 & 0.94 & 0.05 & 0.352 & 0.6 \\
\hline $\mathbf{1 3}$ & 0.242 & 0.06 & 0.94 & 0.085 & 0.352 & 0.6 \\
\hline $\mathbf{1 4}$ & 0.242 & 0.06 & 0.94 & 0.05 & 0.352 & 0.94 \\
\hline $\mathbf{1 5}$ & 0.242 & 0.095 & 0.6 & 0.085 & 0.352 & 0.6 \\
\hline $\mathbf{1 6}$ & 0.242 & 0.06 & 0.6 & 0.05 & 0.288 & 0.94 \\
\hline $\mathbf{1 7}$ & 0.242 & 0.095 & 0.6 & 0.05 & 0.288 & 0.6 \\
\hline $\mathbf{1 8}$ & 0.242 & 0.06 & 0.6 & 0.085 & 0.288 & 0.6 \\
\hline $\mathbf{1 9}$ & 0.242 & 0.06 & 0.6 & 0.05 & 0.352 & 0.6 \\
\hline $\mathbf{2 0}$ & 0.242 & 0.095 & 0.6 & 0.085 & 0.288 & 0.94 \\
\hline $\mathbf{2 1}$ & 0.198 & 0.06 & 0.6 & 0.05 & 0.288 & 0.6 \\
\hline $\mathbf{2 2}$ & 0.22 & 0.0775 & 0.77 & 0.0675 & 0.32 & 0.77 \\
\hline $\mathbf{2 3}$ & 0.198 & 0.06 & 0.94 & 0.085 & 0.288 & 0.6 \\
\hline $\mathbf{2 4}$ & 0.198 & 0.095 & 0.6 & 0.085 & 0.352 & 0.94 \\
\hline $\mathbf{2 5}$ & 0.242 & 0.06 & 0.94 & 0.05 & 0.288 & 0.6 \\
\hline $\mathbf{2 6}$ & 0.242 & 0.06 & 0.94 & 0.085 & 0.288 & 0.94 \\
\hline $\mathbf{2 7}$ & 0.198 & 0.06 & 0.6 & 0.085 & 0.352 & 0.6 \\
\hline $\mathbf{2 8}$ & 0.198 & 0.06 & 0.6 & 0.05 & 0.352 & 0.94 \\
\hline $\mathbf{2 9}$ & 0.242 & 0.095 & 0.94 & 0.085 & 0.288 & 0.6 \\
\hline $\mathbf{3 0}$ & 0.198 & 0.095 & 0.6 & 0.085 & 0.288 & 0.6 \\
\hline $\mathbf{3 1}$ & 0.242 & 0.06 & 0.6 & 0.085 & 0.352 & 0.94 \\
\hline $\mathbf{3 2}$ & 0.198 & 0.095 & 0.94 & 0.05 & 0.352 & 0.94 \\
\hline $\mathbf{3 3}$ & 0.198 & 0.095 & 0.94 & 0.05 & 0.288 & 0.6 \\
\hline & & & & & & \\
\hline
\end{tabular}


Given the potential inadequacy of the first order model, the design was augmented to a Central Composite Design (CCD) by adding face-centered axial points, which added another 12 runs to the design, for a total of 45 runs [20]. Table 6 shows the factor combinations for the additional 12 runs. The additional runs facilitated the building of a full quadratic regression model in favor of the first-order-plus interaction model from the original fractional factorial design. Predicted R-squared values were now greater than 97\% for all bridge responses, except for Roll (93\%). A desirability approach to setting goals for optimization was implemented in Design Expert ${ }^{\circledR}$ software. A target of 15 ksi was set for each of the five responses, excluding Axial (Table 7). Axial stress was not measured by gages in the cage section, but instead was calculated using the simple stress equation [stress $=$ force/area]. The $15 \mathrm{ksi}$ target was chosen to ensure that gage output sensitivity was sufficiently high, and it was close to the $1100 \mu \mathrm{V} / \mathrm{V}$ target without exceeding $1500 \mu \mathrm{V} / \mathrm{V}$. The optimized factor settings for the cage section are shown in Table 8 .

Table 6. Cage Beam Factor Combinations for Additional 12 Runs (dimensions in inches)

\begin{tabular}{|c|c|c|c|c|c|c|}
\cline { 2 - 7 } \multicolumn{1}{c|}{} & $\begin{array}{c}\text { Factor } \\
\mathbf{1}\end{array}$ & $\begin{array}{c}\text { Factor } \\
\mathbf{2}\end{array}$ & $\begin{array}{c}\text { Factor } \\
\mathbf{3}\end{array}$ & $\begin{array}{c}\text { Factor } \\
\mathbf{4}\end{array}$ & $\begin{array}{c}\text { Factor } \\
\mathbf{5}\end{array}$ & $\begin{array}{c}\text { Factor } \\
\mathbf{6}\end{array}$ \\
\cline { 2 - 7 } & $\mathbf{b 1}$ & $\mathbf{h 1}$ & $\mathbf{r 1}$ & $\mathbf{b 2}$ & $\mathbf{h 2}$ & $\mathbf{r 2}$ \\
\hline Run & {$[$ in] } & {$[$ in] } & {$[$ in] } & {$[$ in] } & {$[$ in] } & {$[$ in] } \\
\hline $\mathbf{3 4}$ & 0.22 & 0.078 & 0.77 & 0.085 & 0.32 & 0.77 \\
\hline $\mathbf{3 5}$ & 0.22 & 0.078 & 0.77 & 0.068 & 0.288 & 0.77 \\
\hline $\mathbf{3 6}$ & 0.242 & 0.078 & 0.77 & 0.068 & 0.32 & 0.77 \\
\hline $\mathbf{3 7}$ & 0.22 & 0.078 & 0.94 & 0.068 & 0.32 & 0.77 \\
\hline $\mathbf{3 8}$ & 0.22 & 0.078 & 0.77 & 0.068 & 0.352 & 0.77 \\
\hline $\mathbf{3 9}$ & 0.22 & 0.078 & 0.77 & 0.068 & 0.32 & 0.6 \\
\hline $\mathbf{4 0}$ & 0.22 & 0.078 & 0.6 & 0.068 & 0.32 & 0.77 \\
\hline $\mathbf{4 1}$ & 0.22 & 0.078 & 0.77 & 0.05 & 0.32 & 0.77 \\
\hline $\mathbf{4 2}$ & 0.22 & 0.095 & 0.77 & 0.068 & 0.32 & 0.77 \\
\hline $\mathbf{4 3}$ & 0.22 & 0.078 & 0.77 & 0.068 & 0.32 & 0.94 \\
\hline $\mathbf{4 4}$ & 0.198 & 0.078 & 0.77 & 0.068 & 0.32 & 0.77 \\
\hline $\mathbf{4 5}$ & 0.22 & 0.06 & 0.77 & 0.068 & 0.32 & 0.77 \\
\hline
\end{tabular}


Table 7. FF09X Range of Factors \& Responses from Analytical Stress Calculator Optimization

\begin{tabular}{|c|c|c|c|}
\hline \multicolumn{3}{|c|}{ Factors } \\
\hline Name & Goal & $\begin{array}{c}\text { Lower Limit } \\
\text { [in] }\end{array}$ & $\begin{array}{c}\text { Upper Limit } \\
\text { [in] }\end{array}$ \\
\hline b1 & within range & 0.198 & 0.242 \\
h1 & within range & 0.060 & 0.095 \\
r1 & within range & 0.600 & 0.940 \\
b2 & within range & 0.050 & 0.085 \\
h2 & within range & 0.288 & 0.352 \\
r2 & within range & 0.600 & 0.940 \\
\hline
\end{tabular}

\begin{tabular}{|c|c|c|c|}
\hline \multicolumn{4}{|c|}{ Responses } \\
\hline Name & $\begin{array}{c}\text { Target } \\
\text { [psi] }\end{array}$ & $\begin{array}{c}\text { Lower Limit } \\
\text { [psi] }\end{array}$ & $\begin{array}{c}\text { Upper Limit } \\
\text { [psi] }\end{array}$ \\
\hline NF & 15000 & 10532 & 27532 \\
AF & none & 473 & 951 \\
SF & 15000 & 10851 & 28012 \\
PM & 15000 & 11482 & 34521 \\
RM & 15000 & 117596 & 43375 \\
YM & 15000 & 9985 & 32292 \\
\hline
\end{tabular}

Table 8. DOE Optimized FF09X Factors and Responses with 99\% Desirability

\begin{tabular}{|c|c|c|c|c|c|c|c|c|c|c|c|c|}
\hline b1 & h1 & r1 & b2 & h2 & r2 & AF & NF & PM & YM & RM & SF & Desirability \\
\hline$[$ in] & {$[$ in] } & {$[$ in] } & {$[$ in] } & {$[$ in] } & {$[$ in] } & {$[$ [psi] } & {$[$ psi $]$} & {$[$ [psi $]$} & {$[$ [psi $]$} & {$[$ [psi $]$} & {$[$ [psi] } & {$[\%]$} \\
\hline 0.237 & 0.073 & 0.940 & 0.075 & 0.313 & 0.768 & 606 & 15000 & 15000 & 15000 & 15862 & 15000 & 99.4 \\
\hline
\end{tabular}

\subsection{FEA Design Verification}

The final phase of the design process was to verify the FF09X CAD model and the FEA results based on the optimized cage geometry, as shown in Table 8. First, the optimized cage geometry was evaluated in the Stress Calculator. The FF09X CAD model was then updated with the same optimized cage geometry, and both the single and multi-load schedules were run in the FEA solver. The FEA results for the FF09X single load schedule only were tabulated and were compared against the analytical results from the Stress Calculator. The results of FF09X singleload schedule comparison are shown in Table 9. Finally, a comparison was made between the FEA results from the multi-load schedule for the FF09X and the FF09A CAD models. The assumption was that the FF09A was a functioning balance with adequate sensitivity at each bridge output. The range values for each bridge output, e.g. the AF, for both the FF09X and FF09A FEA results, need to be within 10\% of the target output value. The FEA comparisons can be found in Table 10 and 11. The FF09X results in Table 10 are based on the optimizer values presented in Table 8 that are constrained by the $\left(r_{1}\right)$ and $\left(r_{2}\right)$ upper bound of 0.94-inches. The FF09X results, shown in Table 11, are based upon the relaxation of the upper bound for $\left(r_{1}\right)$ to 0.95 -inches, which reduces the gap between the outer-facing beam surfaces to 0.013-inches. FF09X FEA results aligned with closed-form analytical predictions, based on the MathCAD ${ }^{\circledR}$ stress calculator, except for Rolling Moment (RM), which was higher than predicted [21]. 
Table 9. Single-Load Numerical (FEA) vs. Analytical Results for FF09X with Optimized Cage Section

\begin{tabular}{|c|c|}
\hline \multicolumn{2}{|c|}{ Cage Section } \\
\hline Factor & {$[$ in] } \\
\hline b1 & 0.237 \\
\hline h1 & 0.073 \\
\hline r1 & 0.94 \\
\hline b2 & 0.075 \\
\hline h2 & 0.313 \\
\hline r2 & 0.768 \\
\hline
\end{tabular}

\begin{tabular}{|c|c|c|c|c|c|}
\hline & \multicolumn{4}{|c|}{ FF09X Single Load Case Comparison } & \\
\hline & \multicolumn{2}{|c|}{ Numerical } & \multicolumn{2}{|c|}{ Analytical } & \\
\hline & Stress & $\begin{array}{l}\text { Bridge } \\
\text { Output }\end{array}$ & Stress & $\begin{array}{l}\text { Bridge } \\
\text { Output }\end{array}$ & \\
\hline Response & [psi] & {$[\mu \mathbf{V} / \mathbf{V}]$} & [psi] & {$[\mu \mathrm{V} / \mathrm{V}]$} & \% Diff \\
\hline Axial & 623 & 48 & 613 & 47 & $2 \%$ \\
\hline Normal & 15533 & 1199 & 15438 & 1192 & $4 \%$ \\
\hline Side & 15130 & 1168 & 15133 & 1168 & $1 \%$ \\
\hline Pitch & 15218 & 1175 & 15604 & 1204 & $1 \%$ \\
\hline Roll & 16657 & 1286 & 16669 & 1287 & $5 \%$ \\
\hline Yaw & 15703 & 1212 & 15089 & 1165 & $5 \%$ \\
\hline
\end{tabular}

Table 10. FEA Multi-Load Schedule Results (r1 = 0.94 in.) - Target Bridge Output 15 ksi

\begin{tabular}{|c|c|c|c|c|c|c|c|c|}
\cline { 3 - 9 } \multicolumn{2}{c|}{} & \multicolumn{3}{c|}{ FF09A } & \multicolumn{3}{c|}{ FF09X } \\
\hline \multirow{2}{*}{ Gage } & Average & Units & MIN & MAX & RANGE & MIN & MAX & RANGE \\
\hline \multirow{2}{*}{ NF } & stress & {$[\mathbf{p s i}]$} & 12278 & 12956 & 678 & 11416 & 12179 & 763 \\
\cline { 2 - 10 } & output & {$[\boldsymbol{\mu V} / \mathbf{V}]$} & 948 & 1000 & 52 & 881 & 940 & 59 \\
\hline \multirow{2}{*}{$\mathbf{N F}$} & stress & {$[\mathbf{p s i}]$} & 10449 & 11113 & 664 & 15264 & 16082 & 818 \\
\cline { 2 - 10 } & output & {$[\boldsymbol{\mu V} / \mathbf{V}]$} & 807 & 858 & 51 & 1178 & 1241 & 63 \\
\hline \multirow{2}{*}{$\mathbf{P M}$} & stress & {$[\mathbf{p s i}]$} & 15654 & 15685 & 31 & 14507 & 14611 & 104 \\
\cline { 2 - 9 } & output & {$[\boldsymbol{\mu V} / \mathbf{V}]$} & 1208 & 1211 & 2 & 1120 & 1128 & 8 \\
\hline \multirow{2}{*}{$\mathbf{R M}$} & stress & {$[\mathbf{p s i}]$} & 14253 & 14347 & 94 & 13232 & 14461 & 1229 \\
\cline { 2 - 9 } & output & {$[\boldsymbol{\mu V} / \mathbf{V}]$} & 1100 & 1107 & 7 & 1021 & 1116 & 95 \\
\hline \multirow{2}{*}{$\mathbf{Y M}$} & stress & {$[\mathbf{p s i}]$} & 14936 & 15014 & 78 & 15693 & 15772 & 79 \\
\cline { 2 - 9 } & output & {$[\boldsymbol{\mu V} / \mathbf{V}]$} & 1153 & 1159 & 6 & 1211 & 1217 & 6 \\
\hline \multirow{2}{*}{ SF } & stress & {$[\mathbf{p s i}]$} & 10640 & 11467 & 827 & 14723 & 15054 & 331 \\
\cline { 2 - 9 } & output & {$[\boldsymbol{\mu V} / \mathbf{V}]$} & 821 & 885 & 64 & 1137 & 1162 & 26 \\
\hline
\end{tabular}


Table 11. FEA Multi-Load Schedule Results (r1 = 0.95 in.) - Target Bridge Output 15 ksi

\begin{tabular}{|c|c|c|c|c|c|c|c|c|}
\cline { 4 - 9 } \multicolumn{2}{c|}{} & \multicolumn{4}{c|}{ FF09A } & \multicolumn{3}{c|}{ FF09X } \\
\hline \multirow{2}{*}{ Gage } & Average & Units & MIN & MAX & RANGE & MIN & MAX & RANGE \\
\hline \multirow{2}{*}{ AF } & stress & {$[\mathbf{p s i}]$} & 12278 & 12956 & 678 & 12632 & 13258 & 626 \\
\cline { 2 - 10 } & output & {$[\boldsymbol{\mu V} / \mathbf{V}]$} & 948 & 1000 & 52 & 975 & 1023 & 48 \\
\hline \multirow{2}{*}{ NF } & stress & {$[\mathbf{p s i}]$} & 10449 & 11113 & 664 & 15237 & 15584 & 347 \\
\cline { 2 - 10 } & output & {$[\boldsymbol{\mu V} / \mathbf{V}]$} & 807 & 858 & 51 & 1176 & 1203 & 27 \\
\hline \multirow{2}{*}{$\mathbf{P M}$} & stress & {$[\mathbf{p s i}]$} & 15654 & 15685 & 31 & 14348 & 14463 & 115 \\
\cline { 2 - 10 } & output & {$[\boldsymbol{\mu V} / \mathbf{V}]$} & 1208 & 1211 & 2 & 1108 & 1116 & 9 \\
\hline \multirow{2}{*}{$\mathbf{R M}$} & stress & {$[\mathbf{p s i}]$} & 14253 & 14347 & 94 & 13109 & 14254 & 1145 \\
\cline { 2 - 10 } & output & {$[\boldsymbol{\mu V} / \mathbf{V}]$} & 1100 & 1107 & 7 & 1012 & 1100 & 88 \\
\hline \multirow{2}{*}{ YM } & stress & {$[\mathbf{p s i}]$} & 14936 & 15014 & 78 & 15264 & 15291 & 27 \\
\cline { 2 - 10 } & output & {$[\boldsymbol{\mu V} / \mathbf{V}]$} & 1153 & 1159 & 6 & 1178 & 1180 & 2 \\
\hline \multirow{2}{*}{ SF } & stress & {$[\mathbf{p s i}]$} & 10640 & 11467 & 827 & 14731 & 15079 & 348 \\
\cline { 2 - 9 } & output & {$[\boldsymbol{\mu V} / \mathbf{V}]$} & 821 & 885 & 64 & 1137 & 1164 & 27 \\
\hline
\end{tabular}




\section{CHAPTER 4}

4 RESULTS AND FINAL ANALYSES

Multiple views of the FF09X and FF0A CAD models can be seen in Fig. 27 and 28, respectively.
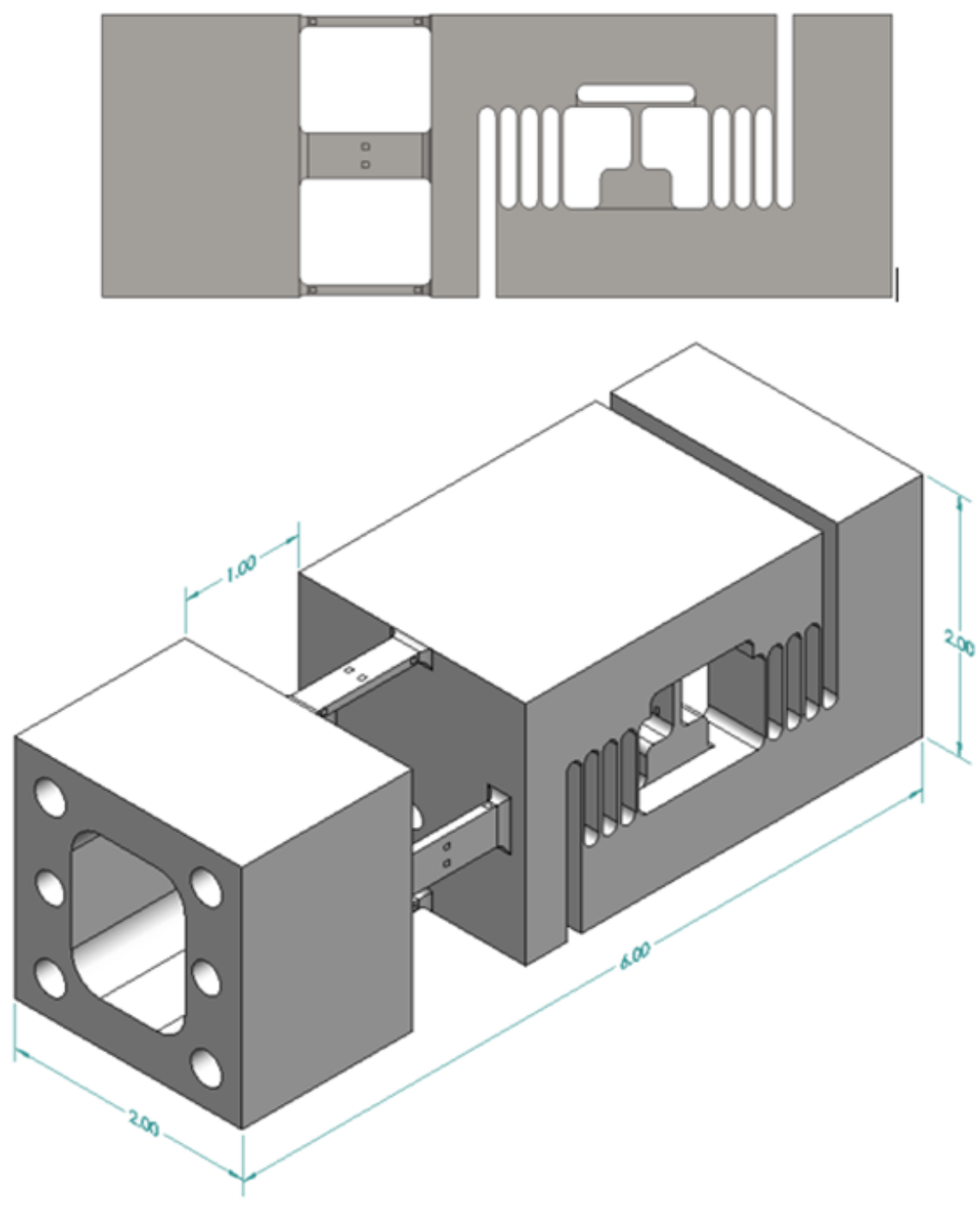

Fig. 27 FF09X Final Design (side \& isometric view) (dimensions in inches). 

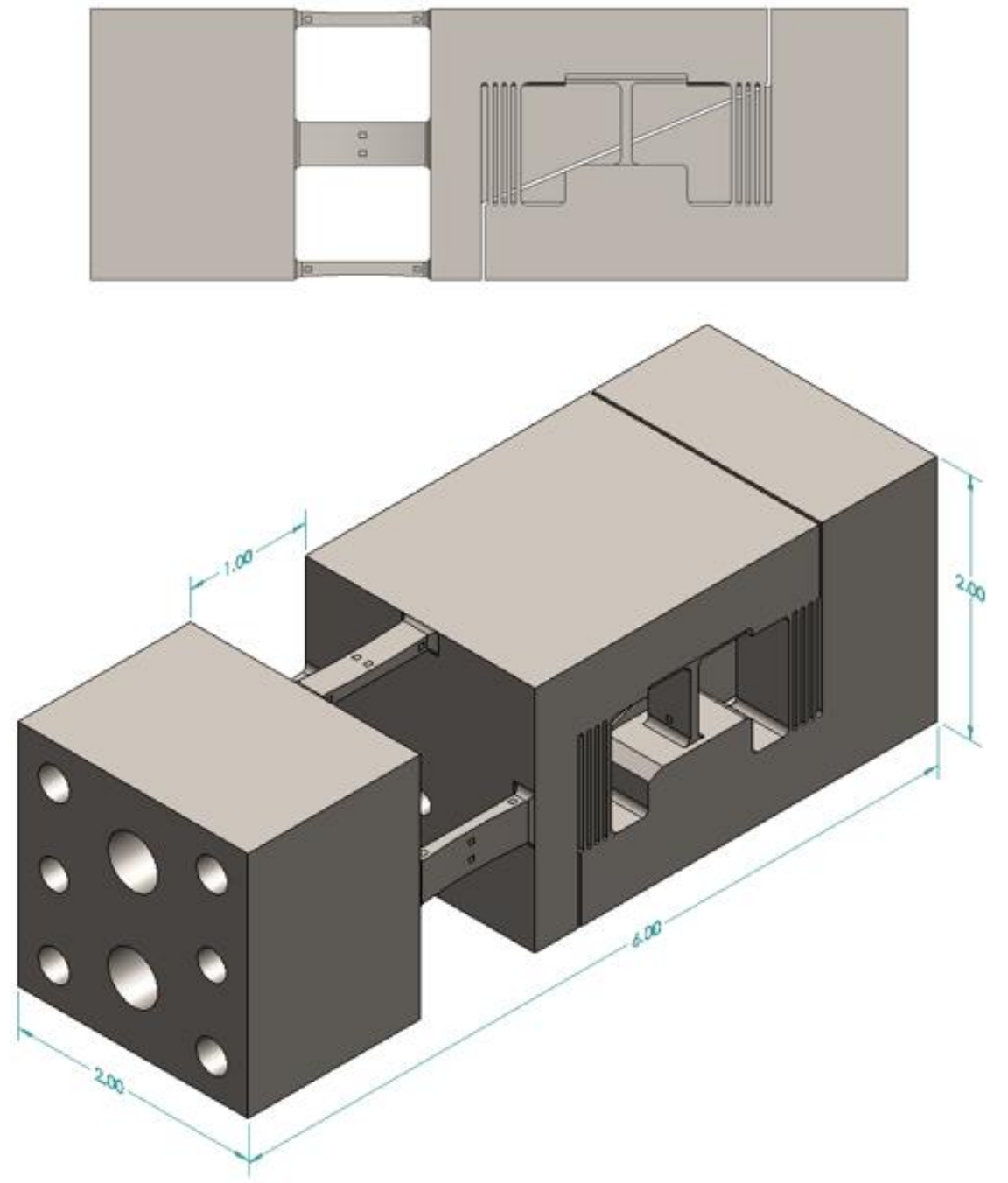

Fig. 28 FF09A Design (side \& isometric view) (dimensions in inches).

In addition to gage stress for each set of Wheatstone bridges, the maximum stress was recorded, based on the von Mises theory, for each of the multi-load cases, including the minimum and maximum values as well as the range. The same was done for both the maximum deflection and the Factor of Safety. The maximum deflection was equivalent to the resultant displacement of the model end of each balance. The results for von Mises stress, maximum deflection, and Factor of Safety can be found in Table 12. The results of the comparison between the bridge outputs from the FF09A calibration data and the FF09A predicted output, using the MathCAD ${ }^{\circledR}$ stress calculator, can be seen in Table 13 . 
Table 12. FF09A vs. FF09X - von Mises, Maximum Deflection, and Factor of Safety

\begin{tabular}{|c|c|c|c|c|}
\cline { 3 - 5 } \multicolumn{2}{c|}{} & $\begin{array}{c}\text { von } \\
\text { Mises } \\
\text { Stress }\end{array}$ & Deflection & $\begin{array}{c}\text { Factor } \\
\text { of } \\
\text { Safety }\end{array}$ \\
\cline { 3 - 5 } & [psi] & \multicolumn{1}{|c|}{$[$ in] } & - \\
\hline \multirow{3}{*}{ FF09A } & MIN & 91243 & 0.006 & 2.1 \\
\cline { 2 - 5 } & MAX & 113664 & 0.011 & 1.6 \\
\cline { 2 - 5 } & RANGE & 22421 & 0.005 & 0.5 \\
\hline \multirow{3}{*}{ FF09X } & MIN & 108611 & 0.008 & 1.7 \\
\cline { 2 - 5 } & MAX & 130623 & 0.022 & 1.4 \\
\cline { 2 - 5 } & RANGE & 22012 & 0.014 & 0.3 \\
\hline
\end{tabular}

Table 13. FF09A Bridge Output - Calibration Data vs. Predicted

\begin{tabular}{|c|c|c|c|}
\cline { 2 - 4 } \multicolumn{1}{c|}{} & \multicolumn{3}{c|}{ FF09A } \\
\cline { 2 - 4 } \multicolumn{1}{c|}{} & $\begin{array}{c}\text { Calibration } \\
\text { Data }\end{array}$ & Predicted & \multirow{2}{*}{$\%$ Difference } \\
\cline { 2 - 4 } & Bridge Output & Bridge Output & \\
\hline Load & {$[\boldsymbol{\mu V} / \mathbf{V}]$} & {$[\boldsymbol{\mu V} / \mathbf{V}]$} & {$[\%]$} \\
\hline Normal & 802 & 874 & $9 \%$ \\
\hline Axial & 899 & 1028 & $13 \%$ \\
\hline Side & 846 & 892 & $5 \%$ \\
\hline Pitch & 1149 & 1193 & $4 \%$ \\
\hline Roll & 1058 & 1139 & $7 \%$ \\
\hline Yaw & 1090 & 1002 & $8 \%$ \\
\hline
\end{tabular}

Modal Analysis was conducted for both the FF09A and FF09X CAD models, in order to find the natural frequency for a range of estimated aerodynamic model masses, including the standalone balance. A gravity function was included in the analyses. Results of the modal analysis can be found in Tables 14 and 15. 
Table 14. FF09A Modal Analysis

\begin{tabular}{|c|c|c|r|r|c|c|r|r|r|}
\hline \multicolumn{10}{|c|}{ FF09A Modal Analysis Summary } \\
\hline $\begin{array}{c}\text { Model } \\
\text { Wt. }\end{array}$ & $\begin{array}{c}\mathbf{0} \\
{[\mathbf{l b}]}\end{array}$ & $\begin{array}{c}\mathbf{5} \\
{[\mathbf{l b}]}\end{array}$ & $\begin{array}{c}\mathbf{1 0} \\
{[\mathbf{l b}]}\end{array}$ & $\begin{array}{c}\mathbf{1 5} \\
{[\mathbf{l b}]}\end{array}$ & $\begin{array}{c}\mathbf{2 0} \\
{[\mathbf{l b}]}\end{array}$ & $\begin{array}{c}\mathbf{3 0} \\
{[\mathbf{l b}]}\end{array}$ & $\begin{array}{c}\mathbf{4 0} \\
{[\mathbf{l b}]}\end{array}$ & $\begin{array}{c}\mathbf{5 0} \\
{[\mathbf{l b}]}\end{array}$ & $\begin{array}{c}\mathbf{6 0} \\
{[\mathbf{l b}]}\end{array}$ \\
\hline Mode & {$[\mathrm{Hz}]$} & {$[\mathrm{Hz}]$} & {$[\mathrm{Hz}]$} & {$[\mathrm{Hz}]$} & {$[\mathrm{Hz}]$} & {$[\mathrm{Hz}]$} & {$[\mathrm{Hz}]$} & {$[\mathrm{Hz}]$} & {$[\mathrm{Hz}]$} \\
\hline $\mathbf{1}$ & 384.35 & 230.63 & 180.02 & 152.64 & 134.85 & 112.40 & 98.35 & 88.45 & 81.03 \\
\hline $\mathbf{2}$ & 408.68 & 237.42 & 182.88 & 154.10 & 135.66 & 112.65 & 98.43 & 88.58 & 81.21 \\
\hline $\mathbf{3}$ & 581.35 & 342.23 & 263.26 & 221.63 & 194.99 & 161.79 & 141.27 & 126.98 & 116.30 \\
\hline $\mathbf{4}$ & 1067.60 & 1061.40 & 1056.50 & 1052.90 & 1050.30 & 1046.90 & 1044.80 & 1043.40 & 1042.30 \\
\hline $\mathbf{5}$ & 2121.10 & 1248.40 & 1176.30 & 1152.10 & 1140.40 & 1129.20 & 1124.00 & 1120.90 & 1119.00 \\
\hline $\mathbf{6}$ & 2521.50 & 1445.80 & 1352.70 & 1319.80 & 1303.10 & 1286.20 & 1277.70 & 1272.50 & 1269.10 \\
\hline $\mathbf{7}$ & 2955.30 & 2193.70 & 2192.10 & 2191.60 & 2191.40 & 2191.10 & 2191.00 & 2190.90 & 2190.80 \\
\hline $\mathbf{8}$ & 3200.30 & 2968.30 & 2961.50 & 2958.20 & 2956.30 & 2954.10 & 2952.90 & 2952.20 & 2951.60 \\
\hline $\mathbf{9}$ & 4311.90 & 4018.50 & 3991.90 & 3934.50 & 3903.70 & 3871.20 & 3854.30 & 3844.00 & 3837.00 \\
\hline $\mathbf{1 0}$ & 5122.70 & 4134.90 & 4009.20 & 4006.00 & 4004.30 & 4002.70 & 4001.90 & 4001.40 & 4001.00 \\
\hline
\end{tabular}

Table 15. FF09X Modal Analysis

\begin{tabular}{|c|c|c|c|c|c|c|c|r|r|}
\hline \multicolumn{10}{|c|}{ FF09X Modal Analysis Summary } \\
\hline $\begin{array}{c}\text { Model } \\
\text { Wt. }\end{array}$ & $\begin{array}{c}\mathbf{0} \\
{[\mathbf{l b}]}\end{array}$ & $\begin{array}{c}\mathbf{5} \\
{[\mathbf{l b}]}\end{array}$ & $\begin{array}{c}\mathbf{1 0} \\
{[\mathbf{l b}]}\end{array}$ & $\begin{array}{c}\mathbf{1 5} \\
{[\mathbf{l b}]}\end{array}$ & $\begin{array}{c}\mathbf{2 0} \\
{[\mathbf{l b}]}\end{array}$ & $\begin{array}{c}\mathbf{3 0} \\
{[\mathbf{l b}]}\end{array}$ & $\begin{array}{c}\mathbf{4 0} \\
{[\mathbf{l b}]}\end{array}$ & $\begin{array}{c}\mathbf{5 0} \\
{[\mathbf{l b}]}\end{array}$ & \multicolumn{1}{c|}{$\begin{array}{c}\mathbf{6 0} \\
{[\mathbf{l b}]}\end{array}$} \\
\hline Mode & {$[\mathrm{Hz}]$} & {$[\mathrm{Hz}]$} & {$[\mathrm{Hz}]$} & {$[\mathrm{Hz}]$} & {$[\mathrm{Hz}]$} & {$[\mathrm{Hz}]$} & {$[\mathrm{Hz}]$} & {$[\mathrm{Hz}]$} & {$[\mathrm{Hz}]$} \\
\hline $\mathbf{1}$ & 360.49 & 211.64 & 160.83 & 134.78 & 118.30 & 97.92 & 85.39 & 76.70 & 70.21 \\
\hline $\mathbf{2}$ & 390.85 & 212.49 & 164.24 & 138.60 & 122.11 & 101.48 & 88.68 & 79.75 & 73.07 \\
\hline $\mathbf{3}$ & 484.16 & 265.35 & 203.43 & 171.17 & 150.59 & 124.97 & 109.13 & 98.11 & 89.86 \\
\hline $\mathbf{4}$ & 894.02 & 862.80 & 853.90 & 849.91 & 847.67 & 845.23 & 843.93 & 843.12 & 842.57 \\
\hline $\mathbf{5}$ & 1794.30 & 1158.90 & 1096.80 & 1067.40 & 1052.20 & 1036.80 & 1029.00 & 1024.30 & 1021.20 \\
\hline $\mathbf{6}$ & 1868.10 & 1178.80 & 1109.70 & 1093.00 & 1084.70 & 1076.50 & 1072.30 & 1069.90 & 1068.20 \\
\hline $\mathbf{7}$ & 2373.00 & 1864.90 & 1862.50 & 1861.80 & 1861.40 & 1861.00 & 1860.80 & 1860.70 & 1860.70 \\
\hline $\mathbf{8}$ & 2716.20 & 1882.40 & 1880.40 & 1879.70 & 1879.40 & 1879.00 & 1878.80 & 1878.70 & 1878.60 \\
\hline $\mathbf{9}$ & 3429.70 & 3381.00 & 3379.90 & 3379.50 & 3379.30 & 3379.10 & 3379.00 & 3378.90 & 3378.90 \\
\hline $\mathbf{1 0}$ & 4794.50 & 3925.70 & 3817.00 & 3774.30 & 3751.60 & 3727.80 & 3715.50 & 3707.90 & 3702.80 \\
\hline
\end{tabular}

Fabrication time, in hours, was used to evaluate the overall effectiveness of the FF09X design compared to the original FF09A balance design. Using SEDM and WEDM, primarily, the time required to fabricate the FF09A was estimated to be 600 hours. In comparison, using a combination of WEDM and conventional machining, the time required to fabricate the FF09X was estimated at 160 hours, which represents a reduction in fabrication time of approximately $73 \%$. Quotes were provided by local machine shops having the necessary experience, skill, and machines required for precision balance fabrication, and copies of the quotes are provided in Appendix E. 


\section{CHAPTER 5}

\section{CONCLUSIONS AND FUTURE WORK}

This design study demonstrated that a direct replacement balance that incorporates simplified geometry can deliver similar performance, while reducing fabrication time by $73 \%$. The time savings should be directly proportional to the cost savings.

The machinability of 17-4 PH, given its hardness, was an initial concern for a conventional machining-only approach, but the partial axial test section trial machined from 17-4 PH H925 material was a success. A 0.125-inch diameter, 0.625-inch cut length AlTiN-coated carbide end mill cut through the 0.5-inch thick test coupon, both successfully and within the $+/-0.005$-inch tolerance.

The FF09A has a larger section modulus than the FF09X, given the absence of the center bore; therefore, the FF09X will deflect more than the FF09A. Deflection comparisons between the FF09A and the FF09X CAD models showed that the maximum deflection of the FF09X exceeded the FF09A by a factor of 2 . The range in deflection values for the FF09X under multiple load cases was greater than the FF09A by a factor of 1.8.

Concerning the modal analysis, the FF09A and FF09X have masses of 0.1517 and 0.1067 slugs respectively - a difference of 29.7 percent. The lower mass of the FF09X leads to a lower natural frequency, as expected. It should be noted that for the first mode, the natural frequency for the FF09X varied as much as 13.3\% less, across the range of additional model weights, when compared to the FF09A.

Stress analysis for the simplified geometry of the FF09X showed that it should deliver comparable and acceptable gage resolution. Predicted bridge output for the FF09X was higher for each component and was closer to the $1100 \mu \mathrm{V} / \mathrm{V}$ target, compared to the FF09A. The strain-gage locations in the cage section, with respect to distances from the nearest bulkhead, are referred to as the Gage Length (GL), and the distances from the inside edge of the beam are referred to as the Gage Length Width (GLW). Both GL and GLW have a significant effect on interactions. As a design goal, the need for variable-inertia beams was eliminated with DOE and optimization efforts. Extending the $\left(r_{1}\right)$ upper bound to 0.95 -inches reduced the net range across all bridge outputs; the longer centroidal distance should be used, if it can be done without fouling the balance. The higher maximum stress (von Mises) and the lower Factor of Safety should be explored, regarding risk of failure due to fatigue, which may be evaluated once a prototype is built and tested. 
Future work includes machining a prototype of the FF09X, mounting the strain gages, calibrating the balance, and collecting experimental data to corroborate the analytical and numerical results presented in this paper. An additional DOE could be used to explore the sensitivity of strain-gage location dimensions, GL and GLW, to evaluate optimal gage placement and to further minimize interactions. 


\section{REFERENCES}

[1] P. A. Parker and R. DeLoach, "Structural Optimization of a Force Balance Using a Computational Experiment Design," in 40th AIAA Aerospace Sciences Meeting \& Exhibit, Reno, 2002.

[2] C. Lynn, "Balance Design Overview \& Lifecycle Discussion," NASA Langley Research Center, Hampton, 2014.

[3] R. D. Rhew, "NASA LaRC Strain Gage Balance Design Concepts," NASA Langley Research Center, Hampton.

[4] J. Gere, Mechanics of Materials, 6th ed., Belmont, CA: Brooks/Cole - Thomson Learning, 2004, pp. 70, 626631.

[5] N. Instruments, "Measuring Strain with Strain Gages," 25 May 2016. [Online]. Available: http://www.ni.com/white-paper/3642/en/. [Accessed 1011 2018].

[6] B. D. Phillips, P. A. Parker and D. E. Burns, Force Balance Design: A NASA Langley Perspective, D. Landman and T. L. Webb, Eds., Hampton: Unpublished, 2018, pp. 51,74.

[7] R. C. Hibbeler, Structural Analysis, 8th ed., Upper Saddle River, NJ: Pearson Prentical Hall, 2012, pp. 316318.

[8] S. Timoshenko, Strength of Materials, 3rd ed., New York: Van Nostrand, 1955.

[9] C. E. Scott, "Translation Characteristics of Variable Inertia Beams with Fixed Ends as Used in Force Transducers," NASA Langley Research Center, Hampton, 1967.

[10] N. B. Sadowski, "A Cost Effective Design for a Propeller Thrust/Torque Balance," ODU Digital Commons, MS Thesis, Norfolk, 2018.

[11] J. G. Bralla, Design for Manufacturability, 2nd ed., J. G. Bralla, Ed., New York, NY: McGraw-Hill, 1999. 
[12] I. Nayak, J. Ran and A. Parida, " Performance optimization in electro- discharge machining using a suitable multiresponse optimization technique," Decision Science Letters, vol. 6, no. 3, pp. 283-294, 2017.

[13] "Fundamental Manufacturing Process Study Guide," Society of Manufacturing Engineers (SME), 2018.

[14] "Diving into Depth of Cut: Peripheral, Slotting, \& HEM Approaches," Harvey Performance Company, LLC, 156 2017. [Online]. Available: https://www.harveyperformance.com/in-the-loupe/depth-of-cut/. [Accessed 19 $102018]$.

[15] L. Y. Chang, Balance FF-09 Details, Hampton: NASA Langley Research Center, 1979.

[16] W. D. Pilkey and D. F. Pilkey, Peterson's Stress Concentration Factors, 3rd ed., Hoboken: John Wiley \& Sons, Inc., 2008.

[17] D. C. Montgomery, Design and Analysis of Experiments, 6th ed., Hoboken, NJ: John Wiley \& Sons, 2005.

[18] Design Expert, Minneapolis, MN: Stat-Ease, Inc., 2018.

[19] H. Berman, "StatTrak.com," 2018. [Online]. Available: https://stattrek.com/statistics/dictionary.aspx?definition=coefficient_of_determination. [Accessed 8102018 ].

[20] R. H. Myers, D. C. Montgomery and C. M. Anderson-Cook, Response Surface Methodology, 4th ed., Hoboken, NJ: John Wiley \& Sons, 2016.

[21] PTC, PTC MathCAD, Needham, MA: PTC, Inc., 2018.

[22] F. P. Beer, E. R. Johnston, Jr. and D. F. Mazurek, Vector Mechanics for Engineers - Statics, 10th ed., New York: McGraw-Hill, 2013, p. 76.

[23] J. A. Villafane and R. A. Mendez-Sanchez, "On the Accuracy of the Timoshenko Beam Theory Above the Critical Frequency: Best Shear Coefficient," Journal of Mechanics, vol. 32, no. 5, pp. 515-518, Oct. 2016. 
[24] G. R. Cowper, "The Shear Coefficient in Timoshenko's Beam Theory," Journal of Applied Mechanics, vol. 33, no. 2, pp. 335-340, 01 June 1966. 


\section{APPENDICES}


APPENDIX A. FF09X Mathcad ${ }^{\circledR}$ Stress Calculator

\section{Highlighted Fields $=$ User Input Required}

Dimensions

Flex Beams

Measurement Beams

Straps

Material Properties

$n_{f}:=16$
$l_{f}:=0.720$ in
$b_{f}:=0.500 \cdot$ in
$h_{f}:=0.030$ in

$$
n_{m}:=2
$$

$l_{m}:=0.440$ in

$h_{m}:=0.072$ in

$n_{s}:=2$

$E \equiv 28.5 \cdot 10^{6} \mathrm{Dsi}$

$l_{s}:=0.900$ in

$h_{s}:=0.030$ in

$G \equiv 11.2 \cdot 10^{6} \mathrm{psi}$

recess $_{m}:=0.220$ in

$\nu:=0.272$

$G_{\text {factor }} \equiv 2.2$

$$
b_{m}:=b_{f}-\text { recess }_{m}=0.28 \text { in } \quad b_{s}:=b_{m}=0.28 \text { in }
$$

Forces

$P_{A}:=50 l b f$

$P_{N}:=100 l b f$

$P_{S}:=60 l b f$
Moments

$$
M_{p}:=480 \text { in } \cdot l b f
$$$$
M_{R}:=180 \text { in } \cdot \text { lbf }
$$

$M_{Y}:=540$ in $\cdot l b f$
Axial Section

Len $:=2.360$ in

endgap $:=0.130$ in

flxgap $:=0.130$ in

$$
D P:=\text { Len }-2 \cdot(\text { endgap })=2.1 \text { in } \quad D:=D P-\frac{n_{f}}{4} \cdot h_{f}-\left(\frac{n_{f}}{4}-1\right) \cdot f l x g a p=1.59 \text { in }
$$

\section{AXIAL 50 lbs}

Correction Factors

$$
\begin{array}{ll}
\alpha_{\text {axial }}:=\frac{\left(\frac{l_{s}}{l_{m}}\right)+16 \cdot\left(\frac{h_{s}}{h_{m}}\right)^{3}}{\left(\frac{l_{s}}{l_{m}}\right)+4 \cdot\left(\frac{h_{s}}{h_{m}}\right)^{3}}=1.372 & \text { vs. } 1.423-\text { FF09 } 1979 \\
\beta_{\text {axial }}:=\frac{8 \cdot\left(\frac{h_{s}}{h_{m}}\right)^{3}}{\left(\frac{l_{s}}{l_{m}}\right)+16 \cdot\left(\frac{h_{s}}{h_{m}}\right)^{3}}=0.1807 & \text { Vs. } 0.1981-\text { FF09 } 1979
\end{array}
$$


Spring Constants

$$
\begin{array}{ll}
K_{m}:=\frac{\alpha_{\text {arial }} \cdot \boldsymbol{n}_{m} \cdot \boldsymbol{E} \cdot \boldsymbol{b}_{m} \cdot \boldsymbol{h}_{m}{ }^{3}}{4 \cdot l_{m}{ }^{3}}=23983 \frac{l b f}{i n} & \text { vs. } 14833 \mathrm{lbs} / \text { in }- \text { FF09 } 1979 \\
K_{f}:=\frac{\boldsymbol{n}_{f} \cdot \boldsymbol{E} \cdot \boldsymbol{b}_{f} \cdot \boldsymbol{h}_{f}{ }^{3}}{l_{f}{ }^{3}}=16493 \frac{l b f}{i n} & \text { vs. } 15789 \mathrm{lbs} / \mathrm{in}-\text { FF09 } 1979 \\
\Sigma K:=K_{m}+K_{f}=40476 \frac{l b f}{i n} & \text { vs. } 30622 \mathrm{lbs} / \text { in }- \text { FF09 } 1979
\end{array}
$$

Load Proportions

$$
\begin{array}{ll}
N_{m}:=\frac{K_{m}}{\Sigma K}=\mathbf{0 . 5 9 3} & \text { vs. } 0.4844-\text { FF09 } 1979 \\
N_{f}:=\frac{K_{f}}{\Sigma K}=\mathbf{0 . 4 0 7} & \text { vs. } 0.5156-\text { FF09 } 1979
\end{array}
$$

\section{$\underline{\text { Stress }}$}

Flexible Beam

$$
S_{A f}:=\frac{3 \cdot P_{A} \cdot N_{f} \cdot l_{f}}{n_{f} \cdot b_{f} \cdot h_{f}^{2}}=6112 p s i \quad \text { vs. } 6550 \text { psi - FF09 } 1979
$$

Measurement Beam

$$
\begin{aligned}
& S_{A m}:=\frac{\mathbf{6} \cdot P_{A} \cdot N_{m} \cdot l_{m} \cdot\left(1-\beta_{\text {axial }}\right)}{n_{m} \cdot b_{m} \cdot h_{m}{ }^{2}}=22074 \mathrm{psi} \quad \text { vs. } 16813 \text { psi - FF09 } 1979 \\
& S_{\text {Agage }}:=\frac{\mathbf{6} \cdot P_{A} \cdot N_{m} \cdot\left(l_{m} \cdot\left(1-\beta_{\text {axial }}\right)-G L_{m}\right)}{n_{m} \cdot b_{m} \cdot h_{m}{ }^{2}}=15798 \mathrm{psi}
\end{aligned}
$$


$\underline{\text { Strap }}$

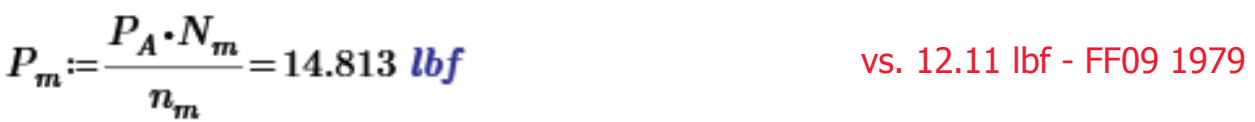

$$
\begin{aligned}
& M_{0}:=P_{m} \cdot\left(l_{m} \cdot \beta_{\text {axial }}\right)=1.178(\text { in } \cdot l b f) \quad \text { vs. } 1.439 \text { in-lbf - FF09 } 1979
\end{aligned}
$$

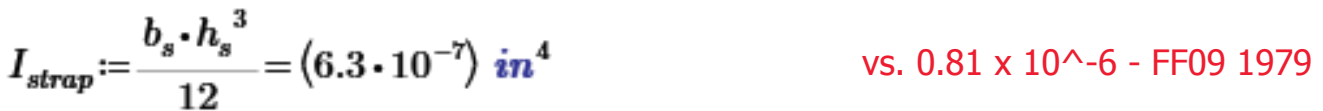

$$
\begin{aligned}
& S_{0 \_b e n d \_s t r a p}:=\frac{\left(\frac{M_{0}}{2}\right)\left(\frac{h_{s}}{2}\right)}{I_{\text {strap }}}=14020 \text { psi } \quad \text { vs. } 13320 \text { psi - FF09 } 1979 \\
& S_{\text {strap_pressure }}:=\frac{\boldsymbol{P}_{\boldsymbol{m}}}{\boldsymbol{b}_{\boldsymbol{s}} \cdot \boldsymbol{h}_{\boldsymbol{s}}}=\mathbf{1 7 6 3} \boldsymbol{p s i} \quad \text { vs. } 1120 \text { psi - FF09 } 1979 \\
& S_{\text {FLxy }}:=S_{\text {0_bend_strap }}+S_{\text {strap_pressure }}=15783 \text { psi } \quad \text { vS. } 14440 \text { psi- FF09 } 1979
\end{aligned}
$$

$$
\text { NORMAL } 100 \mathrm{lbs} \quad D P=2.1 \text { in } \quad D=1.59 \text { in } \quad P_{N}=100 \text { lbf } \quad L=2.055 \text { in }
$$

$\underline{\text { Reaction Forces }}$

$$
\begin{array}{ll}
R_{F 1}:=\left(\frac{L+\frac{D}{2}}{D}\right)\left(P_{N}\right)=179.245 l b f & \text { vs. } 158.1 \text { lbs - FF09 } 1979 \\
R_{A 1}:=R_{F 1}-P_{N}=79.245 l b f & \text { vs. } 58.1 \text { lbs - FF09 } 1979
\end{array}
$$

$\underline{\text { Stress }}$

$$
\begin{array}{ll}
S_{N F}:=\frac{R_{F 1}}{\left(\frac{n_{f}}{2}\right) \cdot b_{f} \cdot h_{f}}=1494 p s i & \text { vs. } 1131 \text { psi - FF09 } 1979 \\
S_{N A}:=\frac{R_{A 1}}{\left(\frac{n_{f}}{2}\right) \cdot b_{f} \cdot h_{f}}=660 p s i & \text { vs. } 416 \text { psi - FF09 } 1979
\end{array}
$$




\section{PITCH 480 in-lbf}

$\underline{\text { Reaction Forces }} \quad M_{P}=480($ in $\cdot l b f)$

$$
\begin{array}{ll}
R_{A 2}:=\frac{M_{P}}{D}=302 l b f & \text { vs. } 268 \mathrm{lbf}-\text { FF09 } 1979 \\
R_{F 2}:=R_{A 2}=302 l b f &
\end{array}
$$

$\underline{\text { Stress }}$

$$
S_{M A}:=\left(\frac{R_{A 2}}{\left(\frac{n_{f}}{2}\right) \cdot b_{f} \cdot h_{f}}\right) \cdot\left(\frac{D P}{D}\right)=3323 p s i \quad \text { vs. } 2170 \text { psi - FF09 } 1979
$$

\section{ROLL 180in-Ibf}

$\underline{\text { Section Properties }}$

$$
\begin{array}{ll}
b_{f r 1}:=2.000 \text { in } \quad b_{f r 2}:=b_{f r 1}-\left(2 \cdot b_{f}\right)=1 \text { in } & c_{R o l l}:=1.000 \text { in } \\
I_{x x}:=\frac{n_{f} \cdot h_{f} \cdot\left(b_{f r 1}{ }^{3}-b_{f r 2}{ }^{3}\right)}{12}=0.28 \mathrm{in}^{4} & \text { vs. } 0.342 \text { in - FF09 } 1979 \\
S_{\text {Roll }}:=\frac{M_{R} \cdot c_{\text {Roll }}}{I_{x x}}=643 p s i & \text { vs. } 526 \text { psi - FF09 } 1979
\end{array}
$$

\section{YAW 540 in-lbf}

Section Properties

$$
\begin{aligned}
& \begin{array}{l}
t_{f}:=h_{f}=0.03 \text { in } \\
t_{m}:=h_{m}=0.072 \text { in }
\end{array} \quad r_{y f}:=\frac{\text { width }}{2}-\frac{b_{f}}{2}=0.75 \text { in } \\
& r_{y m}:=\frac{\text { width }_{y}}{2}-\left(\text { recess }_{m}+\frac{b_{m}}{2}\right)=0.64 \text { in }
\end{aligned}
$$
$r_{x f 1}:=\frac{D P}{2}-\frac{7 h_{f}}{2}-3 \cdot f l x g a p=0.555$ in $\quad$ vs. 0.794 in - FF09 1979 
$r_{x f 2}:=\frac{D P}{2}-\frac{5 h_{f}}{2}-2$ flxgap $=0.715$ in

vs. 0.862 in - FF09 1979

$r_{x f 3}:=\frac{D P}{2}-\frac{3 h_{f}}{2}-f l x g a p=0.875$ in

vs. 0.930 in - FF09 1979

$r_{x f 4}:=\left(\frac{D P}{2}-\frac{h_{f}}{2}\right)=1.035$ in

vs. 0.998 in - FF09 1979

r_xm is the distance from $y$-axis to centroid of msmt beam, which is zero here because the centroid sits along the $y$-axis.

r_yf \& r_ym are the distances from the $x$-axis to centroid of flex \& msmt beams respectively

\section{Top View}

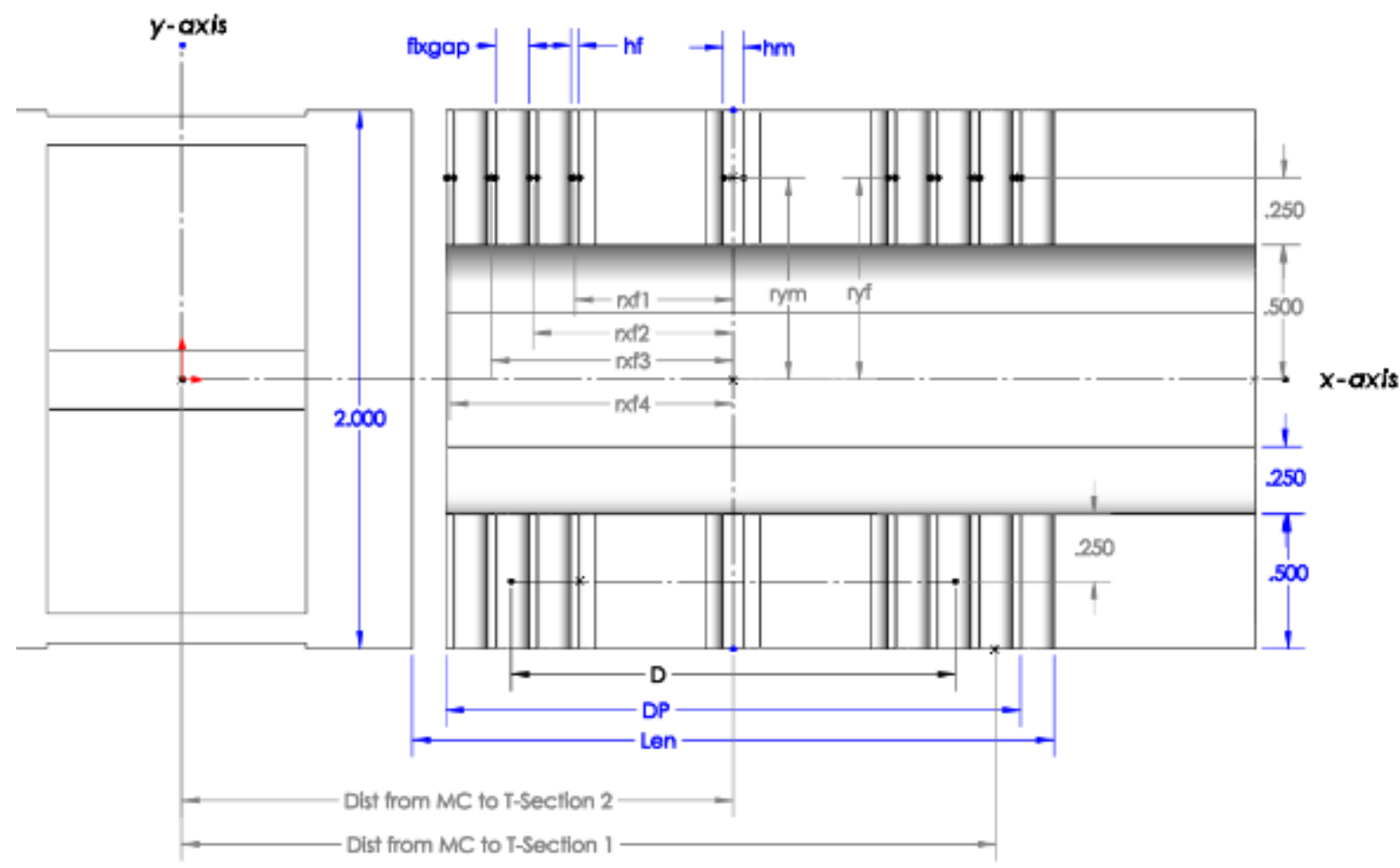

Note: Twist Correction factors, alpha and beta, are based on the ratio between beam base (or width) versus the height (or thickness) and interpolated from a table of values derived from Timoshenko's Beam Theory and published in Strength of Materials, 3rd ed., 1955. 


ratio $:=\left[\begin{array}{c}1.00 \\ 1.50 \\ 1.75 \\ 2.00 \\ 2.50 \\ 3.00 \\ 4.00 \\ 6.00 \\ 8.00 \\ 10.00 \\ \infty\end{array}\right] \quad \alpha:=\left[\begin{array}{c}0.208 \\ 0.231 \\ 0.239 \\ 0.246 \\ 0.258 \\ 0.267 \\ 0.282 \\ 0.299 \\ 0.307 \\ 0.313 \\ 0.333\end{array}\right] \quad \beta:=\left[\begin{array}{l}0.141 \\ 0.196 \\ 0.263 \\ 0.281 \\ 0.228 \\ \end{array}\right] \quad\left[\begin{array}{l}0.299 \\ 0.307 \\ 0.313 \\ 0.333\end{array}\right]$

$\underline{\text { Twist Correction Factors }}$

Beam Ratios

$$
\begin{aligned}
& \text { flex }:=\frac{b_{f}}{h_{f}}=16.667 \\
& \text { vs. } 12.10 \text { - FF09 } 1979 \\
& m s m t:=\frac{b_{m}}{h_{m}}=3.889 \\
& \alpha_{f}:=\operatorname{linterp}(\text { ratio }, \alpha, \text { flex })=0.313 \\
& \text { vs. } 0.316 \text { - FF09 } 1979 \\
& \beta_{f}:=\operatorname{linterp}(\text { ratio }, \beta, \text { flex })=0.313 \\
& \text { vs. } 0.316 \text { - FF09 } 1979 \\
& \alpha_{m}:=\operatorname{linterp}(\text { ratio }, \alpha, m s m t)=0.28 \\
& \text { vs. } 0.288 \text { - FF09 } 1979 \\
& \beta_{m}:=\operatorname{linterp}(\text { ratio }, \beta, \text { msmt })=0.279 \\
& \text { vs. } 0.288 \text { - FF09 } 1979
\end{aligned}
$$

Shear Deflection Correction

$$
\begin{array}{ll}
\gamma_{x f}:=\frac{1}{3.05\left(\frac{t_{f}}{l_{f}}\right)^{2}+1}=0.995 & \text { vs. } 0.955-\text { FF09 } 1979 \\
\gamma_{y f}:=\frac{1}{3.05\left(\frac{b_{f}}{l_{f}}\right)^{2}+1}=0.405 & \text { vs. } 0.5566-\text { FF09 } 1979
\end{array}
$$




$$
\begin{gathered}
\gamma_{x m}:=\frac{1}{3.05\left(\frac{t_{m}}{l_{m}}\right)^{2}+1}=0.924 \\
\gamma_{y m}:=\frac{1}{3.05\left(\frac{b_{m}}{l_{m}}\right)^{2}+1}=0.447
\end{gathered}
$$

Spring Constants due to Torsional Stress

$$
\begin{aligned}
& K_{\tau f}:=\frac{n_{f} \cdot \beta_{f} \cdot b_{f} \cdot t_{f}{ }^{3} \cdot G}{l_{f}}=1052 \frac{\mathrm{in} \cdot l b f}{\mathrm{rad}} \\
& K_{r m}:=\frac{n_{m} \cdot \beta_{m} \cdot b_{m} \cdot t_{m}{ }^{3} \cdot G}{l_{m}}=1484 \frac{\mathrm{in} \cdot l b f}{\mathrm{rad}} \\
& K_{x f}:=\frac{n_{f} \cdot E \cdot b_{f} \cdot h_{f}^{3} \cdot r_{y f}{ }^{2} \cdot \gamma_{x f}}{l_{f}^{3}}=9228 \frac{i n \cdot l b f}{r a d} \\
& K_{x m}:=\frac{n_{m} \cdot E \cdot b_{m} \cdot h_{m}{ }^{3} \cdot r_{y m}{ }^{2} \cdot \gamma_{x m}}{l_{m}{ }^{3}}=26481 \frac{\mathrm{in} \cdot l b f}{\operatorname{rad}} \quad \text { VS. } 23563-\text { FF09 } 1979 \\
& K_{y f 1}:=\frac{\left(\frac{n_{f}}{4}\right) \cdot E \cdot h_{f} \cdot b_{f}{ }^{3} \cdot r_{x f 1}{ }^{2} \cdot \gamma_{y f}}{l_{f}^{3}}=142782 \frac{\mathrm{in} \cdot l b f}{\mathrm{rad}} \quad \text { VS. } 202964-\text { FF09 } 1979 \\
& K_{y f 2}:=\frac{\left(\frac{n_{f}}{4}\right) \cdot E \cdot h_{f} \cdot b_{f}^{3} \cdot r_{x f 2}^{2} \cdot \gamma_{y f}}{l_{f}^{3}}=236974 \frac{\mathrm{in} \cdot l b f}{\operatorname{rad}} \quad \text { vS. } 239217-\text { FF09 } 1979 \\
& K_{y f 3}:=\frac{\left(\frac{n_{f}}{4}\right) \cdot E \cdot h_{f} \cdot b_{f}{ }^{3} \cdot r_{x f 3}{ }^{2} \cdot \gamma_{y f}}{l_{f}{ }^{3}}=\mathbf{3 5 4 8 9 9} \frac{\mathrm{in} \cdot l b f}{\mathrm{rad}} \quad \text { VS. } 278448 \text { - FF09 } 1979 \\
& K_{y f 4}:=\frac{\left(\frac{n_{f}}{4}\right) \cdot E \cdot h_{f} \cdot b_{f}{ }^{3} \cdot r_{x f 4}{ }^{2} \cdot \gamma_{y f}}{l_{f}{ }^{3}}=496557 \frac{\mathrm{in} \cdot l b f}{\mathrm{rad}} \quad \text { VS. } 320656-\text { FF09 } 1979 \\
& K_{x y f}:=\frac{n_{f} \cdot E}{12 \cdot l_{f}^{3}} \cdot\left(b_{f} \cdot h_{f}\right)^{3} \cdot\left(\gamma_{x f}+\gamma_{y f}\right)=481 \frac{\text { in } \cdot l b f}{\operatorname{rad}} \quad \text { VS. } 432 \text { - FF09 } 1979 \\
& r_{y f}=0.75 \text { in }
\end{aligned}
$$

.


$K_{x y m}:=\frac{n_{m} \cdot E}{12 \cdot l_{m}{ }^{3}} \cdot\left(b_{m} \cdot h_{m}\right)^{3} \cdot\left(\gamma_{x m}+\gamma_{y m}\right)=627 \frac{\text { in } \cdot \text { lbf }}{\mathrm{rad}} \quad$ vs. 644 - FF09 1979

Use following equation when flex beam group consists of 4-beams

$\Sigma K_{\tau}:=K_{\tau f}+K_{\tau m}+K_{x f}+K_{x m}+K_{y f 1}+K_{y f 2}+K_{y f 3}+K_{y f 4}+K_{x y f}+K_{x y m}=1270565 \frac{\mathrm{in} \cdot \mathrm{lbf}}{\mathrm{rad}}$

vs. 1,078,525 - FF09 1979

Load Proportions

$$
\begin{aligned}
& N_{\tau f}:=\frac{K_{\tau f}}{\Sigma K_{\tau}}=0.0008 \\
& N_{\tau m}:=\frac{K_{\tau m}}{\Sigma K_{\tau}}=0.0012 \\
& N_{x f}:=\frac{K_{x f}}{\Sigma K_{\tau}}=0.0073 \\
& N_{x m m}:=\frac{K_{x m}}{\Sigma K_{\tau}}=0.0208 \\
& N_{y f 1}:=\frac{K_{y f 1}}{\Sigma K_{\tau}}=0.1124 \\
& N_{y f 2}:=\frac{K_{y f 2}}{\Sigma K_{\tau}}=0.1865 \\
& N_{y f 3}:=\frac{K_{y f 3}}{\Sigma K_{\tau}}=0.2793 \\
& N_{y f 4}:=\frac{K_{y f 4}}{\Sigma K_{\tau}}=0.3908 \\
& N_{x y f}:=\frac{K_{x y f}}{\Sigma K_{\tau}}=0.0004 \\
& N_{x y m m}:=\frac{K_{x y m}}{\Sigma K_{\tau}}=0.0005
\end{aligned}
$$


$\underline{\text { Stresses }}$

$$
\begin{aligned}
& S_{\tau f}:=\frac{M_{Y} \cdot N_{\tau f}}{n_{f} \cdot \alpha_{f} \cdot b_{f} \cdot t_{f}^{2}}=198 \mathrm{psi} \\
& S_{\tau m}:=\frac{M_{Y} \cdot N_{\tau m}}{n_{m} \cdot \alpha_{m} \cdot b_{m} \cdot t_{m}^{2}}=775 \mathrm{psi} \\
& S_{x f}:=\frac{3 \cdot M_{Y} \cdot N_{x f} \cdot l_{f}}{n_{f} \cdot b_{f} \cdot h_{f}^{2} r_{y f}}=1569 \mathrm{psi} \\
& S_{x m}:=\frac{3 \cdot M_{Y} \cdot N_{x m} \cdot l_{m}}{n_{m} \cdot b_{m} \cdot h_{m}{ }^{2} r_{y m}}=7996 \mathrm{psi} \\
& S_{x y f}:=\frac{18 \cdot M_{Y} \cdot N_{x y f} \cdot l_{f} \cdot\left(\gamma_{x f}-\gamma_{y f}\right)}{n_{f} \cdot\left(b_{f} \cdot h_{f}\right)^{2} \cdot\left(\gamma_{x f}+\gamma_{y f}\right)}=\mathbf{3 1 0} p s i \quad \text { vs. } 202 \text { psi - FF09 } 1979 \\
& S_{x y m}:=\frac{18 \cdot M_{Y} \cdot N_{x y m} \cdot l_{m} \cdot\left(\gamma_{x m}-\gamma_{y m}\right)}{n_{m} \cdot\left(b_{m} \cdot h_{m}\right)^{2} \cdot\left(\gamma_{x m}+\gamma_{y m}\right)}=903 p s i \quad \text { vs. } 778 \text { psi - FF09 } 1979 \\
& S_{y f 1}:=\frac{3 \cdot M_{Y} \cdot N_{y f 1} \cdot l_{f}}{\left(\frac{n_{f}}{4}\right) \cdot h_{f} \cdot b_{f}^{2} \cdot r_{x f 1}}=7872 p s \\
& S_{y f 2}:=\frac{3 \cdot M_{Y} \cdot N_{y f 2} \cdot l_{f}}{\left(\frac{n_{f}}{4}\right) \cdot h_{f} \cdot b_{f}^{2} \cdot r_{x f 2}}=10142 p s i \\
& S_{y f 3}:=\frac{3 \cdot M_{Y} \cdot N_{y f 3} \cdot l_{f}}{\left(n_{f}\right)}=12412 \text { psi } \quad \text { vs. } 12590 \text { psi - FF09 } 1979 \\
& \left(\frac{n_{f}}{4}\right) \cdot h_{f} \cdot b_{f}^{2} \cdot r_{x f 3} \\
& S_{y f 4}:=\frac{3 \cdot M_{Y} \cdot N_{y f 4} \cdot l_{f}}{\left(n_{f}\right)}=14681 \text { psi } \quad \text { vs. } 13500 \text { psi - FF09 } 1979 \\
& \text { vs. } 240 \text { psi - FF09 } 1979 \\
& \text { vs. } 710 \text { psi - FF09 } 1979 \\
& \text { vs. } 1532 \text { psi - FF09 } 1979 \\
& \text { vs. } 6620 \text { psi - FF09 } 1979 \\
& \text { vs. } 10740 \text { psi - FF09 } 1979 \\
& \text { vs. } 11660 \text { psi - FF09 } 1979
\end{aligned}
$$$$
\text { Maximum Stress }
$$$$
S_{n f 1}:=S_{x f}+S_{y f 1}+S_{x y f}=9752 p s i
$$$$
\text { vs. } 12472 \text { psi - FF09 } 1979
$$ 


$$
\begin{array}{lr}
S_{n f 2}:=S_{x f}+S_{y f 2}+S_{x y f}=12021 \mathrm{psi} & \text { vs. } 13392 \text { psi - FF09 } 1979 \\
S_{n f 3}:=S_{x f}+S_{y f 3}+S_{x y f}=14291 \mathrm{psi} & \text { vs. } 14322 \text { psi - FF09 } 1979 \\
S_{n f 4 \_y a w}:=S_{x f}+S_{y f 4}+S_{x y f}=16560 \mathrm{psi} & \text { vS. } 15232 \text { psi - FF09 } 1979 \\
S_{y m}:=0 & \\
S_{n m_{y} y a w}:=S_{x m}+S_{y m}+S_{x y m}=8899 \mathrm{psi} & \text { vs. } 7398 \text { psi - FF09 } 1979
\end{array}
$$

\section{SIDE $60 \mathrm{lbf}$}

$\underline{\text { Stresses due to Transfer Moment }}$

$$
\begin{aligned}
& L=2.055 \text { in } \quad P_{S}=60 \text { lbf } \quad M_{Y}=540 \mathrm{in} \cdot l b f \\
& M_{S}:=P_{S} \cdot L=123.3 \mathrm{in} \cdot l b f \\
& S_{x f}:=S_{x f} \cdot\left(\frac{M_{S}}{M_{Y}}\right)=358 \mathrm{psi} \\
& S_{x m}:=S_{x m} \cdot\left(\frac{M_{S}}{M_{Y}}\right)=1826 \mathrm{psi} \\
& S_{y f 1}:=S_{y f 1} \cdot\left(\frac{M_{S}}{M_{Y}}\right)=1798 \mathrm{psi} \\
& S_{y f 2}:=S_{y f 2} \cdot\left(\frac{M_{S}}{M_{Y}}\right)=2316 \mathrm{psi} \\
& S_{y f 3}:=S_{y f 3} \cdot\left(\frac{M_{S}}{M_{Y}}\right)=2834 \mathrm{psi} \\
& S_{x y f}:=S_{x y f} \cdot\left(\frac{M_{S}}{M_{Y}}\right)=71 \mathrm{psi} \\
& S_{y f 4}:=S_{y f 4} \cdot\left(\frac{M_{S}}{M_{Y}}\right)=3352 \mathrm{psi} \\
& \left(\frac{M_{S}}{M_{Y}}\right)=206 \mathrm{psi} \\
& S_{x y m}
\end{aligned}
$$

vs. 329 psi - FF09 1979

vs. 1426 psi - FF09 1979

vs. 2313 psi - FF09 1979

vs. 2511 psi - FF09 1979

vs. 2711 psi - FF09 1979

vs. 2907 psi - FF09 1979

vs. 43 psi - FF09 1979

vs. 168 psi - FF09 1979 
Stresses due to Side Force Missing Fsf-load proportion, due to side force, carried by the flex beams

$S_{b}:=\frac{3 \cdot P_{S} \cdot l_{f}}{n_{f} \cdot h_{f} \cdot b_{f}^{2}}=1080 \mathrm{psi}$

vs. 1259 psi - FF09 1979

Note: Due to the direction of Side Force, the height and base are swapped in this formula.

Maximum Stress

$$
\begin{array}{lr}
S_{n f 1}:=S_{x f}+S_{y f 1}+S_{x y f}+S_{b}=\mathbf{3 3 0 7} \mathbf{p s i} & \text { Vs. } 3944 \text { psi - FF09 } 1979 \\
S_{n f 2}:=S_{x f}+S_{y f 2}+S_{x y f}+S_{b}=3825 \text { psi } & \text { vs. } 4142 \text { psi - FF09 } 1979 \\
S_{n f 3}:=S_{x f}+S_{y f 3}+S_{x y f}+S_{b}=4343 \text { psi } & \text { vs. } 4342 \text { psi - FF09 } 1979 \\
S_{n f 4 \_s i d e}:=S_{x f}+S_{y f 4}+S_{x y f}+S_{b}=4861 \text { psi } & \text { vs. } 4538 \text { psi - FF09 } 1979
\end{array}
$$

Note: The force in the measurement beams is neglected in this case.

$$
\begin{aligned}
& S_{b}:=0 \\
& S_{n m_{-} \text {side }}:=S_{x m}+S_{y m}+S_{x y m}+S_{b}=2032 p s i \quad \text { vs. } 1594 \text { psi - FF09 } 1979
\end{aligned}
$$




\section{$\underline{\text { T-Section \#1 }}$}

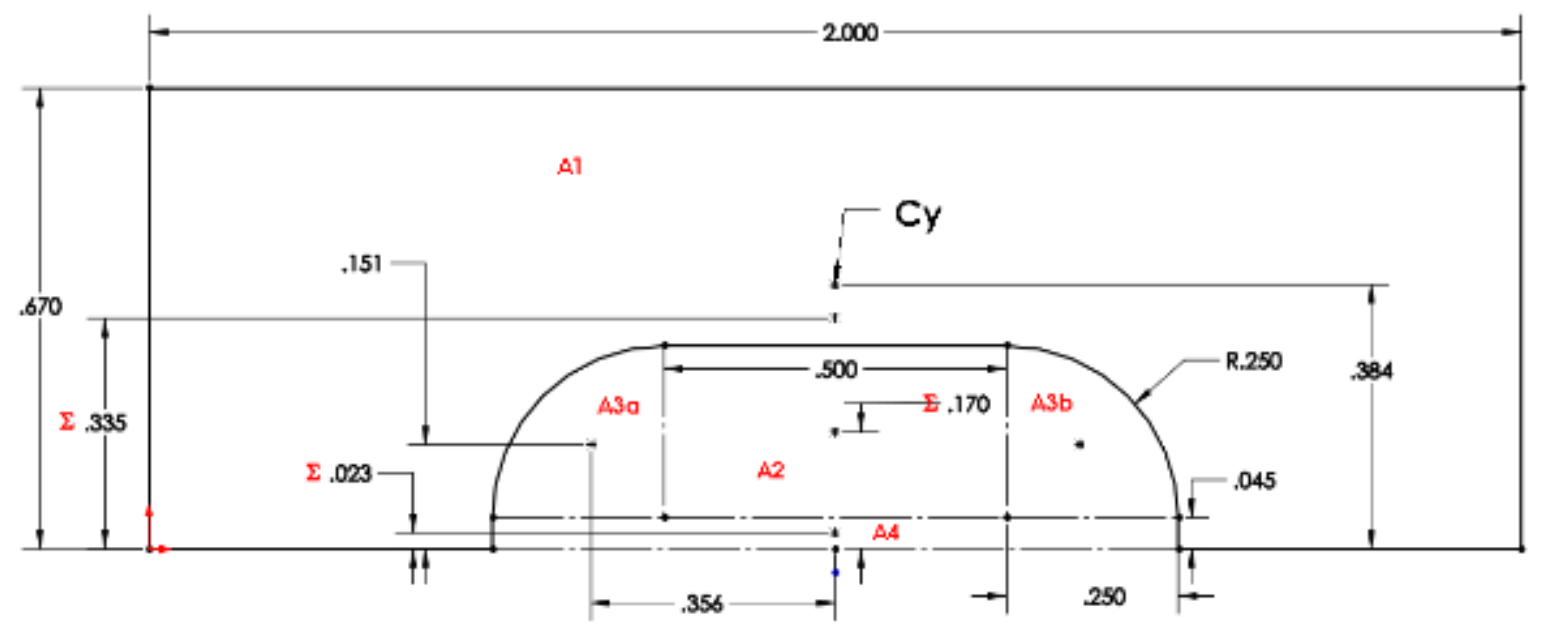

T-Section \#1 Dimensions

$L_{1}:=3.010$ in $\quad L_{-} 1=$ Distance from BMC to T-section \#1

$\begin{array}{ll}b_{1}:=2.00 \text { in } & h_{1}:=0.670 \text { in } \\ b_{2}:=0.500 \text { in } & h_{2}:=0.250 \text { in } \\ r_{3}:=0.25 \text { in } & h_{3}:=0.250 \text { in } \\ b_{4}:=1.00 \text { in } & h_{4}:=0.045 \text { in }\end{array}$

$z_{\text {bar }}:=0.000$ in

Note: T-section is symmetric about the z-axis, therefore zbar is zero.

Element Area Calculations

$A_{1}:=b_{1} \cdot h_{1}=1.34 \mathrm{in}^{2}$

$A_{2}:=b_{2} \cdot h_{2}=0.125 \mathrm{in}^{2}$

$A_{3}:=\left(\frac{\pi \cdot r_{3}{ }^{2}}{4}\right)=0.049 \mathrm{in}^{2}$

$A_{4}:=b_{4} \cdot h_{4}=0.045$ in $^{2}$

$A_{T}:=A_{1}-A_{2}-2 \cdot A_{3}-A_{4}=1.072 \mathrm{in}^{2}$
Ybar Calculations

$y_{\text {bar } 1}:=\frac{h_{1}}{2}=0.335$ in

$y_{\text {bar } 2}:=\left(h_{4}+\frac{h_{2}}{2}\right)=0.17$ in

$y_{\text {bar } 3}:=h_{4}+\left(\frac{4 \cdot r_{3}}{3 \cdot \pi}\right)=0.151$ in

$y_{\text {bar } 4}:=\frac{h_{4}}{2}=0.023$ in 
Centroid Calculations

$$
\begin{aligned}
& A y 1:=A_{1} \cdot y_{\text {bar } 1}=0.449 \mathrm{in}^{3} \\
& A y 2:=\left(-A_{2} \cdot y_{\text {bar } 2}\right)=-0.021 \mathrm{in}^{3} \\
& A y 3:=\left(-A_{3} \cdot y_{\text {bar } 3}\right)=-0.007 \mathrm{in}^{3} \\
& A y 4:=\left(-A_{4} \cdot y_{\text {bar } 4}\right)=-0.001 \mathrm{in}^{3} \\
& A y:=\left[\begin{array}{c}
A y 1 \\
A y 2 \\
2 \cdot A y 3 \\
A y 4
\end{array}\right] \quad \sum(A y)=0.412 \mathrm{in}^{3} \quad C_{y}:=\frac{\sum(A y)}{A_{T}}=0.384 \mathrm{in}
\end{aligned}
$$

Distance from Ybar to Element

Centroids along z-axis

$$
\begin{aligned}
& d_{1 y}:=\left(C_{y}-\frac{h_{1}}{2}\right)=0.049 \text { in } \\
& d_{2 y}:=\left(C_{y}-h_{4}-\frac{h_{2}}{2}\right)=0.214 \text { in } \\
& d_{3 y}:=\left(C_{y}-h_{4}-\left(\frac{4 \cdot r_{3}}{3 \cdot \pi}\right)\right)=0.233 \text { in } \quad d_{3 z}:=\left(\frac{b_{2}}{2}\right)+\left(\frac{4 \cdot r_{3}}{3 \cdot \pi}\right)=0.356 \text { in } \\
& d_{4 y}:=\left(C_{y}-\frac{h_{4}}{2}\right)=0.3617 \text { in }
\end{aligned}
$$

Moment of Inertia Calculations

$$
\begin{aligned}
& I_{Y Y 1}:=\frac{1}{12} \cdot b_{1} \cdot h_{1}{ }^{3}+A_{1} \cdot d_{1 y}{ }^{2}=0.053 \mathrm{in}^{4} \\
& I_{Y Y 2}:=\frac{1}{12} \cdot b_{2} \cdot h_{2}{ }^{3}+A_{2} \cdot d_{2 y}{ }^{2}=\left(6.387 \cdot 10^{-3}\right) \mathrm{in}^{4} \\
& I_{Y Y 3}:=\frac{1}{16} \cdot \pi \cdot r_{3}{ }^{4}+A_{3} \cdot d_{3 y}{ }^{2}=\left(3.434 \cdot 10^{-3}\right) \mathrm{in}^{4}
\end{aligned}
$$

Distance from Ybar to Element Centroids along $y$-axis 


$$
\begin{aligned}
& I_{Y Y 4}:=\frac{1}{12} \cdot b_{4} \cdot h_{4}{ }^{3}+A_{4} \cdot d_{4 y}{ }^{2}=\left(5.895 \cdot 10^{-3}\right) \mathrm{in}^{4} \\
& I_{Y Y}:=I_{Y Y 1}-I_{Y Y 2}-2 \cdot I_{Y Y 3}-I_{Y Y 4}=0.0342 \mathrm{in}^{4} \\
& I_{Z Z 1}:=\frac{1}{12} \cdot b_{1}{ }^{3} \cdot h_{1}=0.447 \mathrm{in}^{4} \\
& I_{Z Z 2}:=\frac{1}{12} \cdot b_{2}{ }^{3} \cdot h_{2}=\left(2.604 \cdot 10^{-3}\right) \mathrm{in}^{4} \\
& I_{Z Z 3}:=\frac{1}{16} \cdot \pi \cdot r_{3}{ }^{4}+A_{3} \cdot d_{3 z}{ }^{2}=\left(6.992 \cdot 10^{-3}\right) \mathrm{in}^{4} \\
& I_{Z Z 4}:=\frac{1}{12} \cdot b_{4}{ }^{3} \cdot h_{4}=\left(3.75 \cdot 10^{-3}\right) \mathrm{in}^{4} \\
& I_{Z Z}:=I_{Z Z 1}-I_{Z Z 2}-2 \cdot I_{Z Z 3}-I_{Z Z 4}=0.4263 \mathrm{in}^{4}
\end{aligned}
$$

Stress in the T-Section

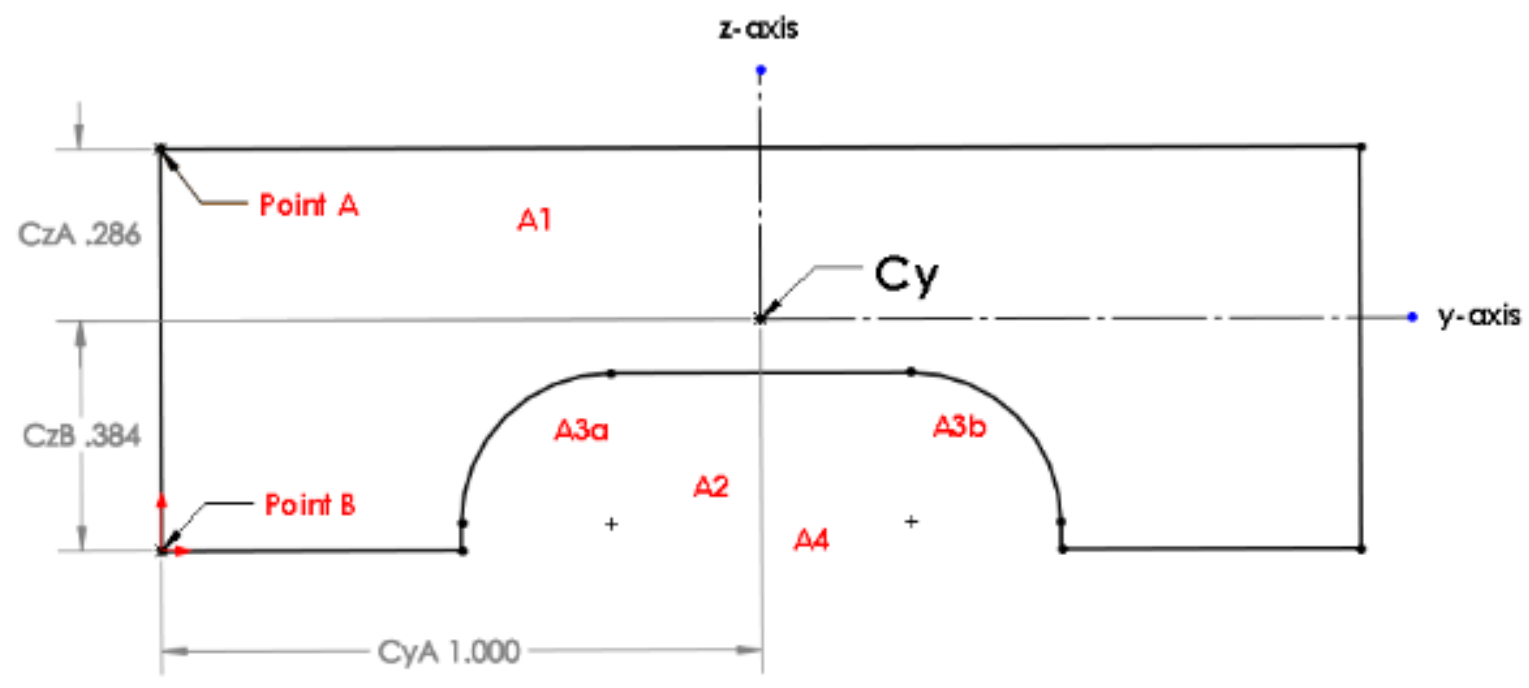

$$
\begin{array}{lll}
M_{m}:=M_{P}=480 \mathrm{in} \cdot \mathrm{lbf} & c_{z A}:=h_{1}-C_{y}=0.286 \text { in } & c_{y A}:=\frac{b_{1}}{2}=1 \text { in } \\
M_{n}:=M_{Y}=540 \mathrm{in} \cdot \mathrm{lbf} & & \\
N:=P_{N}=100 \mathrm{lbf} & c_{z B}:=C_{y}=0.384 \mathrm{in} & c_{y B}:=c_{y A}=1 \text { in } \\
Y:=P_{S}=60 \mathrm{lbf} & &
\end{array}
$$


At Point A

Pitch \& Normal

$S_{A 1}:=\frac{\left(M_{m}+N \cdot L_{1}\right) \cdot c_{z A}}{I_{Y Y}}=6522 \mathrm{psi}$

vs. 1387 psi - FF09 1979

Yaw \& Side

$S_{A 2}:=\frac{\left(M_{n}+Y \cdot L_{1}\right) \cdot c_{y A}}{I_{Z Z}}=1690 \mathrm{psi}$

vs. 1636 psi - FF09 1979

Maximum Stress at Point $\mathrm{A}$

$S_{A \_ \text {max }}:=S_{A 1}+S_{A 2}=8213 \mathrm{psi}$

vs. 3023 psi - FF09 1979

At Point B

Pitch \& Normal

$S_{B 1}:=\frac{\left(M_{m}+N \cdot L_{1}\right) \cdot c_{z B}}{I_{Y Y}}=8768 p s i \quad$ vs. 1958 psi - FF09 1979

Yaw \& Side

$S_{B 2}:=\frac{\left(M_{n}+Y \cdot L_{1}\right) \cdot c_{y B}}{I_{Z Z}}=1690 \mathbf{p s i} \quad$ vs. 818 psi - FF09 1979

Maximum Stress at Point B

$S_{B \_ \text {max }}:=S_{B 1}+S_{B 2}=10459 \mathrm{psi}$

vs. 2776 psi - FF09 1979 


\section{T-Section \#2}

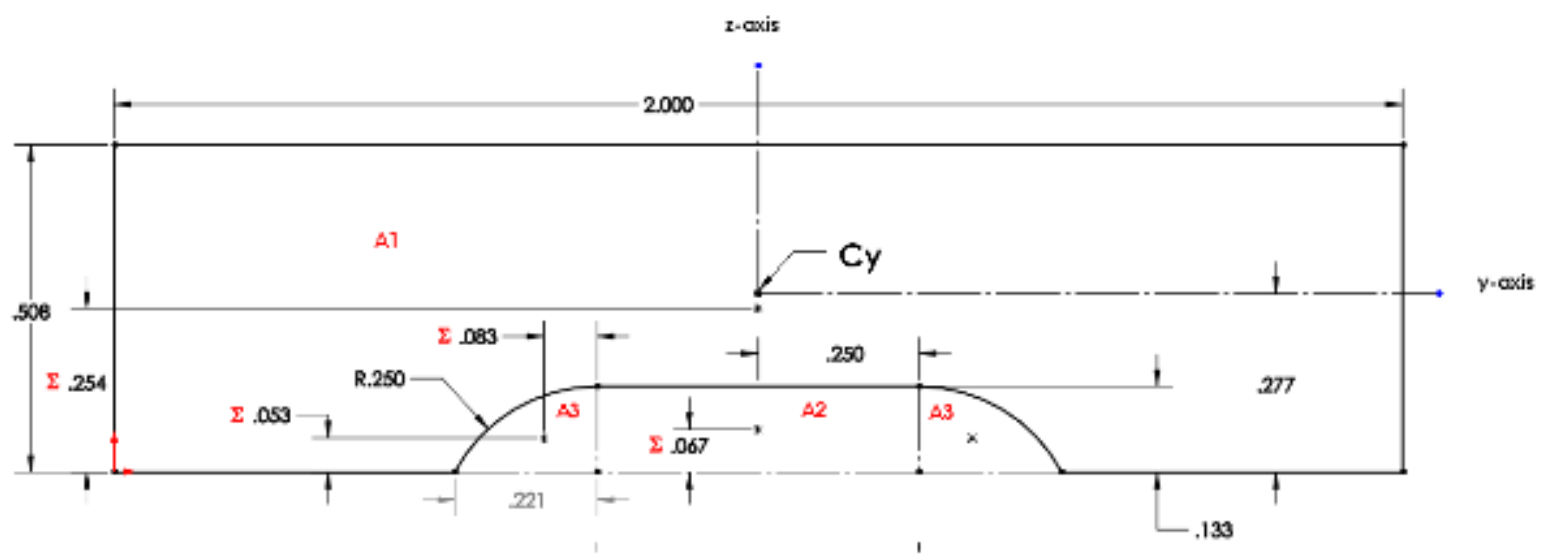

$\underline{\text { T-Section Dimensions }}$

$L_{2}:=2.055$ in

Note: $L$ 2 = Distance of $T$-section \#2 from BMC

$b_{1}:=2.00$ in

$b_{2}:=0.500$ in

$b_{3}:=0.2209$ in

$b_{4}:=b_{3}=0.2209$ in $h_{1}:=0.508$ in

$h_{\text {, }}:=0.133$ in

$h_{3}:=0.133$ in

$h_{4}:=h_{3}=0.133$ in $r_{3}:=0.250$ in

$z_{\text {bar }}:=0.000$ in

Note: T-section is symmetric about the z-axis, therefore zbar is zero.

\section{Element Area Calculations}

$$
\begin{aligned}
& A_{1}:=b_{1} \cdot h_{1}=1.016 \mathrm{in}^{2} \\
& A_{2}:=b_{2} \cdot h_{2}=0.067 \mathrm{in}^{2} \\
& A_{3}:=\frac{\left(r_{3}{ }^{2} \cdot \operatorname{acos}\left(\frac{r_{3}-h_{3}}{r_{3}}\right)-\left(r_{3}-h_{3}\right) \sqrt[2]{2 \cdot r_{3} \cdot h_{3}-h_{3}{ }^{2}}\right)}{2}=0.0209 \mathrm{in}^{2}
\end{aligned}
$$

$A_{T}:=A_{1}-A_{2}-2 \cdot A_{3}=0.908 \mathrm{in}^{2}$ 
$\underline{\text { Ybar Calculations }}$

$$
\begin{aligned}
& y_{\text {bar } 1}:=\frac{h_{1}}{2}=0.254 \text { in } \\
& y_{\text {bar } 2}:=\left(\frac{h_{2}}{2}\right)=0.067 \text { in } \\
& y_{\text {bar } 3}:=\left(\frac{2}{5} \cdot h_{2}\right)=0.053 \text { in } \\
& y_{\text {bar } 4}:=\left(\frac{2}{5} \cdot h_{2}\right)=0.053 \text { in }
\end{aligned}
$$

Centroid Calculations

$$
\begin{aligned}
& A y 1:=A_{1} \cdot y_{\text {bar } 1}=0.258 \mathrm{in}^{3} \\
& A y 2:=\left(-A_{2} \cdot y_{\text {bar } 2}\right)=-0.004 \mathrm{in}^{3} \\
& A y 3:=\left(-A_{3} \cdot y_{\text {bar } 3}\right)=-0.001 \mathrm{in}^{3} \\
& \text { Ay } 4:=\left(-A_{3} \cdot y_{\text {bar } 3}\right)=-0.001 \mathrm{in}^{3}
\end{aligned}
$$

$$
A y:=\left[\begin{array}{l}
A y 1 \\
A y 2 \\
A y 3 \\
A y 4
\end{array}\right] \quad \sum(A y)=0.251 i n^{3}
$$

Distance from Ybar to Element

$$
\begin{aligned}
& d_{1 y}:=\left(C_{y}-\frac{h_{1}}{2}\right)=0.023 \text { in } \\
& d_{2 y}:=\left(C_{y}-\frac{h_{3}}{2}\right)=0.2105 \text { in } \\
& d_{3 y}:=\left(C_{y}-\left(\frac{2 \cdot h_{3}}{5}\right)\right)=0.224 \text { in } \quad d_{3 z}:=\left|z_{\text {bar }}-\frac{3 \cdot b_{3}}{8}\right|=0.083 \text { in }
\end{aligned}
$$

Centroid Locations for Element 3 \& 4
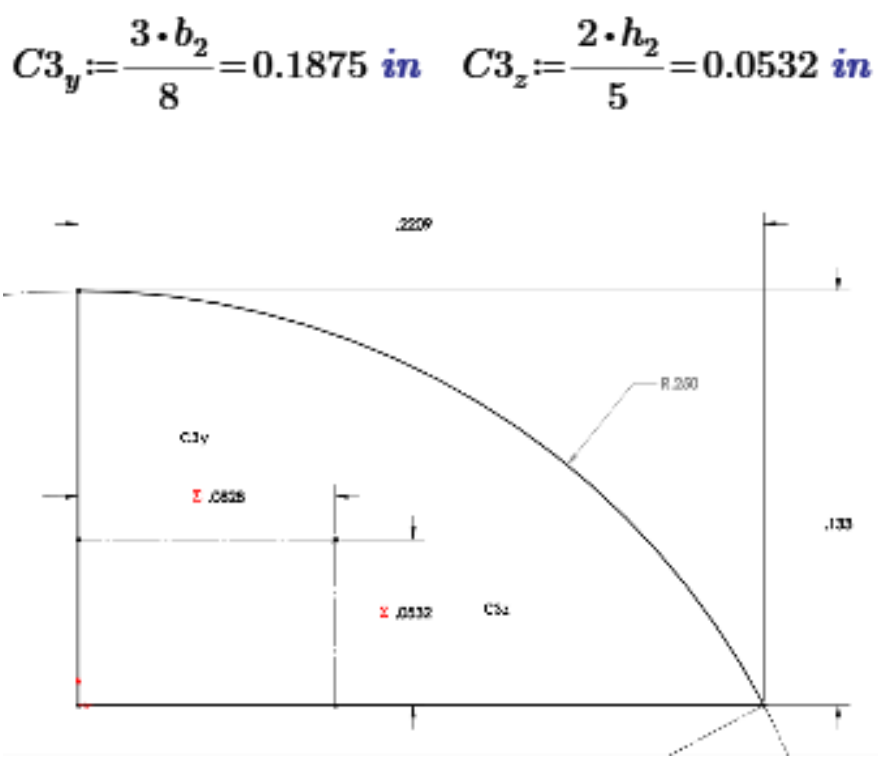

Distance from Ybar to Element Centroids along y-axis 
Moment of Inertia Calculations

$$
\begin{aligned}
I_{Y Y 1} & :=\frac{1}{12} \cdot b_{1} \cdot h_{1}{ }^{3}+A_{1} \cdot d_{1 y}{ }^{2}=0.0224 \mathrm{in}^{4} \\
I_{Y Y 2} & :=\frac{1}{12} \cdot b_{2} \cdot h_{2}{ }^{3}+A_{2} \cdot d_{2 y}{ }^{2}=0.003 \mathrm{in}^{4} \\
I_{Y Y 3} & :=\frac{8}{175} \cdot b_{3} \cdot h_{3}{ }^{3}+A_{3} \cdot d_{2 y}{ }^{2}=0.001 \mathrm{in}^{4} \\
I_{Y Y} & :=I_{Y Y 1}-I_{Y Y 2}-2 \cdot I_{Y Y 3}=0.0174 \mathrm{in}^{4} \\
I_{Z Z 1}: & :=\frac{1}{12} \cdot b_{1}{ }^{3} \cdot h_{1}=0.339 \mathrm{in}^{4} \\
I_{Z Z 2}:= & \frac{1}{12} \cdot b_{2}{ }^{3} \cdot h_{2}=0.00139 \mathrm{in}^{4} \\
I_{Z Z 3} & :=\frac{19}{480} \cdot b_{3}{ }^{3} \cdot h_{3}+A_{3} \cdot d_{3 z}{ }^{2}=0.0002 \mathrm{in}^{4} \\
I_{Z Z} & :=I_{Z Z 1}-I_{Z Z 2}-2 \cdot I_{Z Z 3}=0.337 \mathrm{in}^{4}
\end{aligned}
$$


Stress in the T-Section \#2

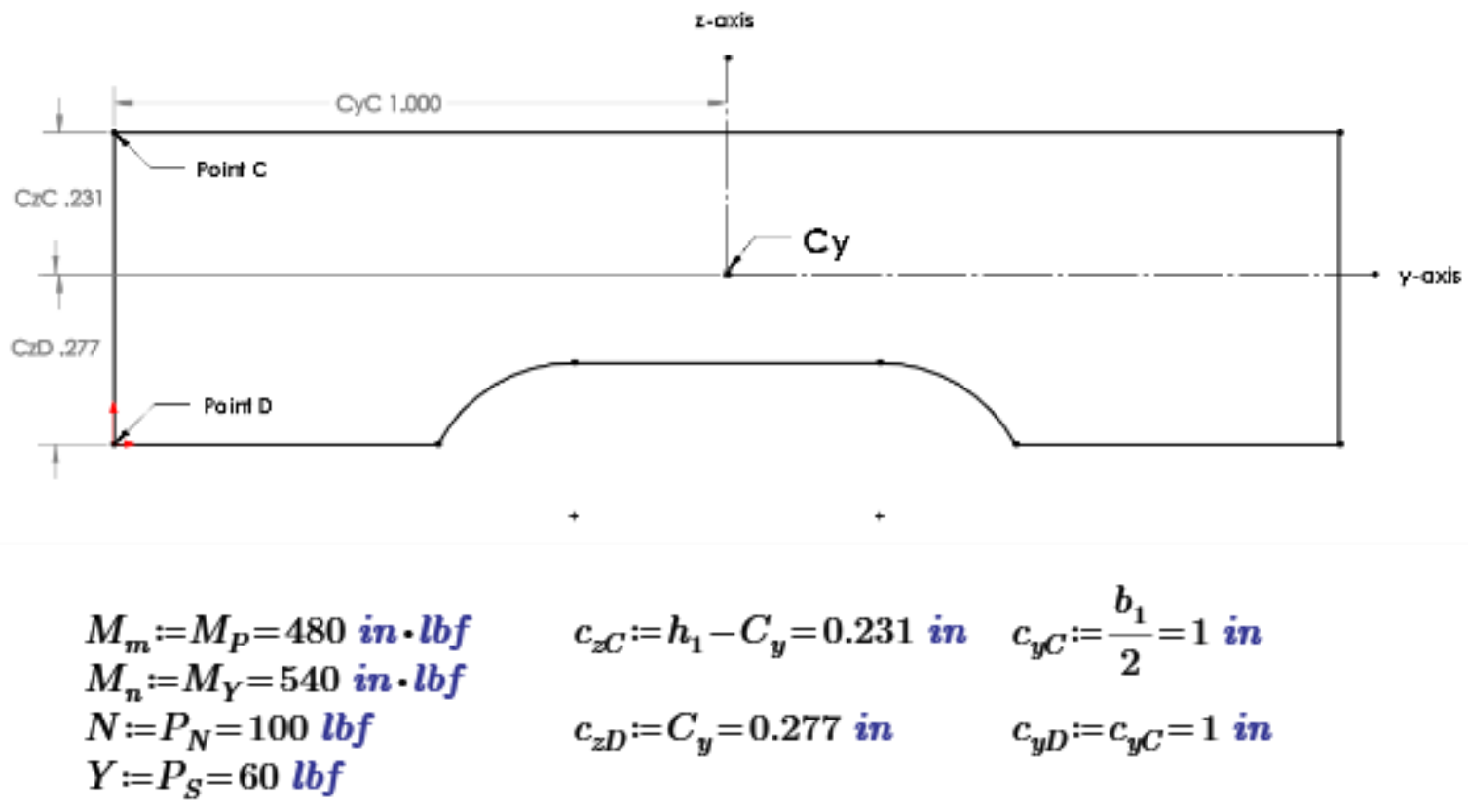

At Point C

Pitch \& Normal

$S_{C 1}:=\frac{\left(M_{m}+N \cdot L_{2}\right) \cdot c_{z C}}{I_{Y Y}}=9080 \mathrm{psi}$

Yaw \& Side

$S_{C 2}:=\frac{\left(M_{n}+Y \cdot L_{2}\right) \cdot c_{y C}}{I_{Z Z}}=1969 \mathrm{psi}$

Maximum Stress at Point C

$S_{C_{-} \max 1}:=S_{C 1}+S_{C 2}=11049 \mathrm{psi}$ 
At Point D

Pitch \& Normal

$S_{D 1}:=\frac{\left(M_{m}+N \cdot L_{2}\right) \cdot c_{z D}}{I_{Y Y}}=10889 \mathrm{psi}$

Yaw \& Side

$S_{D 2}:=\frac{\left(M_{n}+Y \cdot L_{2}\right) \cdot c_{y D}}{I_{Z Z}}=1969 p s i$

$\underline{\text { Maximum Stress at Point D }}$

$S_{D \_\max 1}:=S_{D 1}+S_{D 2}=12858 \mathrm{psi}$

Bending Stress at 2.055" after Moment Center

Forces at Flex Beam

Note: Contributions due to measurement beams are neglected in this case due to "slot"

$r_{f n}:=\frac{D}{2}=0.795$ in $\quad D=1.59$ in $\quad D P=2.1$ in

$R_{F_{n}}:=\frac{M_{Y}}{2 \cdot r_{f n}}=339.6 \mathrm{lbf}$

vs. 301.3 lbf - FF09 1979

$R_{A y}:=\frac{P_{S} \cdot\left(L_{2}+r_{f n}\right)}{2 \cdot r_{f n}}=107.5 l b f$

vs. 94.9 lbf - FF09 1979

$M_{Z Z}:=\left(R_{F n}+R_{A y}\right) \cdot r_{f n}=356 \mathrm{in} \cdot l b f$

vs. 382 in-lbf - FF09 1979

$R_{F_{m}}:=\frac{M_{P}}{2 \cdot r_{f n}}=301.9 \mathrm{lbf}$

vs. 267.9 lbf - FF09 1979

$R_{F N}:=\frac{P_{N} \cdot\left(L_{2}+r_{f n}\right)}{2 \cdot r_{f n}}=179.2 l b f$

vs. 158.2 lbf - FF09 1979 


$$
M_{Y Y}:=\left(R_{F m}+R_{F N}\right) \cdot r_{f n}=383 \text { in } \cdot \text { lbf } \quad \text { vs. } 355 \text { in-lbf - FF09 } 1979
$$

Maximum Bending Stress at Point $\mathrm{C}$

$$
S_{C_{-} \max 2}:=\left|\frac{M_{Y Y} \cdot c_{z C}}{I_{Y Y}}\right|+\left|\frac{M_{Z Z} \cdot c_{y C}}{I_{Z Z}}\right|=6122 \text { psi } \quad \text { vs. } 2337 \text { psi - FF09 } 1979
$$

Maximum Bending Stress at Point D

$$
S_{D \_\max 2}:=\left|\frac{M_{Y Y} \cdot c_{z D}}{I_{Y Y}}\right|+\left|\frac{M_{Z Z} \cdot c_{y D}}{I_{Z Z}}\right|=7131 \text { psi } \quad \text { vs. } 2441 \text { psi - FF09 } 1979
$$

\section{Bolting for Model Attachment End}

Stress due to Shear

Max Shearing Force

$$
\begin{aligned}
& F_{l}:=\frac{M_{R}}{r_{\text {MEbolts }}}=185.185 \mathrm{lbf} \\
& F_{S}:=\left(\left(\left(\left|\frac{P_{N}}{4}\right|\right)+\left|\frac{F_{l}}{4} \cdot \sin \left(45^{\circ}\right)\right|\right)^{2}+\left(\left|\frac{P_{S}}{4}\right|+\left|\frac{F_{l}}{4} \cdot \cos \left(45^{\circ}\right)\right|\right)^{2}\right)^{.5}=74.9 l b f
\end{aligned}
$$

vs. 77.2 lbf - FF09 1979

$$
\begin{aligned}
& A_{S}=0.0524 \mathrm{in}^{2} \quad \text { NOTE: minor diameter area of 5/16-24 unf bolt } \\
& S_{S \max }:=\frac{F_{S}}{A_{S}}=1430 \mathrm{psi}
\end{aligned}
$$

$\underline{\text { Stress due to Tension }}$

NOTE: Assume center of compression area is $1.500 "$ from tension bolts

$$
F_{t}:=\frac{1}{2} \cdot\left(\frac{P_{N} \cdot L_{M C M E}+M_{P}}{1.500 \text { in }}\right)+\frac{1}{2} \cdot\left(\frac{P_{S} \cdot L_{M C M E}+M_{Y}}{1.500 \text { in }}\right)+\frac{P_{A}}{4}=459.2 \text { lbf }
$$

vs. 539.2 lbf - FF09 1979 
Tensile Area

$$
A_{t}=\mathbf{0 . 0 5 8} \mathrm{in}^{2} \quad \underline{\text { NOTE: }} \text { Tensile stress area of 5/16-24 unf bolt }
$$

Tensile Stress

$$
S_{t}:=\frac{F_{t}}{A_{t}}=7917 \mathrm{psi}
$$

vs. 9297 psi - FF09 1979

Combined Stress

$$
S_{\text {maxm }}:=\frac{S_{t}}{2}+\sqrt{\left(\frac{S_{t}}{2}\right)^{2}+S_{S_{\max }}^{2}}=8167 \mathrm{psi}
$$

\section{Bolting for Sting Attachment End}

$\underline{\text { Stresses due to shear }}$

Max Shearing Force

$$
\begin{aligned}
& F_{l}:=\frac{M_{R}}{r_{\text {SEbolts }}}=170 \mathrm{lbf} \\
& F_{S}:=\left(\left(\left(\left|\frac{P_{N}}{4}\right|\right)+\left|\frac{F_{l}}{4} \cdot \sin \left(45^{\circ}\right)\right|\right)^{2}+\left(\left|\frac{P_{S}}{4}\right|+\left|\frac{F_{l}}{4} \cdot \cos \left(45^{\circ}\right)\right|\right)^{2}\right)^{.5}=71 l b f \\
& \text { vs. } 71.08 \text { lbf - FF09 } 1979 \\
& A_{S}=0.052 \mathrm{in}^{2} \\
& \text { NOTE: minor diameter area of 5/16-24 unf bolt } \\
& S_{S \max }:=\frac{F_{S}}{A_{S}}=1357 \mathrm{psi}
\end{aligned}
$$


Stress due to tension

NOTE: Assume center of compression area is 1.5625 " from tension bolts

$$
F_{t}:=\frac{1}{2}\left(\frac{P_{N} \cdot L_{M C S E}+M_{P}}{1.5625 \text { in }}\right)+\frac{1}{2}\left(\frac{P_{S} \cdot L_{M C S E}+M_{Y}}{1.5625 \text { in }}\right)+\frac{P_{A}}{4}=543.7 \mathrm{lbf}
$$

vs. 978.9 lbf - FF09 1979

Tensile Area

$$
A_{t}=0.058 \mathrm{in}^{2} \quad \text { NOTE: Tensile stress area of 5/16-24 unf bolt }
$$

Tensile Stress

$$
S_{t}:=\frac{F_{t}}{A_{t}}=9374 \mathrm{psi}
$$

vs. 16878 psi - FF09 1979

Combined Stress

$$
S_{\text {maxs }}:=\frac{S_{t}}{2}+\sqrt{\left(\frac{S_{t}}{2}\right)^{2}+S_{S_{\max }}^{2}}=9567 \mathrm{psi}
$$

vs. 16986 psi - FF09 1979 


\section{Axial Section \& DMSK Stress Summary}

Flex Beams

$\begin{array}{ll}\text { Normal } & f_{1}:=S_{N F}=1494 \mathrm{psi} \\ \text { Axial } & f_{2}:=S_{A f}=6112 \mathrm{psi} \\ \text { Pitch } & f_{3}:=S_{M A}=3323 \mathrm{psi} \\ \text { Roll } & f_{4}:=S_{\text {Roll }}=643 \mathrm{psi} \\ \text { Yaw } & f_{5}:=S_{\text {nf } 4 \text { yaw }}=16560 \\ \text { Side } & f_{6}:=S_{\text {nf4_side }}=4861 \mathrm{p} \\ \text { Strap } & S_{\text {FLxy }}=15783 \mathrm{psi} \\ \text { TSection } & S_{D_{-} \text {max } 1}=12858 \mathrm{psi} \\ & \\ & f_{i}:=\left[\begin{array}{l}f_{1} \\ f_{2} \\ f_{3} \\ f_{4} \\ f_{5} \\ f_{6}\end{array}\right]\end{array}$

Total $\sum f_{i}=32993 p s i$
Msmt Beams

Gage Stress

$g_{1}:=S_{A m}=22074 \mathrm{psi} \quad S_{\text {Agage }}=15798 \mathrm{psi}$

$g_{2}:=S_{\text {nm_yaw }}=8899 \mathrm{psi}$

$g_{3}:=S_{\text {nm_side }}=2032 \mathrm{psi}$

Bolting - Model end

Bolting - Sting Attach

$S_{\text {maxm }}=8167 \mathrm{psi}$

$S_{\text {maxs }}=9567 \mathrm{psi}$

$g_{i}:=\left[\begin{array}{l}g_{1} \\ g_{2} \\ g_{3}\end{array}\right]$

$h_{i}:=\left[S_{\text {Agage }}\right]$

$\sum g_{i}=33004 p s i$

$\sum h_{i}=15798 p s i$ 


\section{Cage Section}

Dimensions

Beam 1

Beam 2

$n_{1}:=2$

$n_{2}:=2$

$b_{1}:=0.237$ in

$b_{2}:=0.075$ in

$G_{L}:=0.1025$ in

$h_{1}:=0.073$ in

$h_{2}:=0.313$ in

$r_{z 1}:=0.94$ in

$r_{z 2}:=0$ in

$r_{y 1}:=0$ in

$r_{y 2}:=0.768 \cdot i n$

Note: Dist from BMC to Beam Centroid

$d_{1}:=1.960$ in

$d_{2}:=1.960$ in

$D_{1}:=1.960$ in

$D_{2}:=1.960$ in

$a_{1}:=1.740$ in

$a_{2}:=1.740$ in

$l_{1}:=1.000$ in

$l_{2}:=l_{1}=1.000 \mathrm{in}$

$h_{c 1}:=0.090$ in

$b_{c 2}:=0.080$ in

$\begin{array}{ll}C_{z 1}:=r_{z 1}+\frac{h_{1}}{2}=0.977 \text { in } & C_{z 2}:=r_{z 2}+\frac{h_{2}}{2}=0.157 \text { in } \\ C_{y 1}:=r_{y 1}+\frac{b_{1}}{2}=0.12 \text { in } & C_{y 2}:=r_{y 2}+\frac{b_{2}}{2}=0.806 \text { in }\end{array}$

Note: Dist from respective axis to outermost edge of Beam

Alpha and Beta Calculations

$\underline{\text { Torsional Constants for rectangular cross section }}$

$$
\begin{aligned}
\tanh _{1}:= & \left.\tanh \left(\frac{\pi \cdot b_{1}}{2 \cdot h_{1}}\right)+\frac{\tanh \left(\frac{3 \pi \cdot b_{1}}{2 \cdot h_{1}}\right)}{3^{5}}+\frac{\tanh \left(\frac{5 \pi \cdot b_{1}}{2 \cdot h_{1}}\right)}{5^{5}}+\frac{\tanh \left(\frac{7 \pi \cdot b_{1}}{2 \cdot h_{1}}\right)}{7^{5}}\right)=1.004 \\
\cosh _{1}:= & \frac{1}{\cosh \left(\frac{\pi \cdot b_{1}}{2 \cdot h_{1}}\right)}+\frac{1}{3^{2} \cdot \cosh \left(\frac{3 \pi \cdot b_{1}}{2 \cdot h_{1}}\right)}+\frac{1}{5^{2} \cdot \cosh \left(\frac{5 \pi \cdot b_{1}}{2 \cdot h_{1}}\right)}+\frac{1}{7^{2} \cdot \cosh \left(\frac{7 \pi \cdot b_{1}}{2 \cdot h_{1}}\right)}=0.012
\end{aligned}
$$




$$
\begin{aligned}
& \beta_{1}:=\frac{1}{3}-\frac{64 \cdot h_{1}}{\pi^{5} \cdot b_{1}} \cdot \tanh _{1}=0.269 \\
& \alpha_{1}:=\frac{\beta_{1}}{1-\frac{8}{\pi^{2}} \cdot \cosh _{1}}=0.271 \\
& \text { vs. .240 - UT-63 } 1991 \\
& \text { vs. .250 - UT-63 } 1991 \\
& \tanh _{2}:=\left(\tanh \left(\frac{\pi \cdot h_{2}}{2 \cdot b_{2}}\right)+\frac{\tanh \left(\frac{3 \pi \cdot h_{2}}{2 \cdot b_{2}}\right)}{3^{5}}+\frac{\tanh \left(\frac{5 \pi \cdot h_{2}}{2 \cdot b_{2}}\right)}{5^{5}}+\frac{\tanh \left(\frac{7 \pi \cdot h_{2}}{2 \cdot b_{2}}\right)}{7^{5}}\right)=1.004 \\
& \cosh _{2}:=\left(\frac{1}{\cosh \left(\frac{\pi \cdot h_{2}}{2 \cdot b_{2}}\right)}+\frac{1}{3^{2} \cdot \cosh \left(\frac{3 \pi \cdot h_{2}}{2 \cdot b_{2}}\right)}+\frac{1}{5^{2} \cdot \cosh \left(\frac{5 \pi \cdot h_{2}}{2 \cdot b_{2}}\right)}+\frac{1}{7^{2} \cdot \cosh \left(7 \frac{\pi \cdot h_{2}}{2 \cdot b_{2}}\right)}\right)=0.003 \\
& \beta_{2}:=\frac{1}{3}-\frac{64 \cdot b_{2}}{\pi^{5} \cdot h_{2}} \cdot \tanh _{2}=0.282996 \\
& \text { vs. .270 - UT-63 } 1991 \\
& \alpha_{2}:=\frac{\beta_{2}}{1-\frac{8}{\pi^{2}} \cdot \cosh _{2}}=0.283650
\end{aligned}
$$

\section{Moment Of Inertia For Cage Beams Calculations}

Normal Moments (DB)

$$
\begin{aligned}
& I_{N 1}:=\frac{n_{1} \cdot b_{1} \cdot h_{1}{ }^{3}}{12}=0.0000154 \mathrm{in}^{4} \\
& I_{N 2}:=\frac{n_{2} \cdot b_{2} \cdot h_{2}{ }^{3}}{12}=0.0003833 \mathrm{in}^{4}
\end{aligned}
$$

Pitch Moments (SB) Use Parallel Axis Theorem

$$
\begin{aligned}
& I_{m 1}:=I_{N 1}+n_{1} \cdot\left(b_{1} \cdot h_{1} \cdot r_{z 1}{ }^{2}\right)=0.03059 i n^{4} \\
& I_{m 2}:=I_{N 2}+n_{2} \cdot\left(b_{2} \cdot h_{2} \cdot r_{z 2}{ }^{2}\right)=0.0003833 i n^{4}
\end{aligned}
$$


Side Moments (DB)

$$
\begin{aligned}
& I_{Y 1}:=\frac{n_{1} \cdot h_{1} \cdot b_{1}{ }^{3}}{12}=0.000162 \mathrm{in}^{4} \\
& I_{Y 2}:=\frac{n_{2} \cdot h_{2} \cdot b_{2}{ }^{3}}{12}=0.000022 \mathrm{in}^{4}
\end{aligned}
$$

Yaw Moments (SB)

$$
\begin{aligned}
& I_{n 1}:=I_{Y 1}+n_{1} \cdot\left(h_{1} \cdot b_{1} \cdot r_{y 1}{ }^{2}\right)=0.000162 i n^{4} \\
& I_{n 2}:=I_{Y 2}+n_{2} \cdot\left(h_{2} \cdot b_{2} \cdot{r_{y 2}}^{2}\right)=0.02771 i n^{4}
\end{aligned}
$$

\section{Bending Spring Constant Correction Factor Due to Shearing Deflection}

$$
\begin{aligned}
& \gamma_{y 1}:=\frac{1}{\left(\frac{b_{1}}{l_{1}}\right)^{2} \cdot(2.4) \cdot(1+\nu)+1}=0.854 \\
& \gamma_{y 2}:=\frac{1}{\left(\frac{b_{2}}{l_{2}}\right)^{2} \cdot(2.4) \cdot(1+\nu)+1}=0.983 \\
& \gamma_{z 1}:=\frac{1}{\left(\frac{h_{1}}{l_{1}}\right)^{2} \cdot(2.4) \cdot(1+\nu)+1}=0.984 \\
& \gamma_{z 2}:=\frac{1}{\left(\frac{h_{2}}{l_{2}}\right)^{2} \cdot(2.4) \cdot(1+\nu)+1}=0.77 \\
& \gamma_{y 1}+\gamma_{z 1}=1.838 \\
& \gamma_{y 2}+\gamma_{z 2}=1.753 \\
& \gamma_{z 1}-\gamma_{y 1}=0.13 \\
& \gamma_{y 2}-\gamma_{z 2}=0.213
\end{aligned}
$$




\section{Normal $100 \mathrm{lb}$}

Normal Spring Constants

$$
\begin{aligned}
& K_{N_{1}}:=\frac{12 \cdot E \cdot I_{N 1} \cdot \gamma_{z 1}}{l_{1}{ }^{3}}=5171 \frac{l b f}{i n} \\
& K_{N_{2}}:=\frac{12 \cdot E \cdot I_{N 2} \cdot \gamma_{z 2}}{l_{2}{ }^{3}}=100910 \frac{l b f}{i n} \\
& K_{N T}:=\sum K_{N}=106081 \frac{l b f}{i n}
\end{aligned}
$$

Normal Load Proportions (due to double bending)

$$
\begin{aligned}
& N_{N 1}:=\frac{K_{N_{1}}}{K_{N T}}=0.049 \\
& N_{N 2}:=\frac{K_{N_{2}}}{K_{N T}}=0.951
\end{aligned}
$$

\section{Pitch 480 in-lb}

Pitch Spring Constant

$$
\begin{aligned}
& K_{m_{1}}:=\frac{E \cdot I_{m 1}}{l_{1}{ }^{3}}=871806 \frac{l b f}{i n} \\
& K_{m_{2}}:=\frac{E \cdot I_{m 2}}{l_{2}{ }^{3}}=10924 \frac{l b f}{i n} \\
& K_{m T}:=\sum K_{m}=882730 \frac{l b f}{i n}
\end{aligned}
$$

Pitch Load Proportions (due to single bending)

$$
\begin{aligned}
& N_{m 1}:=\frac{K_{m_{1}}}{K_{m T}}=0.988 \\
& N_{m 2}:=\frac{K_{m_{2}}}{K_{m T}}=0.012
\end{aligned}
$$


$\underline{\text { Stress Calculations for Normal \& Pitch }}$

$\underline{\text { Normal Stress }}$

$$
\begin{aligned}
& S_{N 1}:=\frac{P_{N} \cdot L_{M C} \cdot C_{z 1} \cdot N_{m 1}}{I_{m 1}}+\frac{3 \cdot P_{N} \cdot l_{1} \cdot N_{N 1}}{n_{1} \cdot b_{1} \cdot h_{1}{ }^{2}}=5790 p s i \quad \text { (126) } \\
& S_{N 2}:=\frac{P_{N} \cdot L_{M C} \cdot C_{z 2} \cdot N_{m 2}}{I_{m 2}}+\frac{3 \cdot P_{N} \cdot l_{2} \cdot N_{N 2}}{n_{2} \cdot b_{2} \cdot h_{2}{ }^{2}}=19419 p s i \quad \text { (126) } 5590 \text { FF09 } 1979
\end{aligned}
$$

$\underline{\text { Normal Gage Stress }}$

$$
S_{\text {Ngage }}:=S_{N 2} \cdot\left(1-\frac{2 \cdot G L_{m}}{l_{2}}\right)=15438 p s i
$$

$$
\text { Output }_{\text {Normal }}:=\frac{S_{\text {Ngage }} \cdot G_{\text {factor }}}{E}=1192 \frac{\mu V}{V}
$$

Pitch Gage Stress

$$
\begin{gathered}
S_{m_{1}}:=\frac{M_{P} \cdot N_{m 1} \cdot C_{z 1}}{I_{m 1}}=15133 \mathrm{psi} \\
S_{m_{2}}:=\frac{M_{P} \cdot N_{m 2} \cdot C_{z 2}}{I_{m 2}}=2425 \mathrm{psi} \\
S_{\text {mgage }}:=S_{m_{1}}=15133 \mathrm{psi}
\end{gathered}
$$

$$
\text { Output }_{\text {Pitch }}:=\frac{S_{\text {mgage }} \cdot G_{\text {factor }}}{E}=1168 \frac{\mu V}{V}
$$




\section{Roll 180 in-lb}

$$
\begin{aligned}
& K_{\tau_{1}}:=\frac{n_{1} \cdot \beta_{1} \cdot b_{1} \cdot h_{1}{ }^{3} \cdot G}{l_{1}}=555 \frac{\text { in } \cdot l b f}{r a d} \\
& K_{\tau_{2}}:=\frac{n_{2} \cdot \beta_{2} \cdot h_{2} \cdot b_{2}{ }^{3} \cdot G}{l_{2}}=837 \frac{\text { in } \cdot l b f}{r a d} \\
& K_{y_{1}}:=\frac{n_{1} \cdot E \cdot h_{1} \cdot b_{1}{ }^{3} \cdot \gamma_{y 1} \cdot r_{z 1}{ }^{2}}{l_{1}{ }^{3}}=41780 \frac{\text { in } \cdot l b f}{r a d} \\
& K_{y_{2}}:=\frac{n_{2} \cdot E \cdot h_{2} \cdot b_{2}{ }^{3} \cdot \gamma_{y 2} \cdot r_{z 2}{ }^{2}}{l_{2}{ }^{3}}=0 \frac{\text { in } \cdot l b f}{r a d}
\end{aligned}
$$

Load Proportions

$$
\begin{aligned}
& N_{\tau 1}:=\frac{K_{\tau_{1}}}{K_{T}}=0.0054 \\
& N_{\tau 2}:=\frac{K_{\tau_{2}}}{K_{T}}=0.0081 \\
& N_{y 1}:=\frac{K_{y_{1}}}{K_{T}}=0.4062
\end{aligned}
$$

vs. .2767 - FF09 1979 


$$
\begin{aligned}
& N_{z 2}:=\frac{K_{z_{2}}}{K_{T}}=0.5787 \\
& N_{y 2}:=\frac{K_{y_{2}}}{K_{T}}=0 \\
& N_{z 1}:=\frac{K_{z_{1}}}{K_{T}}=0 \\
& N_{y z 1}:=\frac{K_{y z_{1}}}{K_{T}}=0.0004 \\
& N_{y z 2}:=\frac{K_{y z_{2}}}{K_{T}}=0.001
\end{aligned}
$$

vs. 00014 - FF09 1979

\section{$\underline{\text { Rolling Moment Stresses }}$}

$$
\begin{aligned}
& S_{\tau 1}:=\frac{M_{R} \cdot N_{\tau 1}}{n_{1} \cdot \alpha_{1} \cdot b_{1} \cdot h_{1}{ }^{2}}=1417 \mathrm{psi} \\
& S_{\tau 2}:=\frac{M_{R} \cdot N_{\tau 2}}{n_{2} \cdot \alpha_{2} \cdot h_{2} \cdot b_{2}{ }^{2}}=1467 \mathrm{psi} \\
& S_{y 1}:=\frac{3 \cdot M_{R} \cdot l_{1} \cdot N_{y 1}}{n_{1} \cdot h_{1} \cdot b_{1}{ }^{2} \cdot r_{z 1}}=28458 \mathrm{psi}
\end{aligned}
$$

$S_{y 2}:=0$ psi $\quad$ because $\quad N_{y 2}=0$

User Input division by 0

$$
S_{z 1}:=0 \mathrm{psi} \quad \text { because } \quad N_{z 1}=0
$$$$
S_{z 2}:=\frac{3 \cdot M_{R} \cdot l_{2} \cdot N_{z 2}}{n_{2} \cdot b_{2} \cdot h_{2}{ }^{2} \cdot r_{y 2}}=27691 \mathrm{psi}
$$

$$
S_{y z 1}:=\frac{18 \cdot M_{R} \cdot l_{1} \cdot N_{y z 1}}{n_{1} \cdot b_{1}{ }^{2} \cdot h_{1}{ }^{2}} \cdot\left|\frac{\gamma_{y 1}-\gamma_{z 1}}{\gamma_{y 1}+\gamma_{z 1}}\right|=169 p s i
$$

vs. 21290 - FF09 1979

vs. 108 - FF09 1979 


$$
\begin{aligned}
& S_{y z 2}:=\frac{18 \cdot M_{R} \cdot l_{2} \cdot N_{y z 2}}{n_{1} \cdot b_{2}{ }^{2} \cdot h^{2}} \cdot\left|\frac{\gamma_{y 2}-\gamma_{z 2}}{\gamma_{y 2}+\gamma_{z 2}}\right|=375 p s i \quad \text { (152) } \quad \text { vs. } 313 \text { - FF09 } 1979 \\
& S_{\text {lgage }}:=S_{z 2} \cdot\left(1-\frac{2 \cdot G L_{m}}{l_{2}}\right) \cdot\left(1-\frac{2 \cdot g_{l}}{h_{2}}\right)=16669 \mathrm{psi} \quad \text { (154) } \quad \text { vS. } 12987 \text { - FF09 } 1979 \\
& \text { Output }_{\text {Roll }}:=\frac{S_{\text {lgage }} \cdot G_{\text {factor }}}{E}=1287 \frac{\mu V}{V}
\end{aligned}
$$

$\underline{\text { Max Rolling Moment Stresses }}$

$$
\begin{array}{lll}
S_{t T 1}:=S_{y 1}+S_{z 1}+S_{y z 1}=28627 \mathrm{psi} & \text { (153) } & \text { VS. } 16886 \text { - FF09 } 1979 \\
S_{t T 2}:=S_{y 2}+S_{z 2}+S_{y z 2}=28065 \mathrm{psi} & \text { (153) } & \text { Vs. } 21603-\text { FF09 } 1979
\end{array}
$$

\section{Side 60 lb \& Yaw 540 in-lb}

Side Spring Constants

$$
\begin{aligned}
& K_{Y_{1}}:=\frac{12 \cdot E \cdot I_{Y 1} \cdot \gamma_{y 1}}{l_{1}{ }^{3}}=47284 \frac{l b f}{i n} \\
& K_{Y_{2}}:=\frac{12 E \cdot I_{Y 2} \cdot \gamma_{y 2}}{l_{2}{ }^{3}}=7400 \frac{l b f}{i n} \\
& K_{Y T}:=\sum K_{Y}=54683 \frac{l b f}{i n}
\end{aligned}
$$

Side Load Proportions

$$
\begin{aligned}
& N_{Y 1}:=\frac{K_{Y_{1}}}{K_{Y T}}=0.865 \\
& N_{Y 2}:=\frac{K_{Y_{2}}}{K_{Y T}}=0.135
\end{aligned}
$$

vs. .777 - FF09 1979 
Yaw Spring Constants

$$
\begin{aligned}
& K_{n_{1}}:=\frac{E \cdot I_{n 1}}{l_{1}}=4616 \frac{\mathrm{in} \cdot \mathrm{lbf}}{\mathrm{rad}} \\
& K_{n_{2}}:=\frac{E \cdot I_{n 2}}{l_{2}}=789856 \frac{\mathrm{in} \cdot \mathrm{lbf}}{\mathrm{rad}} \\
& K_{n T}:=\sum K_{n}=794472 \frac{\mathrm{in} \cdot \mathrm{lbf}}{\mathrm{rad}}
\end{aligned}
$$

Yaw Load Proportions

$$
\begin{aligned}
& N_{n 1}:=\frac{K_{n_{1}}}{K_{n T}}=0.00581 \\
& N_{n 2}:=\frac{K_{n_{2}}}{K_{n T}}=0.99419
\end{aligned}
$$

$\underline{\text { Stress Calculations for Side and Yaw Stress }}$

Side Stresses

$$
\begin{aligned}
& S_{y 1}:=\frac{P_{S} \cdot L_{M C} \cdot C_{y 1} \cdot N_{n 1}}{I_{n 1}}+\frac{3 \cdot P_{S} \cdot l_{1} \cdot N_{Y 1}}{n_{1} \cdot h_{1} \cdot b_{1}{ }^{2}}=18979 p s i \\
& S_{y 2}:=\frac{P_{S} \cdot L_{M C} \cdot C_{y 2} \cdot N_{n 2}}{I_{n 2}}+\frac{3 \cdot P_{S} \cdot l_{2} \cdot N_{Y 2}}{n_{2} \cdot h_{2} \cdot b_{2}{ }^{2}}=6917 p s i
\end{aligned}
$$

$\underline{\text { Side Gage Stresses }}$

$$
\begin{array}{r}
S_{\text {ygage }}:=S_{y 1} \cdot\left(1-\frac{2 \cdot G L_{m}}{l_{1}}\right)=15089 \mathrm{psi} \\
\text { Output }_{\text {Side }}:=\frac{S_{\text {ygage }} \cdot G_{\text {factor }}}{E}=1165 \frac{\mu V}{V}
\end{array}
$$


Yaw Stresses

$$
\begin{aligned}
& S_{n 1}:=\frac{M_{Y} \cdot N_{n 1} \cdot C_{y 1}}{I_{n 1}}=2296 \mathrm{psi} \\
& S_{n 2}:=\frac{M_{Y} \cdot N_{n 2} \cdot C_{y 2}}{I_{n 2}}=15604 \mathrm{psi}
\end{aligned}
$$

Yaw Gage Stress

$$
S_{Y \text { gage }}:=S_{n 2}=15604 \mathrm{psi}
$$

$$
\text { Output }_{Y a w}:=\frac{S_{Y_{\text {gage }}} \cdot G_{\text {factor }}}{E}=1204 \frac{\mu V}{V}
$$

\section{Axial $50 \mathrm{lb}$}

$$
\begin{aligned}
& A_{1}:=n_{1} \cdot b_{1} \cdot h_{1}=0.0346 \mathrm{in}^{2} \\
& A_{2}:=n_{2} \cdot h_{2} \cdot b_{2}=0.047 \mathrm{in}^{2} \\
& A_{T}:=A_{1}+A_{2}=0.0816 \mathrm{in}^{2} \\
& S_{A}:=\frac{P_{A}}{A_{T}}=613 \mathrm{psi}
\end{aligned}
$$

vs. 0.0908 - FF09 1979

vs. 550 - FF09 1979 


\section{Cage Section Stress Summary}

\begin{tabular}{|c|c|c|c|}
\hline \multicolumn{3}{|c|}{$\begin{array}{l}S_{T 1}:=S_{N 1}+S_{A}+S_{m_{1}}+S_{l T 1}+S_{n 1}+S_{y 1}=71437 \mathrm{psi} \\
S_{T 2}:=S_{N 2}+S_{A}+S_{m_{2}}+S_{l T 2}+S_{n 2}+S_{y 2}=73044 \mathrm{psi}\end{array}$} & $\begin{array}{l}\text { vs. 52,845 - FF09 } 1979 \\
\text { vs. 57,711 - FF09 } 1979\end{array}$ \\
\hline & Beam 1 & Beam 2 & Gage Stress \\
\hline Normal & $S_{N 1}=5790 \mathrm{psi}$ & $S_{N 2}=19419 \mathrm{psi}$ & $S_{\text {Ngage }}=15438 \mathrm{psi}$ \\
\hline Axial & $S_{A}=613 p s i$ & $S_{A}=613 \mathrm{psi}$ & $S_{\text {Agage }}:=S_{A}$ \\
\hline Pitch & $S_{m_{1}}=15133 p s i$ & $S_{m_{n}}=2425 p s i$ & $S_{\text {mgage }}=15133$ psi \\
\hline Roll & $S_{t T 1}^{1}=28627 p s i$ & $S_{l T 2}^{2}=28065 \mathrm{psi}$ & $S_{\text {lgage }}=16669 \mathrm{psi}$ \\
\hline Yaw & $S_{n 1}=2296 p s i$ & $S_{n 2}=15604 p s i$ & $S_{Y g a g e}=15604 \mathrm{psi}$ \\
\hline Side & $\begin{array}{l}S_{y 1}=18979 \mathrm{psi} \\
S_{T 1}=71437 \mathrm{psi}\end{array}$ & $\begin{array}{l}S_{y 2}=6917 \mathrm{psi} \\
S_{T 2}=73044 \mathrm{psi}\end{array}$ & $S_{\text {ygage }}=15089 \mathrm{psi}$ \\
\hline
\end{tabular}

Stress Output

$\begin{array}{lll}\text { Axial } & S_{\text {Agage }}=613 \mathrm{psi} & \text { Output }_{\text {Axial }}:=S_{\text {Agage }} \cdot \frac{\left(G_{\text {factor }}\right)}{E}=47 \frac{\mu V}{V} \\ \text { Normal } & S_{\text {Ngage }}=15438 \mathrm{psi} & \text { Output }_{\text {Normal }}:=S_{\text {Ngage }} \cdot \frac{\left(G_{\text {factor }}\right)}{E}=1192 \frac{\mu V}{V} \\ \text { Pitch } & S_{\text {mgage }}=15133 \mathrm{psi} & \text { Output }_{\text {Pitch }}:=S_{\text {mgage }} \cdot \frac{\left(G_{\text {factor }}\right)}{E}=1168 \frac{\mu V}{V} \\ \text { Yaw } & S_{\text {Ygage }}=15604 \mathrm{psi} & \text { Output }_{\text {Yaw }}:=S_{Y \text { gage }} \cdot \frac{\left(G_{\text {factor }}\right)}{E}=1204 \frac{\mu V}{V} \\ \text { Roll } & S_{\text {lgage }}=16669 \mathrm{psi} & \text { Output }_{\text {Roll }}:=S_{\text {lgage }} \cdot \frac{\left(G_{\text {factor }}\right)}{E}=1287 \frac{\mu V}{V} \\ \text { Side } & S_{\text {ygage }}=15089 \mathrm{psi} & \text { Output }_{\text {Side }}:=S_{\text {ygage }} \cdot \frac{\left(G_{\text {factor }}\right)}{E}=1165 \frac{\mu V}{V}\end{array}$


APPENDIX B. FF09 Outline Drawing

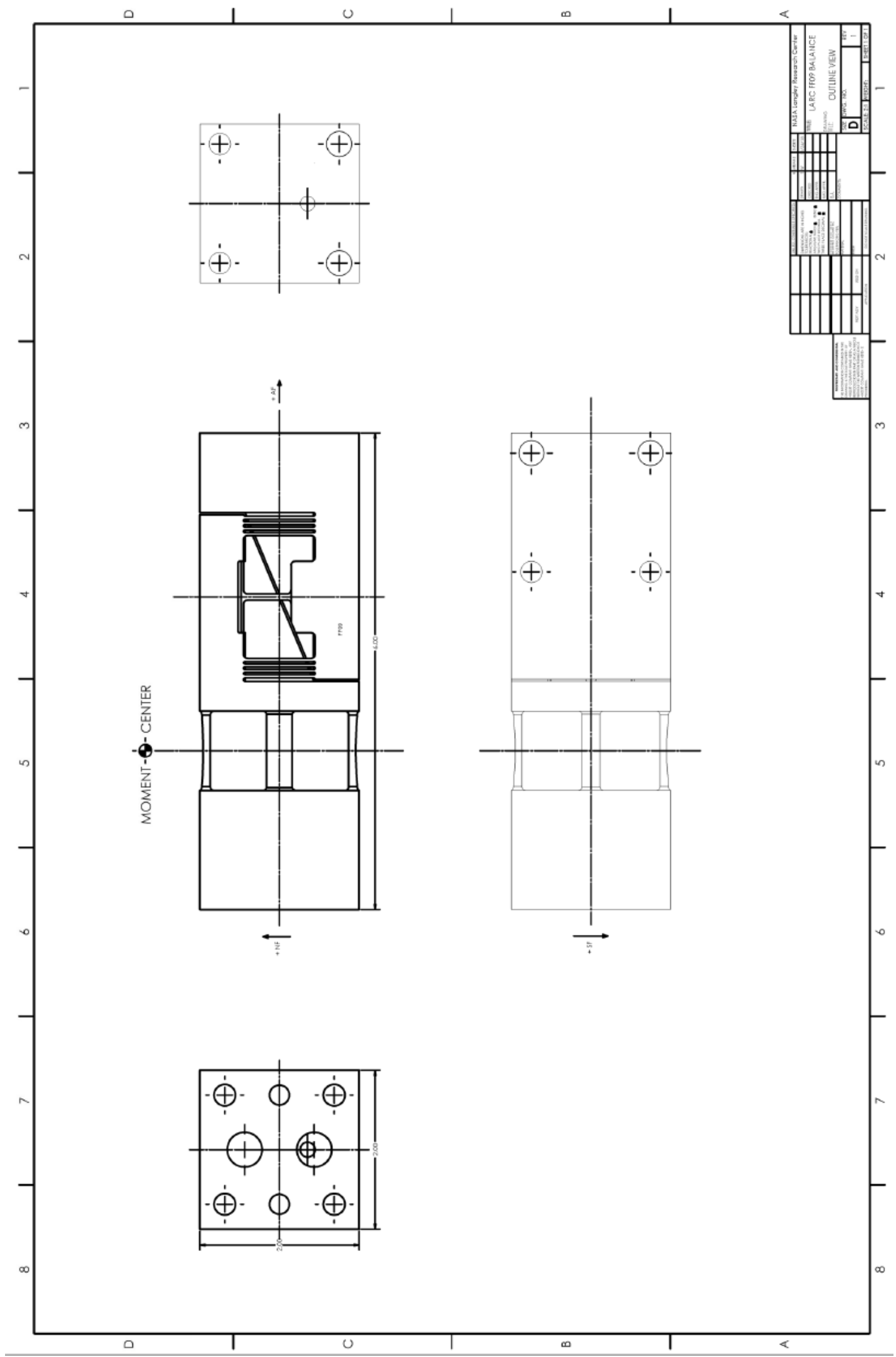


APPENDIX C. $\quad$ FF09X Detailed Drawing

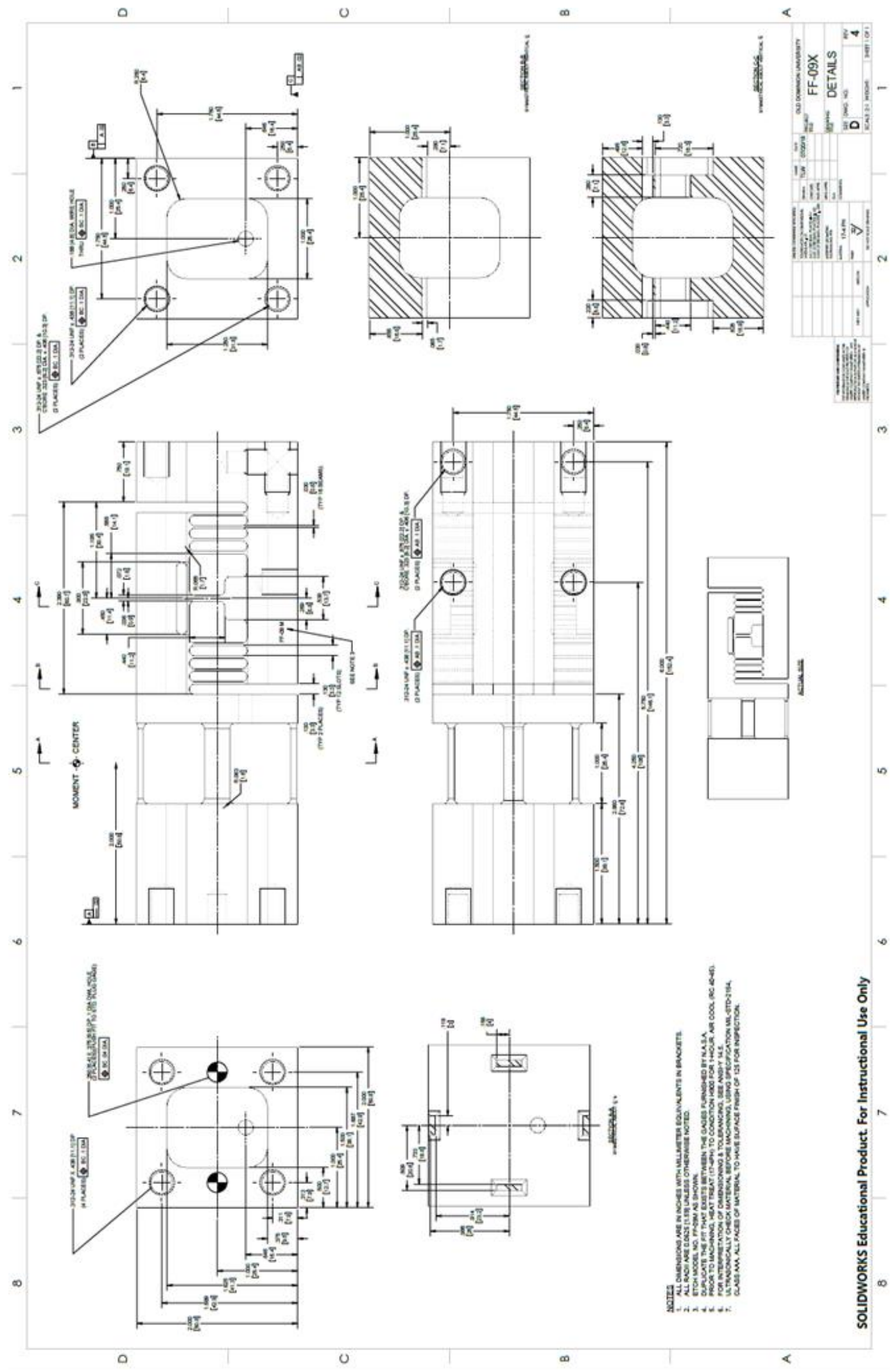


APPENDIX D. FF09X Wiring Diagram

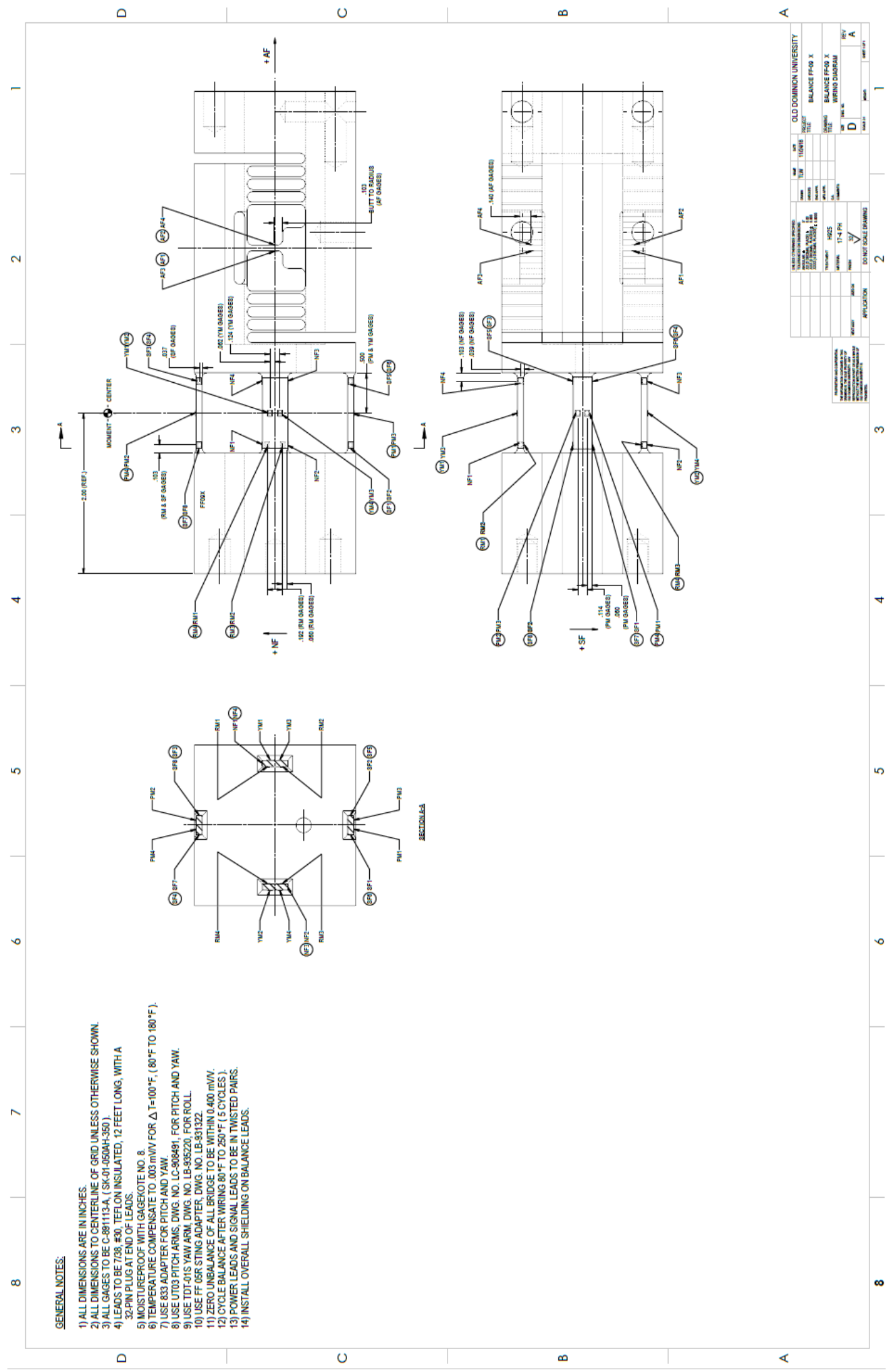


APPENDIX E. Prototype Fabrication Quotes

C \& B Technology, LLC

QUOTE

804-H Industrial Avenue

Chesapeake, VA 23324

Phone: $757-545-3112$, Fax: $757-545-3114$

\begin{tabular}{|c|c|}
\hline Date & Quote \# \\
\hline $7 / 24 / 2018$ & $18-3833-\mathrm{E}$ \\
\hline Terms & Net 30 \\
\hline
\end{tabular}

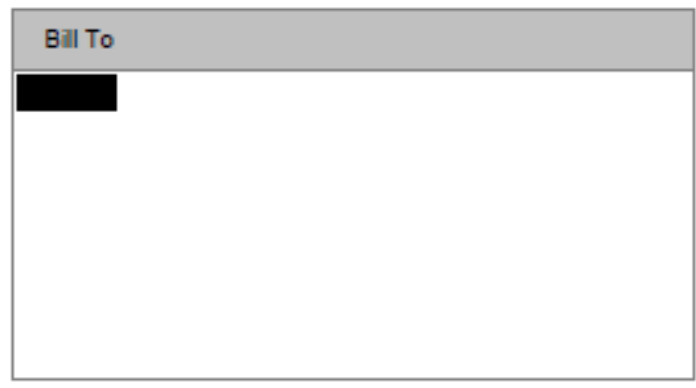

Task Description/Number

This Quote is Valid for 30 days! Delivery dates are based on workload at time of quote and are subject to adjustment at order placement. Firm dates will be confirmed upon acceptance.

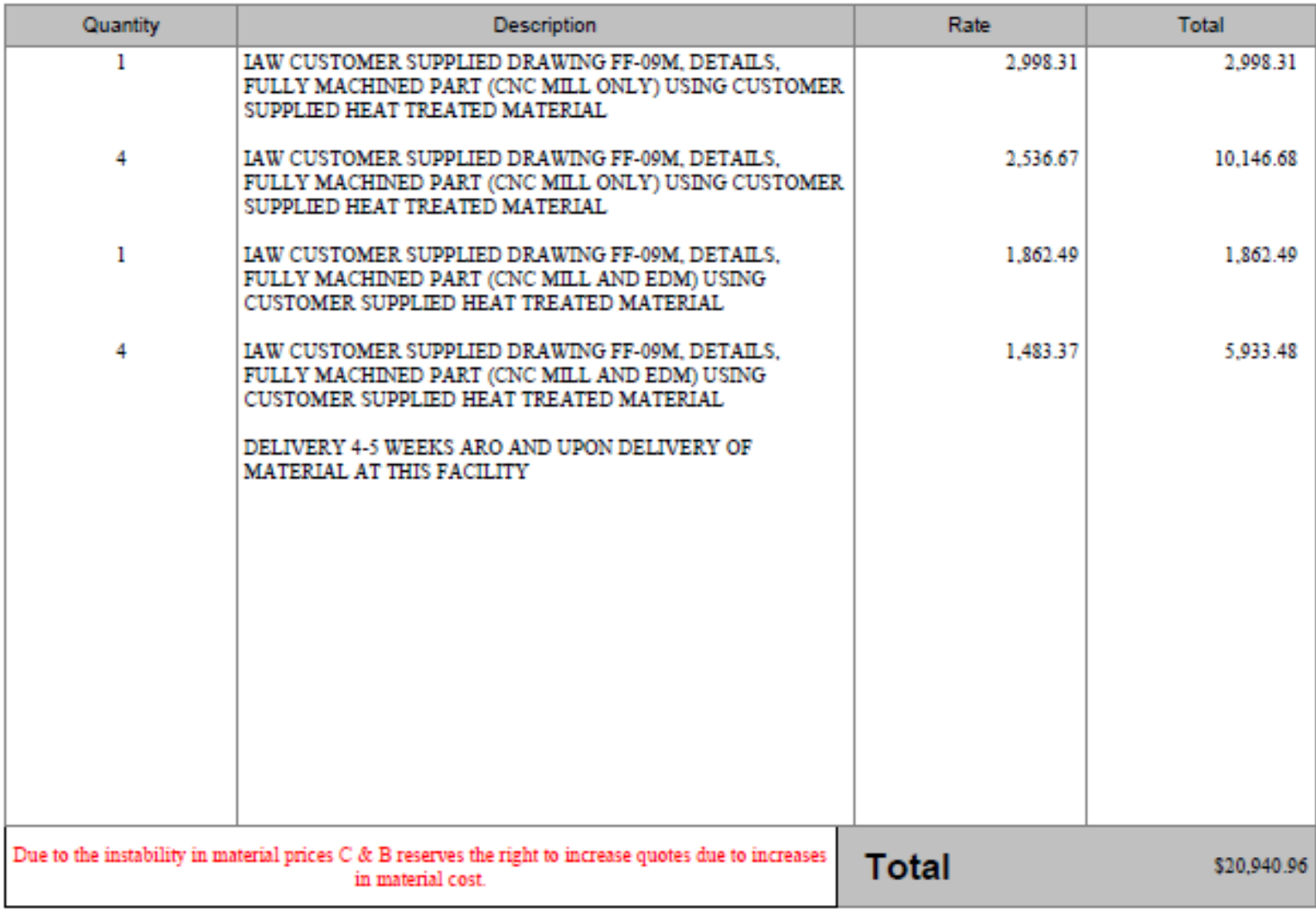

We accept VISA and M/C! All of C \& B Technology pricing is based on a cash price. There is a $5 \%$ convience fee added to the total invoice for credit card charges. FNANCE CHARGE: $2 \%$ PER MONTH, $24 \%$ PER ANNUM ON ALL PAST DUE INVOICES. Customer responsible for all collection fees incurred, including attomey's fees. 


\section{QUOTATION \\ WS MODERN MACHINE \& TOOL CO., INC.}

PRECISION - ACCURACY - DEPENDABILITY

11844 Jefferson Avenue Newport News, Virginia 23606-2587

Telephone (757) 873-1212 Fax (757) 873-8239

Date Quoted: July 25, 2018

Quotation No.: 9957

Quoted To: Old Dominion University

Norfolk, VA 23259

Your Reference No.: $\quad$ Per Email 7-24-18

ATTN: Ladson Webb

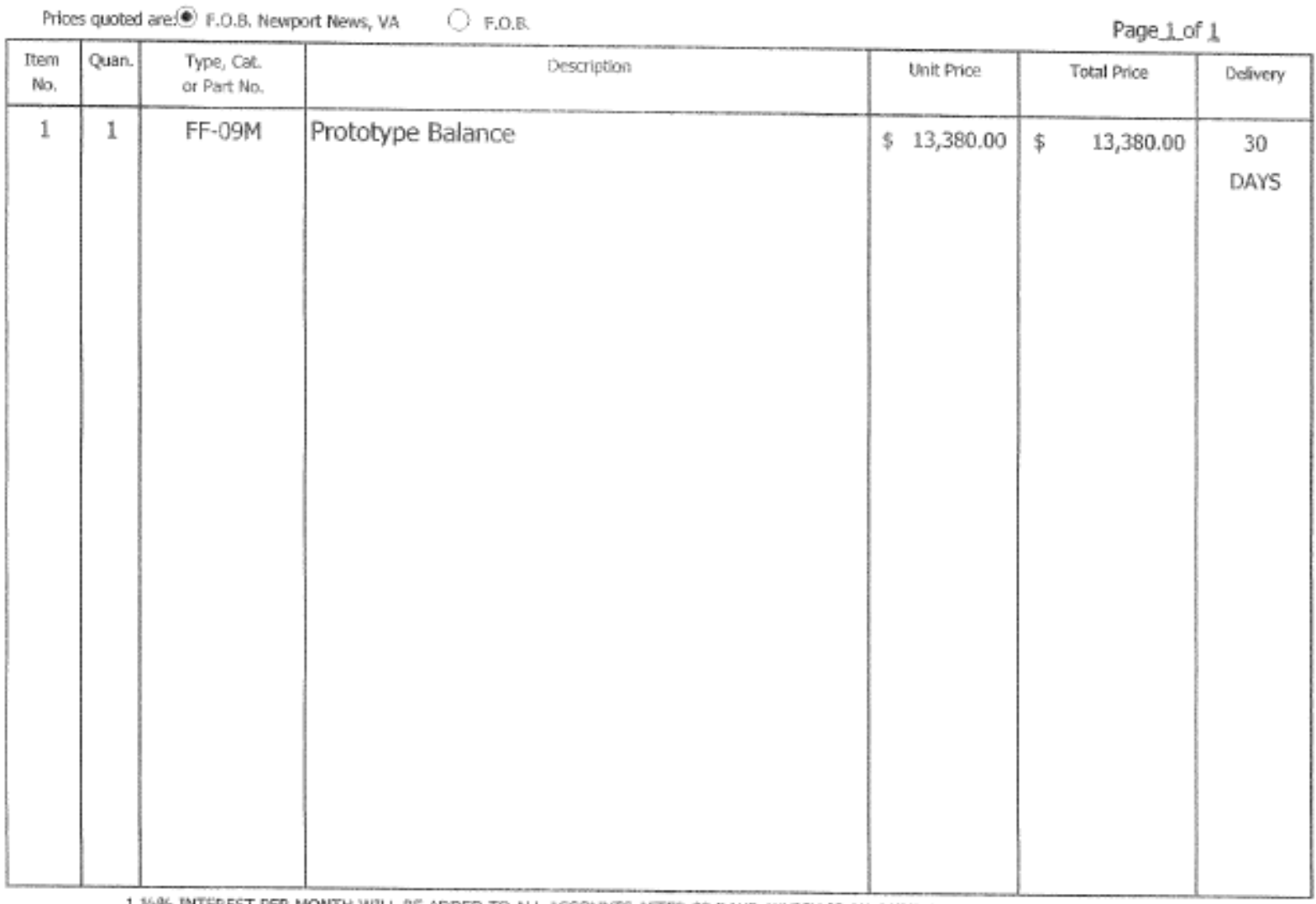

1 1\%\% DNTEREST PER MONTH WILL BE ADOED TO ALL ACCOUWTS AFIER 30 DAYS, WHICH IS AN ANNUAL PERCENTAGE RATE OF 18\%.

Terms: Net 30 Days

(Upon Credit Approwal)
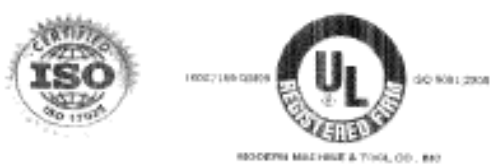

MODERWMACHINE \& TOOL COMPANY, INC.

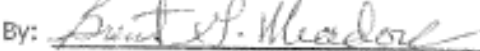
Name: Brent G. Meadors

Title: President

This quotation is subject to the conditions of the Standard Conditions of Sale and VALID for 30 DAYS ONLY. 
VITA

\author{
Thomas Ladson Webb III \\ Mechanical \& Aerospace Engineering \\ Old Dominion University \\ 241A Kaufman Hall, Norfolk, VA 23529
}

\title{
EDUCATION
}

Master of Science in Mechanical Engineering at Old Dominion University, December 2018

Thesis title: "A Monolithic Internal Strain-Gage Balance Design based on Design for Manufacturability"

Bachelor of Science in Mechanical Engineering at Old Dominion University, December 2017

Bachelor of Science in Marketing Management at Virginia Polytechnic Institute and State University, May 2001

\section{ACADEMIC EMPLOYMENT}

Graduate Research Assistant to Dr. Drew Landman, Department of Mechanical \& Aerospace Engineering, Old Dominion University, December 2017-December 2018. Research activities included design and structural analysis of a direct-read, moment balance for use in wind tunnel aerodynamic testing.

Undergraduate Teaching Assistant, Department of Mechanical \& Aerospace Engineering, Old Dominion University, May 2017-December 2017. Responsibilities included: development of lab curriculum on racecar data acquisition and analytics and facilitation of lab in conjunction with the Motorsports Minor.

\section{PROFESSIONAL EMPLOYMENT}

Director of Marketing and Relationship Management, TwoFisted Heart Productions, Alexandria, VA January 2013-December 2013

Senior Business Development Specialist, Aon Affinity Insurance Services, Washington, D.C., November 2004-January 2013

Project Manager, Pac-Tec Enclosures, Inc., Concordville, PA, June 2002-November 2004 